IZA DP No. 8916

Severe Air Pollution and Labor Productivity:

Evidence from Industrial Towns in China

Jiaxiu He

Haoming Liu

Alberto Salvo

October 2016 


\title{
Severe Air Pollution and Labor Productivity: Evidence from Industrial Towns in China
}

\author{
Jiaxiu He \\ National University of Singapore \\ Haoming Liu \\ National University of Singapore \\ and IZA \\ Alberto Salvo \\ National University of Singapore
}

Discussion Paper No. 8916

October 2016

\author{
IZA \\ P.O. Box 7240 \\ 53072 Bonn \\ Germany \\ Phone: +49-228-3894-0 \\ Fax: +49-228-3894-180 \\ E-mail: iza@iza.org
}

\begin{abstract}
Any opinions expressed here are those of the author(s) and not those of IZA. Research published in this series may include views on policy, but the institute itself takes no institutional policy positions. The IZA research network is committed to the IZA Guiding Principles of Research Integrity.

The Institute for the Study of Labor (IZA) in Bonn is a local and virtual international research center and a place of communication between science, politics and business. IZA is an independent nonprofit organization supported by Deutsche Post Foundation. The center is associated with the University of Bonn and offers a stimulating research environment through its international network, workshops and conferences, data service, project support, research visits and doctoral program. IZA engages in (i) original and internationally competitive research in all fields of labor economics, (ii) development of policy concepts, and (iii) dissemination of research results and concepts to the interested public.
\end{abstract}

IZA Discussion Papers often represent preliminary work and are circulated to encourage discussion. Citation of such a paper should account for its provisional character. A revised version may be available directly from the author. 


\title{
Severe Air Pollution and Labor Productivity: Evidence from Industrial Towns in China*
}

\begin{abstract}
We examine day-to-day fluctuations in worker-level output at two manufacturing sites located in different industrial towns in China. Ambient air pollution in both towns, as proxied alternatively by fine-particle (PM2.5) and sulfur dioxide (SO2) levels, is severe but significantly variable, in part due to exogenous atmospheric ventilation. Across sites, pollution proxies and estimators, and correcting for worker heterogeneity and seasonality, we find a precisely estimated zero response on daily worker output from concurrent (same-shift) variation in air pollution. This is consistent with the stated perceptions of managers during our visits to over 10 firms in four provinces. We then follow the epidemiological literature and allow worker outcomes to respond to day-to-day variation in pollution with up to 30 days of delay. We uncover statistically significant adverse output effects from more prolonged pollution exposure, but these effects are not large. The cumulative effect - scaled for a large $+10 \mu \mathrm{g} / \mathrm{m} 3$ PM2.5 variation in exposure on the day of output and on each of the previous 25 days - amounts to -0.5 to $-3 \%$ of mean daily output. Estimates using SO2 are similar. Consistent with a simple model, more productive workers tend to respond more to pollution.
\end{abstract}

JEL Classification: J24, Q51, Q52, Q53, O44, R11

Keywords: air pollution, acute exposure, labor productivity, labor supply, heterogeneous effects, thermal inversions, wind, PM2.5, SO2, environmental damage, environmental valuation, air pollutants/adverse effects, distributed lags, instrumental variables

Corresponding author:

Haoming Liu

Department of Economics

National University of Singapore

1 Arts Link

Singapore 117570

E-mail: ecsliuhm@nus.edu.sg

\footnotetext{
"We are very grateful to employees at numerous firms who have met with us and supported our research and, in particular, managers at two firms who gave us access to their worker output records, data that we can make available to other researchers both in original form (with anonymous worker identifiers) and in digitized form. We thank Min Zhong, Chi Zhang, and Wanzhong Cao for excellent research assistance, interpreting the original worker records and digitizing their content. For feedback at different stages of our research project, we thank audiences and discussants at the Energy Policy Institute at the University of Chicago, NBER Chinese Economy Meeting, IZA workshop on Labor Market Effects of Environmental Policies, and US Northeast Workshop on Energy Policy and Environmental Economics.
}

Note: This is a revised version posted on October 21, 2016. The original version of the paper published as IZA Discussion Paper No. 8916 in March 2015 was retracted by the authors after they found some duplicates in the data provided by the original firm, which they were unable to resolve with the provider. The current version uses two new worker samples, provided by different firms in China. These firms have provided hard copies of the original worker records and have agreed that the authors make these publicly available, including in digitized form. 


\section{Introduction}

Several densely populated areas in China today, and the country's industrial towns in particular, exhibit severe levels of air pollution (e.g., Economist, 2015). Levels of pollutants in ambient air can rise to an order of magnitude above the thresholds deemed by the US Environmental Protection Agency (EPA) and the World Health Organization (WHO) to protect public health. For example, at one of the industrial towns examined in this study, in northern Henan province several hundred kilometers south of Beijing, the mass concentration of PM2.5 (particulate matter of diameter up to 2.5 micrometers), measured hourly and averaged over winter/spring 2015 , amounted to $101 \mu \mathrm{g} / \mathrm{m}^{3}$, to be contrasted with the primary one-year average National Ambient Air Quality Standard (NAAQS) of $12 \mu \mathrm{g} / \mathrm{m}^{3}$ set by the US EPA. ${ }^{1}$ For added perspective, hourly PM2.5 levels measured by the US State Department at the US embassy in Beijing, a city notorious for poor air quality, averaged $85 \mu \mathrm{g} / \mathrm{m}^{3}$ over the same period, i.e., $16 \%$ less than in the Henan town. Similarly, taking $\mathrm{SO}_{2}$ (sulfur dioxide) as an alternative proxy for industrial air pollution, including emissions from coal-fired electricity generators and steel mills, 24-hour mean $\mathrm{SO}_{2}$ concentrations at this same Henan town and time averaged $59 \mu \mathrm{g} / \mathrm{m}^{3}$ (with hourly maximum of $375 \mu \mathrm{g} / \mathrm{m}^{3}$ ), to be compared to a 24-hour average Air Quality Guideline of $20 \mu \mathrm{g} / \mathrm{m}^{3}$ set by the WHO (World Health Organization, 2006).

Against this backdrop, and aiming to inform pollution control policies in the fastindustrializing developing world, a small but growing literature seeks to quantify the damage from human exposure - both chronic and acute - to severe air pollution. Partly due to data availability, this literature has focused on health outcomes, for which there are encounters with health suppliers or vital records (e.g., mortality, birth outcomes). For example, in the environmental economics literature, Chen et al. (2013) find reduced life expectancy from exposure to airborne particles following a winter heating policy that increased coal combustion in China's north relative to the country's south. In epidemiology, Bell and Davis (2001) examine public health insurance claims, hospitalizations and

\footnotetext{
${ }^{1}$ Concentrations were measured at an ambient air monitoring site located $3 \mathrm{~km}$ from one of the work sites we study. The maximum hourly PM2.5 level recorded in the sample is $422 \mu \mathrm{g} / \mathrm{m}^{3}$. For the US NAAQS, see epa.gov/criteria-air-pollutants/naaqs-table.
} 
mortality records to reassess the consequences of acute exposure to London's 1952 winter smog, during which "(p)ollution levels... were 5-19 times above current regulatory standards... and approximate current levels in some rapidly developing regions" (p.389). When it comes to more subtle forms of human impact that do not lead to health encounters, such as the effect of short-term variation in air quality on the day-to-day productivity of relatively young and otherwise healthy workers, the state of knowledge is very limited.

We address this gap in the literature by engaging, through personal connections, with managers at about one dozen manufacturing firms in four Chinese provinces. We requested high-frequency (daily) output records of "piece rate" workers, who are paid according to how much they individually produce (Lazear, 2000) and thus these records exist - which we could then combine with environmental data. Beyond observability, our key criteria for inclusion in this study are twofold: (i) that the original output records be credible, such as containing annotations made on the original forms by team leaders analyzing and documenting the flow of production; and (ii) that the original records be made open access, enabling replication and scrutiny by other researchers. In particular, criterion (ii) is not common in empirical economics research that uses proprietary firm data, with researchers typically invoking non-disclosure agreements (NDAs). Output records obtained from two firms in the textiles industry, each located in an industrial town in a different provinceJiangsu on the east coast, and Henan - meet our credibility and open-access criteria.

We find a "precisely estimated zero" response of daily worker output to concurrent variation in air pollution, which we alternatively proxy, in separate regression models, by mean PM2.5 and $\mathrm{SO}_{2}$ concentrations measured during the 12-hour work shift at outdoor air monitoring sites located a few $\mathrm{km}$ from the work sites. Our models control for individual heterogeneity in worker productivity, via worker fixed effects, and time-varying omitted variables, via year-month and day-of-week fixed effects. The source of identifying variation is the day-to-day co-variation in worker-level output and air pollution that remains once we account for systematic worker and seasonal variation. The indoor workplaces we examine have temperature control, this being the norm in the industry, whereas the significant air exchanged between the outdoor and indoor environments (e.g., by way of doors through 
which workers and materials continually transit) is not filtered. Indeed, controlling for temperature and humidity in the regression model for worker output does not change the estimated relationship between output and concurrent air pollution.

Of importance to our identifying strategy, we show that, empirically, de-seasoned pollution levels at both Jiangsu and Henan sites exhibit large fluctuation. This residual variation is due in large part to day-to-day variation in atmospheric ventilation and other meteorological shifts such as precipitation. Observed ventilation conditions include surface wind and "atmospheric mixing height," proxied by temperature gradients in the lower atmosphere that impact the dispersion of pollutants, or thermal inversions. These shifts are unlikely to correlate with local economic activity, including emissions from surrounding firms and road traffic. To address possible omitted variables or measurement error in pollution exposure, in most specifications we instrument for measured pollution using pollution predicted from meteorological variation that should not, by design of the workplace, impact worker output directly. ${ }^{2}$ Across both sites, our finding that output does not respond to concurrent acute exposure to pollution is robust.

We note that our estimated zero response of daily worker output to concurrent variation in the pollution dose is consistent with interview evidence at all the firms we visited, not only the two that provided worker output data. On over 10 field visits to firms in the provinces of Jiangsu, Henan, Hebei and Sichuan, sites that are routinely exposed to severe air pollution - which is mostly visible - all the managers we interviewed, without exception, opined that the severity of a day's pollution did not impact a worker's flow of output. (In contrast, managers at plants without heating/air-conditioning systems stated that extreme temperatures did affect worker output.) $)^{3}$ Our precisely estimated zero concurrent pollution response contrasts with a recent publication that reports a large $6 \%$ drop in daily worker output at an indoor pear-packing plant in California for a $10 \mu \mathrm{g} / \mathrm{m}^{3}$

\footnotetext{
${ }^{2}$ A challenge to identification would be, for example, unobserved drops in the region's industrial activity that might reduce both pollution and worker output, leading to upward bias. Alternatively, shocks to road congestion might raise vehicle emissions and, say through stress, lower worker output, leading to downward bias. Variation in ventilation (horizontal and vertical) is plausibly exogenous to such unobserved shocks (and, to add, many of the workers we examine live in firm dormitories and do not commute).

${ }^{3}$ Again, we reached these managers through personal, often long-term, connections. We informed managers of our research question and that their firm's identity would be safeguarded. All managers allowed us to visit their production facilities. We do not believe managers were responding strategically.
} 
increase in concurrent PM2.5 (Chang et al., 2016). In Chang et al.'s setting, PM2.5 levels measured near the plant exceeded $15 \mu \mathrm{g} / \mathrm{m}^{3}$ on only $12 \%$ of the sample, namely on 26 daily observations. ${ }^{4}$ If one were to extrapolate a marginal effect of this magnitude $(-6 \%$ output per $+10 \mu \mathrm{g} / \mathrm{m}^{3}$ concurrent PM2.5) to our sample means of 70 and $100 \mu \mathrm{g} / \mathrm{m}^{3}$ at the Jiangsu and Henan work sites, respectively, it is likely that Chinese managers would take note. It is conceivable that workers in California are more susceptible than those we observe in China, perhaps through selection or adaptation to different routine pollutant levels - and possibly composition, e.g., biomass burning versus industry. Yet, the difference in estimated marginal effects from concurrent exposure, $-6 \%$ versus $0 \%$, is wide. As another candidate explanation for the difference in findings, sharp non-linearity in the concurrent dose-response function-i.e., $-6 \%$ per $+10 \mu \mathrm{g} / \mathrm{m}^{3}$ at about $25 \mu \mathrm{g} / \mathrm{m}^{3}$, flattening out thereafter-seems unlikely. ${ }^{5}$

A strand in the epidemiological literature allows health outcomes to respond to dayto-day variation in pollution exposure with up to 30 or 40 days of delay (Schwartz, 2000; Zanobetti et al., 2002, 2003). Zanobetti et al. (2003) find that "the adverse response to pollution persists to a month or longer after exposure not only for total mortality but also for respiratory and cardiovascular mortality" (p.1192). In their study of London's five days (December 5-9, 1952) of severe pollution, as proxied by suspended particle and $\mathrm{SO}_{2}$ levels and driven by thermal inversion, Bell and Davis (2001) report: "Mortality remained almost twice that of pre-episode levels for the next 2 weeks, and rates did not decline to normal levels over the next 2 months" (p.391). This literature finds that models that consider only the concurrent effect of pollution, ignoring more prolonged acute exposure, significantly underestimate overall health impacts (Zanobetti et al., 2003).

We follow this literature and estimate distributed lag models with up to 30 days of delay. On doing so, we uncover adverse effects of more prolonged pollution exposure on daily worker output. Overall, cumulative effects - scaled for a $+10 \mu \mathrm{g} / \mathrm{m}^{3}$ variation in

\footnotetext{
${ }^{4}$ Chang et al. (2016) observe mean PM 2.5 concentrations collected over 24 hours (24-hour filters) once every 6 days. Their PM2.5 data consists of 214 days. Due to a wildfire, 24 -hour PM2.5 exceeded $25 \mu \mathrm{g} / \mathrm{m}^{3}$ on 11 observations, or $5 \%$ of the sample, with a sample maximum of $60 \mu \mathrm{g} / \mathrm{m}^{3}$.

${ }^{5}$ Minimum values in our samples (mean PM2.5 over the 12 -hour shift) are about $20 \mu \mathrm{g} / \mathrm{m}^{3}$, so we do not examine lower levels of pollution. Chang et al. (2016) claim: "The nonlinear estimates suggest a possible threshold around $15 \mu \mathrm{g} / \mathrm{m}^{3}$ with a roughly linear effect beyond the threshold" (p.155).
} 
PM2.5 levels not only on the day of output but also on all previous days all the way back to the maximum modeled lag - decline gradually from $0 \%$ for a model without lags (or a short lag structure), and peak at an overall effect of about -0.5 to $-3 \%$ of mean output when 25 days of delay are allowed. Importantly, $+10 \mu \mathrm{g} / \mathrm{m}^{3}$ in PM2.5 exposure sustained over the $25+1=26$ days prior (and concurrent) to the output realization is a sizable variation in dose. While point estimates of the cumulative effect fall gradually as we add more lags, $95 \%$ confidence intervals fall below $0 \%$ for models with about 10 or more lagged days of exposure. As in epidemiology, we obtain that constraining the estimated lag coefficients to follow a smooth (polynomial) pattern in lagged days buys us precision but does not significantly change the estimated overall effect (Schwartz, 2000). Our result is qualitatively similar across the different proxies for pollution exposure, identification assumptions, and the Jiangsu and Henan work sites. Again, estimates are robust to controlling for outdoor temperature (concurrent day and up to a 2-day lag structure).

We further show that while there is individual heterogeneity in workers' output response to more prolonged pollution exposure, the average overall effect just reported is not driven by a few highly sensitive workers. Instead, we estimate that the workforce is adversely affected, to a varying degree, with the median worker producing 0.5 to $3 \%$ less output for $+10 \mu \mathrm{g} / \mathrm{m}^{3}$ of PM2.5 exposure sustained over 25 days. A worker's rank in terms of output sensitivity to PM2.5 correlates tightly with her rank in terms of output sensitivity to $\mathrm{SO}_{2}$, underscoring the role of both pollutants as reasonable proxies for severe pollution at these industrial towns. Consistent with a simple model of how effort responds to pollution exposure across workers of varying abilities, workers who rank higher in terms of output sensitivity tend to be those workers with higher mean output in the sample.

In sum, we find that in our Chinese industrial town samples: (i) the estimated pollution-productivity response is not statistically distinguishable from zero when we allow only concurrent exposure, or even a few past days of exposure, to impact worker productivity; (ii) the overall effect in models with richer lag structures, while statistically and economically significant, is modest, and probably not immediately perceptible to managers, consistent with what was stated during our field interviews; and (iii) this 
response to more prolonged (yet still acute, sub-chronic) exposure is distributed across the workforce, and the response appears more pronounced among higher ability workers. Evidence along the extensive margin of labor supply - how worker attendance responds to concurrent and lagged pollution exposure - is less robust, similarly small in magnitude, and unlikely to bias our estimates along the intensive margin.

\section{Institutional background and data}

Access to original annotated records at two sites. We have gained access to daily worker-level panel data on output for production workers at specific departments of two different firms in the textile industry. Each firm is located in an industrial town in a different province of China: (I) Jiangsu, on the east coast, and (II) Henan, a province southwest of Beijing. Air monitoring sites located nearby to each plant indicate that air pollution is severe: mean ambient PM2.5 and $\mathrm{SO}_{2}$ mass concentrations in $\mu \mathrm{g} / \mathrm{m}^{3}$ are, respectively, (I) 69 and 31 in the Jiangsu sample, and (II) 99 and 61 in Henan.

Key aspects of the output data are its longitudinal structure and high frequency. Since we follow the same worker day by day, we can control for individual heterogeneity and seasonality. We were allowed to make copies of the original handwritten paper records, which include credible and informative annotations from supervisors on shocks to the operation or to specific workers, e.g., power outage (which happens rarely) or a worker training a new colleague. Open access is another key aspect. We are making these original copies available to other researchers, with anonymous identifiers in place of worker names, and also sharing digital files containing data that we transcribed from the paper records.

We now describe the two production departments and datasets. Table 1 summarizes the discussion that follows, and the Appendix provides further details. Operations in both departments involve the transformation of yarn (or pre-yarn), already downstream of the cleaning and drawing of raw cotton, into higher-value products. Cotton is domestically sourced, including the eastern provinces of Shandong and Jiangsu and the northwestern province of Xinjiang. In order of typical upstream to downstream textile operations: (II) the Henan workers we observe oversee a "ring spinning" process producing yarn threads 
and stored in ring bobbins. The material input is supplied from within the plant. The output is supplied to another department within the plant. (I) Jiangsu workers oversee a "cone winding" process transforming ring bobbins of yarn, supplied from within the plant, into large cones of yarn, supplied both to another department within the plant as well as to external buyers across China and abroad. The widespread geographic nature of demand for each firm's end products, as well as of cotton supply, suggests that the operations' production is unlikely to depend on local economic activity.

Both departments run around the clock, seven days per week, shutting down only over short multi-day periods which typically include or overlap with public holidays such as the weeks of Chinese New Year and National Day. Workers are divided into teams that operate on different and rotating 12-hour shifts, described next. Sample periods amount to 9 and 14 months, overlapping as follows: (I) September 1, 2014 to May 31, 2015 in Jiangsu, and (II) April 1, 2014 to May 31, 2015 in Henan. Excluding department holidays, in which aggregate output falls to zero, our samples consist of (I) 264 days, or 525 day by shift pairs, in Jiangsu, and (II) 401 days, or 784 day-shifts, in Henan. Department holidays account for another 8.5 and 20.5 days (17 and 41 date-shifts) in Jiangsu and Henan, respectively, equivalent to $3 \%$ and $5 \%$ of the sample periods.

Work shifts. Both departments operate continuous shifts of fixed 12-hour duration, from 8 am to $8 \mathrm{pm}$, and from $8 \mathrm{pm}$ to 8 am the next day. Table 2(I)-2(II) reports further sample statistics, separately by work site.

Jiangsu workers are divided into two teams that rotate every month, as a team, between the two shifts. For example, in September 2014 we observe Team 1 work the night shift and Team 2 work the day shift; the next month Team 1 worked the day shift and Team 2 worked the night shift. Each team consists of about 15 workers. The department has 17 machines, requiring a staff of 8 to 9 workers to operate them, according to a rule of thumb of two machines per worker. ${ }^{6}$ This arrangement frees up the remaining workers to rest, by design, with each worker scheduled to take leave one day every two to four consecutive

\footnotetext{
${ }^{6}$ Thus, when 9 workers are attendant, 1 worker operates a single machine and her recorded output is about half that of her peers. This low-output worker may additionally perform other duties; these are not recorded, but we are able to control for the number of machines used to produce the recorded output (in the example, 1 worker with 1 machine and the other 8 workers with 2 machines, since $1 \times 1+2 \times 8=17$ ).
} 
work days. Thus, a workstation is comprised by a single worker individually responsible for two machines side by side. Workstations operate in parallel, not in series (as would be the case in an assembly line). We discuss worker inputs and pay below.

Henan workers are divided into three teams which operate on a 36-hour cycle, working 12 consecutive hours followed by resting for 24 hours. Thus, on a given day, two teams work and one team rests. For a given team, the work shift alternates between day and night, spaced 24 hours apart. Each team consists of about 15 workers, some of whom operate machines only intermittently during the sample period (Figure A.1). We observe a minority of workers do not follow the standard "work 12 hours followed by rest 24 hours" shift pattern, for example, they may follow a more intense "work 12 hours, rest 12 hours" cycle, with (and some without) periodic 24 hours of rest. The department has 34 "regular" machines and 3 "extended" machines, differentiated only by their production rate - an extended machine is counted as 2.1 regular machines (they respectively hold 1008 and 480 ring bobbins). Each workstation consists of one worker and about 5 regular machines. For over nine-tenths of worker by day observations, the observed number of machines ranges between 4 and 7 machines to a worker (workstation). Again, workstations operate in parallel, with no complementarity across the workers who staff them.

At both sites we observe each worker and her team repeatedly working in each of the shifts. We control for any shift-specific variation in productivity using shift fixed effects. For example, to the extent that machine adjustments or maintenance are more likely to take place in the morning, this may impact the day shift. Managers at both sites informed us that workers typically work the fixed 12-hour shift along with their team, and do not select the number of hours worked, as it is costly to idle machines. Consistent with this information, the number of hours worked is not recorded in the Jiangsu sample. For Henan, the number of hours worked is recorded, averaging 11.6 hours in the sample (Table 2(II)). We control for the $16 \%$ of observations in which a worker worked less than 12 hours - mostly working, in such cases, 10 hours (and we do not find that these few occurrences are explained by pollution).

Worker inputs. The price of the machines in the departments we study can run into 
the tens of thousands of dollars apiece. Physical capital in a worker's workstation can thus amount to hundreds of thousands of dollars. Judged by the physical capital they employ, these are not low-skill workers. Tasks are similar across workers, and include carefully but quickly loading a machine with material inputs and removing its output (ring bobbins or cones of yarn), as well as reconnecting threads that naturally break apart during operation, while the machine is on standby. While work is capital intensive, productivity depends critically on the quality of labor. Key worker inputs are skill (experience, dexterity) and effort (attentiveness, speed). With workstations operating in parallel, the appropriate unit of analysis is the individual production worker.

With worker effort and skill being critical, complementarity across workers minimal, and individual output measurable, workers are paid according to the level of output they individually produce in each shift. In both departments, there is no base pay and, other than through benefits such as subsidized housing and health insurance, compensation is variable. There is no minimum wage or threshold level above which variable compensation applies. Again, this reflects the importance of skill and effort as inputs to the production function, with the worker's "skin in the game." The monthly level of pay varies from 3000 to 4000 Chinese Yuan (CNY) in Jiangsu, and CNY 2000 to 2500 in Henan, equivalent to US\$ 500-670 and 330-420, respectively. ${ }^{7}$ Workers are aware of their flow of pay and that of others, ensuring that the output records are accurate and, according to management interviews, this encourages hard work.

In total, our samples include 46 and 80 workers in Jiangsu and Henan, respectively. In Jiangsu, most workers are in their 20s or early 30s, are female and Han (race), and have completed secondary schooling. Workers tend to live in the vicinity of the plant. This means that the closest monitor measures air outdoor both to their workplace and to their home. We observe some workers who leave the department during the sample period, and others who join, whether temporarily (such as on probation) or on a longer-term basis. Because the output data suggests they are learning, we control for an initial two months

\footnotetext{
${ }^{7}$ We take a rough 2014 exchange rate of CNY 6 to 1 US\$. Mean annual earnings in the town that hosts each department follow the same rank: CNY 57,000 (Jiangsu) and 40,000 (Henan). Source: Provincial statistics bureaus www.jsstjj.cn/wcm/wshd/msg_show.jsp?MessageId=452\&lxlb=1 and www.ha.stats . gov.cn/hntj/tjfw/tjfx/qsfx/ndfx/webinfo/2015/06/1431316377540699.htm.
} 
at the firm. Workers in Henan also tend to live by the plant, including in firm dormitories. They are mostly female and schooled as in Jiangsu, while a little older and with longer tenure on the job. In both departments, turnover is most pronounced around Chinese New Year holiday (February 2015), particularly among workers from out of town. ${ }^{8}$

The work day choice. In each 30-day period of department activity (that is, excluding department holidays with zero aggregate output), we observe workers typically producing on: (I) 21 to 25 12-hour shifts in Jiangsu, and (II) 17 to 21 12-hour shifts in Henan. ${ }^{9}$ Noting Henan's standard shift design - a "work 12 hours, rest 24 hours" cycleand that mathematically there are 20 such 36 -hour cycles in a 30 -day period, the evidence indicates that worker absenteeism is low. In Jiangsu - "work 12 hours, rest 12 hours, and take leave one day every two to four consecutive work days" - hours worked are higher than in Henan. We do not observe which of a given worker's days with zero output were scheduled (pre-determined) leave days, and which days were absences, possibly in response to air pollution. However, to judge by the higher work hours than in Henan, worker absenteeism in Jiangsu is similarly low.

Our empirical analysis accounts for the possibility of selection on pollution in our worker-day output samples. A worker's absence on a given day could be due to pollutionrelated sickness, or to weather - a determinant of pollution (Table A.2(I)-A.2(II)) - shifting the value of the outside option, such as a clear day inducing the worker to spend a leisure day outdoors (Shi and Skuterud, 2015). We do not find evidence that pollution significantly drives the probability of positive versus zero output on a given day. This is not surprising given the low worker absenteeism. Our interpretation is that these are Chinese workers who live close to their employer, an employer that has much information about the employee, say to verify a shirking employee's false claim of sickness on justifying an

\footnotetext{
${ }^{8}$ In the Jiangsu sample, 23 workers are actively producing both before and after Chinese New Year. Another 8 workers produced only before this long holiday and 15 workers produced only after it, totaling 46 workers. In Henan, 26 workers produced both before and after Chinese New Year, as many as 43 workers produced only before the holiday, and 11 workers produced only after it, totaling 80 workers.

${ }^{9}$ This density can be seen in the frequency charts by worker shown in Figure A.1. We ignore the density at 30 days for Henan, as this consists of 15 temporary workers who appear briefly in the records, with positive output for up to three consecutive days only (i.e., 3 days with output / 3 days from worker's first day to last day in sample $\times 30$ days in a 30 -day period).
} 
unplanned absence. In addition, scheduled leaves, like department holidays, are predetermined, so they are unlikely to depend on short-run variation in environmental quality. In practice, we find that attempting to control for selection in the output equation-using exogeneity restrictions based on weather (see Conceptual Framework) - makes little difference to our estimates of the relationship between air pollution and worker productivity.

Worker productivity. Given some differentiation across the product varieties that a worker (or department) produces within a shift and over time, we aggregate across products to obtain a single measure of output. ${ }^{10}$ To do this, we use weights set by the departments themselves in determining worker compensation. Output records detail the quantities by product that a worker produces in each shift worked, in cases for Jiangsu, and $\mathrm{kg}$ for Henan, to which we apply the weights directly. Henan weights are the individual piece rates in $\mathrm{CNY} / \mathrm{kg}$ of each product produced. Jiangsu weights are adjusted cases/physical case of each product produced; a single piece rate is then applied to aggregate adjusted cases. Piece rates are invariant across workers. A worker's weighted output (compensation) on her shift is then the outcome in the output regression analysis.

Taking a worker by day pair as an observation, panel (a) of Figure 1(I)-1(II) plots the distribution of individual output, across workers and over time, separately for Jiangsu and Henan. ${ }^{11}$ Means are 112 cases/worker-day and $125 \mathrm{CNY} /$ worker-day, respectively. For every worker in each sample, we then calculate her mean individual output per shift worked over the entire sample period. The distribution of mean worker performance is plotted in panel (b) of Figure 1(I)-1(II). The most productive workers can sustain a significantly higher production rate than the least productive workers. Several of the least productive workers have very few output observations. They are either new workers on probation or substitute workers, on temporary loan from other departments in the firm. For example, most Jiangsu workers with mean output below 70 cases have less than 20 observations in the 9-month sample. The plots illustrate the importance of controlling for

\footnotetext{
${ }^{10}$ The modal number of products (varieties) a worker produces in a shift is two (Table 2(I)-2(II)), and the assignment of products to a worker is persistent from shift to shift (Figure A.3).

${ }^{11}$ Table A.1 describes the minimal data cleaning we apply to the raw records. We drop a few date-shifts for which exceptional conditions were annotated and observed, such as the occurrence of a power outage, and the one shift that precedes (resp., follows) a department holiday, during which machines are turned off early (resp., late) for cleaning (resp., setting up).
} 
individual heterogeneity. All our regressions include a full set of worker fixed effects.

Besides comparing mean performance across workers, the remaining panels of Figure 1(I)-1(II) compare mean performance over days, separately by shift (or time of day). To prepare these plots, we compute a department's output, adjusted by the number of attendant workers, for each date-shift combination in the sample. This day-to-day variation in the average productivity of the workforce is of key importance to our empirical strategy - our task is to uncover the extent to which this temporal variation in output is driven by variation in concurrent up to month-long exposure to ambient air pollution, as proxied by PM2.5 and $\mathrm{SO}_{2}$ levels.

Environment workers are exposed to. We match the worker output data to outdoor pollutant mass concentrations, available from the Chinese Ministry of Environmental Protection, and to surface/atmospheric meteorological conditions available from NOAA and NASA (Table 2(I)-2(II)). ${ }^{12}$ As the main regressors of interest, PM2.5 and $\mathrm{SO}_{2}$, examined separately, serve as proxies for severe - mostly industrial-air pollution.

In part because the plants are located in built-up, including residential, areas, we are fortunate that official PM2.5 and $\mathrm{SO}_{2}$ monitors were in place as close as 3-4 km away. ${ }^{13}$ The exception is Henan for part of the sample period. Air monitoring in the immediate vicinity of the Henan plant, and in its host town, began only in January 2015, whereas the output sample starts in April 2014. We complement pollution data recorded nearby to the Henan work site in 2015 with PM2.5 and $\mathrm{SO}_{2}$ concentrations measured over the entire period at ambient monitors in three neighboring cities at most $60 \mathrm{~km}$ away. We show below that pollution at the Henan department's town is highly correlated with average pollution in the neighboring cities, suggesting that key pollution shocks are regional- - e.g., thermal inversions - rather than local in nature. In Henan's case, pollutant levels at the neigh-

\footnotetext{
${ }^{12}$ Meteorological variables include: (NASA) ground-level temperature, humidity and precipitation; (NOAA) wind speed and direction, and atmospheric temperature gradients. To capture thermal inversions close to the ground, we compute differences in temperature between the following pressure points: from 1000 to $925 \mathrm{mbar}, 925$ to $850 \mathrm{mbar}, 850$ to $700 \mathrm{mbar}$, and 700 to $500 \mathrm{mbar}$. The frequency for each series is either every three hours (NASA) or twice daily (NOAA), and the reference location is either specific to the town (NASA) or within $100 \mathrm{~km}$ of it (NOAA). As we explain in the Appendix, local air and weather monitoring sites/technologies appear well maintained and joint patterns in the data are plausible.

${ }^{13}$ The closest monitor is 3.7 and $3.4 \mathrm{~km}$ from the Jiangsu and Henan workplaces, respectively.
} 
boring cities matched to the full output sample complements the analysis of same-town pollution matched to part of the sample. In our main specifications, we allow for measurement error in workers' pollution exposure, as well as time-varying omitted variables, by instrumenting for measured pollution (nearby or up to $60 \mathrm{~km}$ away) using pollution predicted from meteorological conditions, such as thermal inversions, which should not affect worker output directly or correlate with unobserved output determinants.

For each date-shift in an output sample, we aggregate the one-hour pollutant readings into concurrent 12-hour means by date-shift, for the analysis of contemporaneous pollution exposure, as well as 24-hour means on each of the 30 days that precede the date-shift, for the analysis of more prolonged exposure. Figure 2 shows, over the days in each of the two samples, the evolution of mean output per worker in panels (a) and (c), alongside the evolution of concurrent PM2.5 levels at the closest monitor in panels (b) and (d) - see the solid lines. For reference, the one-year average primary NAAQS for PM2.5 is marked in panels (b) and (d) by the dashed horizontal line $\left(12 \mu \mathrm{g} / \mathrm{m}^{3}\right)$. Pollution, always severe, shows some seasonal variation (higher in the winter), but there is substantial variation within a month, from day to day, as there is for mean output/worker. Panel (b) (Jiangsu) adds the 10-day moving average for PM2.5 - see the dotted line. Substantial variation in pollution remains within season even as we aggregate over 10 consecutive days (and longer) - this is key to uncover any effect on output from longer exposure to air pollution. Panel (d) (Henan) adds concurrent PM2.5 levels at three neighboring cities up to $60 \mathrm{~km}$ away, showing these to correlate tightly with PM2.5 measured at the closest monitor 3.4 $\mathrm{km}$ from the work site. Similar points follow had we plotted $\mathrm{SO}_{2}$. The gradual trend in mean output/worker shown in panels (a) and (c) illustrates why we flexibly control for year-month in all our regression models. Moreover, our output regressions add controls for product composition. For example, the output share of 32s to 40s thread products at the Henan department was higher in 2015 relative to 2014, and this appears to contribute to a slight reduction in weighted output; also, in 2015 some machines were purchased from bankrupt firms and added to the second story of the building (see below).

Figure 3 further describes outdoor pollutant levels at each work site. The top panels 
show the distribution of within-shift (12-hour) mean PM2.5 measured by the closest official monitor (solid line), and how this tends to exceed PM2.5 levels measured by the US State Department on the rooftop of the regional US embassy (dashed line) - in Shanghai and Beijing for the Jiangsu and Henan samples, respectively, over the same period as the corresponding output sample for comparability. The comparison serves only to illustrate that air measured by the Chinese Ministry in the vicinity of the work sites we study is significantly dirtier than air measured by the US State Department at its urban sites, hundreds of $\mathrm{km}$ away and already notorious for pollution. For Henan, we also show the distribution of mean PM2.5 at the neighboring cities over the full output sample period (dotted line). The middle panels of Figure 3 plot the distribution of residuals of within-shift mean PM2.5 levels when these are regressed on year-month, day-of-week and time-of-day (shift) fixed effects. Much variation in ambient pollution remains even after we account for systematic seasonal, weekly and diurnal variation. Finally, the bottom panels show that PM2.5 and $\mathrm{SO}_{2}$ levels (again aggregated to date-shift) are correlated, but not excessively so, justifying why we examine both proxies for severe pollution.

Since workers spend much time indoors at work and at home, rather than outside where the air monitors are located, they may be exposed to lower levels of PM2.5 and $\mathrm{SO}_{2}$ than what the values of our pollution variables imply. Thus, as in the epidemiological literature, any output effects (response) should be interpreted for changes in outdoor concentrations (dose). We note from the environmental engineering literature that particles, from "fine" (PM2.5) to "ultrafine" (one to three orders of magnitude smaller than PM2.5, such as "nanoparticles"), do penetrate indoors. For example, Cyrys et al. (2004) reports, for a given microenvironment, that with "closed windows, the I/O (indoor-outdoor) ratios for PM2.5 are $\ldots 0.63 \ldots$ (and) that more than $75 \%$ of the daily indoor variation could be explained by the daily outdoor variation for those pollutants." 14

Importantly, the work sites we study are directly linked to ventilated outdoor environments by way of doors and imperfectly sealed windows - this is likely to be the case for workers' residences as well. The workplaces are located inside a single-story facility

\footnotetext{
${ }^{14}$ Other examples include Morawska et al. (2001), Gupta and Cheong (2007) and Buonanno et al. (2013), who find I/O ratios "varying in a relatively narrow range from 0.63 to 0.74 " (p.38) in schools in Italy.
} 
(Jiangsu) or mainly on the ground level of a two-story facility (Henan). In Henan, the second story is used for production on $13 \%$ of date-shifts (Table 2(II)), and only $3 \%$ of worker by date-shift observations in the sample - we allow this observed characteristic to shift output in our regression analysis. Building conditions vary according to age, from three decades (Henan) to one decade (Jiangsu). Significant air exchange between the outdoor and indoor environments is suggested by doors that lead into the workplace directly from outside, through which workers and materials/product continually transit, as well as old windows (Henan). ${ }^{15}$

Also important to disentangle any effect of pollution from that of temperature on worker productivity, both departments are heated in the winter and air conditioned in the summer, because extreme temperatures, which are observed in these locations, might damage inputs (e.g., machines, labor) and outputs (e.g. yarn, fabric). For the same reason, there is also humidity control. Heating, ventilation and air-conditioning (HVAC) systems are not exceptional but follow the norm in this industry. Importantly, the HVAC systems do not filter outdoor air. Consistent with this, we emphasize that not one manager among one dozen or so managers in China whom we have met with recently expressed the notion that short-term exposure to air pollution might impact a worker's productivity.

\section{Conceptual framework and empirical model}

\subsection{Conceptual framework}

Output sensitivity. To fix ideas, consider a worker of ability $a$ who works individually over a fixed shift of 12 hours. The worker is exposed to ambient air pollution $Z$, where $Z$ is a vector of concurrent and lagged pollution levels, $Z_{p}$, and $p=0,1, \ldots, P$ indexes the daily lag (starting with the concurrent period, $p=0$ ). Faced with pollution exposure $Z$, the worker chooses effort level $e$, and produces output quantity $q$. The worker incurs an

\footnotetext{
${ }^{15}$ In a field trip to the Jiangsu department, the newest building and which features no windows, we took a portable PM2.5 mass concentration monitor. Even in this relatively sheltered environment, we measured an I/O ratio of 0.5: PM2.5 levels outside were about $60 \mu \mathrm{g} / \mathrm{m}^{3}$ compared to about $30 \mu \mathrm{g} / \mathrm{m}^{3}$ inside (December 26, 2015 afternoon). The aerosol monitor is a TSI Dusttrak DRX 8533, calibrated on July 31, 2015, operating with size correction factor (SCF) and photometer calibration factor (PCF) of 1.17 and 0.38 , respectively.
} 
effort cost given by the function $c(e, Z)$, which exhibits the following properties:

$$
\frac{\partial c(\cdot)}{\partial e}>0, \frac{\partial c(\cdot)}{\partial Z_{p}} \geq 0, \frac{\partial^{2} c(\cdot)}{\partial e^{2}} \geq 0, \frac{\partial^{2} c(\cdot)}{\partial e \partial Z_{p}} \geq 0
$$

These conditions state that the cost of working increases in effort and lag- $p$ pollution (strictly and weakly, respectively), and that the positive marginal cost of effort increases weakly in both effort and pollution. We need not specify the sign of $\partial^{2} c(\cdot) / \partial Z_{p}{ }^{2}$. Output quantity $q=q(e, a)$ is an increasing and concave function of the effort level, with production and marginal product increasing strictly and weakly, respectively, in ability:

$$
\frac{\partial q(\cdot)}{\partial e}>0, \frac{\partial^{2} q(\cdot)}{\partial e^{2}}<0, \frac{\partial q(\cdot)}{\partial a}>0, \frac{\partial^{2} q(\cdot)}{\partial e \partial a} \geq 0
$$

The worker is paid a piece rate $w$ per unit of output. The piece rate is invariant to air quality, and does not vary across workstations, with workers performing the same parallel tasks on similar machines.

Conditional on coming to work, the worker solves:

$$
\arg \max _{e} w q(e, a)-c(e, Z)
$$

(The model can be extended dynamically to incorporate the probability of job retention as increasing in the level of output.) The optimal effort level, $e^{*}=e(Z, a)$, satisfies:

$$
\left.\left(w \frac{\partial q(e, a)}{\partial e}-\frac{\partial c(e, Z)}{\partial e}\right)\right|_{e=e^{*}}=0
$$

and output is $q=q\left(e^{*}, a\right)$. The first-order condition's first term captures the marginal benefit from exerting effort while the second term depicts the marginal cost. The total derivative of (1), with respect to the cost- and output-shifters $Z$ and $a$, yields:

$$
\left(\left(w \frac{\partial^{2} q(e, a)}{\partial e^{2}}-\frac{\partial^{2} c(e, Z)}{\partial e^{2}}\right)\left(\begin{array}{c}
\frac{\partial e(Z, a)}{\partial Z} \\
\frac{\partial e(Z, a)}{\partial a}
\end{array}\right)^{\prime}+\left(\begin{array}{c}
-\frac{\partial^{2} c(e, Z)}{\partial e \partial Z} \\
w \frac{\partial^{2} q(e, a)}{\partial e \partial a}
\end{array}\right)\right)^{\prime}\left(\begin{array}{c}
d Z \\
d a
\end{array}\right)=0
$$


Consider an increase in pollution $d Z_{p}>0$ (and fix the worker, $d a=0$ ). The worker's optimal response to this shift in the environment is to reduce effort, and the magnitude of the effort reduction depends on the magnitude of the shift in marginal cost, $\frac{\partial^{2} c(\cdot)}{\partial e \partial Z_{p}} \geq 0$ :

$$
\frac{\partial e(Z, a)}{\partial Z_{p}}=\frac{\partial^{2} c(e, Z) / \partial e \partial Z_{p}}{w \partial^{2} q(e, a) / \partial e^{2}-\partial^{2} c(e, Z) / \partial e^{2}} \leq 0
$$

noting that the rate at which the difference between marginal product and marginal cost changes in effort, in the denominator, is negative. This is illustrated in Figure 4, panel (a). (As drawn, both production and cost functions can be reasonably approximated by quadratic functions in the neighborhood of $e^{*}$, such that the denominator of $(3)$ is approximately constant.) Thus, a worker who is more sensitive to pollution, for whom the shift in marginal cost $\frac{\partial^{2} c(\cdot)}{\partial e \partial Z_{p}}$ is larger, will reduce effort more than a less sensitive worker. (For convenience, we do not index the cost function by $i$ to denote worker.)

Now compare two workers, $H$ and $L$, with different levels of ability, $a_{H}>a_{L}$. From (2), the optimal effort choice is weakly increasing in ability, $\frac{\partial e(Z, a)}{\partial a} \geq 0$, and this relationship is strict if marginal output strictly increases in ability, $\frac{\partial^{2} q(\cdot)}{\partial e \partial a}>0$. As illustrated in Figure 4, panel (b), the equilibrium marginal cost and revenue product are higher for the higher ability worker. As drawn, to the extent that variation in pollution shifts the marginal cost of either type of worker similarly (and marginal product schedules are approximately parallel across different ability levels), a change in pollution $d Z_{p}>0$ may lead to an optimal effort response of similar magnitude across the workers of different ability, i.e., $d e_{H}^{*} \approx d e_{L}^{*}$. The assumed properties of the production function then imply that the output response to pollution for the higher ability worker will exceed that of her lower ability counterpart. This can be seen in the panel by comparing the areas of the shaded trapezoids (of similar base).

The discussion highlights that worker sensitivity and worker ability are potential sources of heterogeneity in the individual response of output to pollution. This heterogeneity can be examined empirically. While we do not observe a worker's health status, which would enable us to examine the correlation with her output response (e.g., workers who suffer from asthma), we do observe a proxy for the worker's ability, based on mean 
performance in the sample (Figure 1(I)-1(II)). We can then examine whether the predicted pattern that more able workers exhibit a stronger dose-response holds up in the data.

Attendance sensitivity. More generally, one can model the worker's choice of attending work, with the reservation utility $\phi$ being a function of air pollution $Z$ and weather $W$. Exposure to pollution may not only impact output conditional on attending work, $q=q\left(e^{*}, a\right)$ : pollution may also affect selection into work on a given day. ${ }^{16}$ Pathways include the worker's own health and that of dependents that demand home care from the worker. In addition, weather may shift the relative value of outdoor leisure (e.g., moderate temperature and humidity), or shift the cost of commuting to work (e.g., precipitation increasing road congestion). In this more general setup, the worker's problem is:

$$
\max \left\{\phi(Z, W), \max _{e} w q(e, a)-c(e, Z)\right\}
$$

with the worker choosing between an unplanned absence (i.e., excluding predetermined leave days) or attending work as planned, and, conditional on attending work, optimizing over the effort level. Features of the labor markets we study, namely that the work shift starts at a predetermined time for the worker's team and is of fixed duration, imply that we need not model these additional margins of labor supply.

As discussed, our empirical setting of industrial workers in China, many of whom are migrants and/or live in firm dormitories, suggests that a selection effect of pollution on the composition of our worker-day output samples is unlikely to be large. Nevertheless, the empirical model presented next allows for this possibility. The sheltered workplace in our settings - temperature and humidity control, indoor protection from rain and windprovides a natural exclusion restriction for identifying the selection equation, since weather should not affect output directly, conditional on the choice of work. The exclusion of $W$ from the production and cost functions above - and thus from the output equation we specify below - allows us to control, by design, for an otherwise potentially important

\footnotetext{
${ }^{16}$ Studies of work loss associated with air pollution include Ostro (1983), Hausman et al. (1984), Diette et al. (2000), Hanna and Oliva (2015) and Aragon et al. (2016).
} 
confounder of output. We also show that the estimates of the output equation are indeed robust to adding $W$.

\section{$3.2 \quad$ Empirical models}

The empirical counterpart to the more general framework (4) can be written:

$$
\begin{aligned}
& d_{i t}^{*}=\gamma_{0}+Z_{t} \delta+W_{t} \gamma_{1}+\gamma_{t}+\gamma_{i}+\zeta_{i t}, \quad d_{i t}=1\left[d_{i t}^{*}>0\right], \\
& q_{i t}=\alpha_{0}+Z_{t} \beta+X_{i t} \alpha_{1}+\alpha_{t}+\alpha_{i}+\epsilon_{i t} \quad \text { if } d_{i t}=1,
\end{aligned}
$$

where $d_{i t}=1[$.$] indicates worker i$ 's choice of coming to work on day (date-shift) $t\left(d_{i t}^{*}>0\right)$, and $q_{i t}$ is her output conditional on the choice of work. Row vector $Z_{t}$ consists of concurrent pollution or, more generally, concurrent and lagged day pollution levels. $W_{t}$ are concurrent weather covariates, namely, temperature, humidity, precipitation and wind speed that may shift the worker's reservation utility. $X_{i t}$ is a vector of observed worker-day output controls, including product composition (e.g., the output share of high-thread products), indicators for the number of products produced, and the number of machines in the workstation. To account for systematic seasonal variation and worker heterogeneity, both selection and output equations include: (i) time fixed effects, $\gamma_{t}$ and $\alpha_{t}$, namely year-month fixed effects, day-of-week fixed effects (including public holidays in which the department was not on holiday), and shift (time-of-day) fixed effects; and (ii) individual worker fixed effects, $\gamma_{i}$ and $\alpha_{i}$. The remaining, idiosyncratic error terms are $\zeta_{i t}$ and $\epsilon_{i t}$.

Possibility of selection. In a regression of (6), but without the worker fixed effects $\alpha_{i}$, a sufficient condition to obtaining a consistent estimate of $\beta$, the effect of pollution on output, using pooled OLS is (e.g., Dustmann and Rochina-Barrachina, 2007):

$$
E\left[\alpha_{i}+\epsilon_{i t} \mid Z_{t}, X_{i t}, \alpha_{t}, d_{i t}=1\right]=0 .
$$

The OLS estimator will be biased, for example, if higher-ability workers, with higher $\alpha_{i}$, are more likely to call in absent when faced with high pollution exposure $Z_{t}$. Or say that asthmatic workers who are more sensitive to pollution are more likely to call in sick when 
faced with high exposure, and these workers happen to be less (resp., more) productive than other workers, in which case the estimate for $\beta$ will biased downward (resp., upward).

The inclusion of worker fixed effects in (6) can remove the bias caused by selection on $\alpha_{i}$. To obtain a consistent estimate of $\beta$, a sufficient condition is (Wooldridge, 1995):

$$
E\left[\epsilon_{i t}-\epsilon_{i s} \mid Z_{t}, X_{i t}, \alpha_{t}, Z_{s}, X_{i s}, \alpha_{s}, d_{i t}=d_{i s}=1\right]=0 \text { for periods } s \neq t
$$

This condition will only be violated if there is selection on $\epsilon_{i t}$. This would be the case if, for example, a worker who experiences a positive productivity shock on day $t$ (high $\left.\epsilon_{i t}\right)$ is more likely to call in absent when faced with high pollution versus low pollution exposure. In addition, the worker would need to observe her productivity shock $\epsilon_{i t}$ prior to making the work versus non-work choice. To account for this possibility, we can use (5) to estimate the probability that a worker chooses work on each day, and correcting for this probability in (6).

Distributed lag structure. We estimate models with varying distributed lag structures. The more restrictive model allows only concurrent pollution exposure to affect worker outcomes, and vector $Z_{t}$ has one element, $Z_{0 t}$. More generally, we specify $Z_{t}=$ $\left(Z_{0 t} Z_{1 t} \ldots Z_{P t}\right)$ and estimate models with an increasing number of lags, $P=0,1, \ldots, P_{\max }$. Following Zanobetti et al. $(2002,2003)$, we estimate models with as many as $P_{\max }=30$ lagged days. For example, a model (with concurrent day and) 15 lagged days would be indexed by $P=15$. For each model $P$, we estimate $1+P$ parameters of interest, $\beta_{p}$ in the output equation (6), and report the cumulative effect on a given worker day's output from a unit increase in pollution in each of $P+1$ concurrent and lagged days of exposure: $\sum_{p=0}^{P} \beta_{p}$. This is the unconstrained distributed lag specification, $\operatorname{UDL}(P)$. (The selection equation (5) can be specified similarly, allowing work attendance to be driven by concurrent and lagged pollution.)

Our preferred specification, following Schwartz (2000), is the polynomial distributed lag (PDL), where the coefficients on the lag structure are disciplined according to some (smooth) polynomial function. In a $\operatorname{PDL}(P, Q)$ model, with $P$ lags and polynomial degree 
$Q<P$, the coefficients on exposure are constrained as follows:

$$
\beta_{p}=\sum_{k=0}^{Q} \eta_{k} p^{k}, \quad p=0,1, \ldots, P
$$

where $\eta_{k}$ are parameters constraining the $\beta_{p}$. (Constraints on the dose-attendance response coefficients can be applied similarly.) We set $Q=4$, a quartic polynomial or $\operatorname{PDL}(P, 4)$, and show that our results are robust to freeing the $\beta_{p}$ entirely (i.e., $\operatorname{UDL}(P)$ ), or instead to further constraining the $\beta_{p}$ to follow a quadratic, $Q=2(\operatorname{PDL}(P, 2))$. The epidemiological literature finds that constraining the shape of variation in the lagged dose-health response coefficients substantially reduces noise relative to the unconstrained distributed lag model, since the exposure variable $Z$ tends to be serially correlated, at the expense of minimal bias (Schwartz, 2000).

Allowing for measurement error in pollution exposure. To alleviate concern that pollution exposure is measured with error, and to the extent that (7) holds and selection on idiosyncratic output shocks $\epsilon_{i t}$ is of lesser concern, we can use variation in meteorology $W$ to form an instrument for the exposure variable $Z$, as follows:

$$
Z_{t}=\delta_{0}+W_{t} \delta_{1}+\delta_{t}+\nu_{t}
$$

$\delta_{t}$ are time fixed effects (year-month, day-of-week including public holidays indicators, time-of-day), and $\nu_{t}$ is a disturbance. As Table A.2(I)-A.2(II) reports, surface and atmospheric meteorology, including wind speed, thermal inversions and precipitation, are key determinants of pollution, and such variables are excluded from the output equation. Similarly, such variables are unlikely to correlate with unobserved output determinants, $\epsilon_{i t}$. As such, we predict $Z$ using (8) and employ the predicted values to instrument for measured $Z$ in the output equation (6).

Individual heterogeneity. We further estimate the output equation allowing the response to pollution exposure to vary by worker, i.e., we can write $\beta_{i}$ instead of $\beta$ in (6). 


\section{Severe air pollution and worker outcomes}

We first examine the relationship between output and concurrent air pollution, as proxied by ambient PM2.5 or $\mathrm{SO}_{2}$ levels averaged over the 12 hours of each work shift. Table 3(I)3(II) reports estimates, a separate table by work site. The top panel in each table considers output data aggregated to the department by date-shift level, whereas the bottom panel examines output over time at the level of the individual worker.

For each site (across tables) and level of output aggregation (department or individual, across panels), we consider three models (across columns). We estimate each model taking the concurrent mean for either PM2.5 (odd numbered columns) or $\mathrm{SO}_{2}$ (even numbered columns) to proxy for contemporaneous exposure to air pollution. In the first model, "OLS categorical," pollution variation enters via bins (categorical variables) of width $50 \mu \mathrm{g} / \mathrm{m}^{3}$ for PM2.5, or bins of width $25 \mu \mathrm{g} / \mathrm{m}^{3}$ for $\mathrm{SO}_{2}$, and the model is estimated via OLS. In the second model, "OLS linear," the pollution variable enters linearly and the model is again estimated via OLS. In the third model, "2SLS linear," we allow for measurement error in pollution exposure and instrument for measured pollution using pollution predicted from variation in meteorology on the surface and in the lower atmosphere (Table A.2(I)-A.2(II)). This variation (e.g., surface wind speed, thermal inversions) is excluded from the output equation. The pollution variable is specified linearly and the model is estimated by 2SLS. We consider PM2.5 from the closest monitor to the workplace, within $4 \mathrm{~km}$. For $\mathrm{SO}_{2}$, we take mean levels across each host town's monitors, also located nearby to the workplace. ${ }^{17}$ Since using pollution data at the Henan host town restricts that sample to 2015, in the final two columns of Table 3(II) we additionally implement the 2SLS estimator on the full output sample using observed neighboring-city pollution, instrumenting for the regional pollution component that is explained by (regional) meteorological conditions.

In the aggregate analysis, with average output per worker as the outcome variable, an observation is a date-shift. In the individual analysis, the outcome variable is individual output (weighted sum across products, as explained) and an observation is a worker by

\footnotetext{
${ }^{17}$ A given monitor's hourly $\mathrm{SO}_{2}$ records can exhibit short-lived and isolated spikes, so we aggregate across monitors. See the Appendix.
} 
day pair with positive output. ${ }^{18}$ All models control for potentially confounding seasonal, weekly and time-of-day variation via year-month fixed effects, day-of-week fixed effects (including public holidays in which the department was not on holiday), and shift fixed effects. We use the same controls across sites, wherever these are observable, namely: (i) in the aggregate analysis, the average number of machines per worker and output shares for product types of similar thread; and (ii) in the individual analysis, the number of machines, output shares for product types of similar thread, the number of products produced (exactly two, three or more, as distinct categories from a single product produced by the worker), and, importantly, worker fixed effects. ${ }^{19}$ The objective is to reduce potential omitted variable bias and raise estimation precision.

As Table 3(I)-3(II) indicates, we do not find significant output effects from acute exposure when restricting models to concurrent (within-shift) air pollution, whether this is proxied by ambient PM2.5 or $\mathrm{SO}_{2}$ levels. For example, in Table 3(I), column (9) (Jiangsu site, OLS, linear form for PM2.5), a $10 \mu \mathrm{g} / \mathrm{m}^{3}$ increase in concurrent PM2.5 is associated with a rather precisely estimated small change in individual output of 0.00 case, with standard error (s.e.) clustered on day of 0.04 case. A $95 \%$ confidence interval (CI) of $[-0.08,0.08]$ per $10 \mu \mathrm{g} / \mathrm{m}^{3}$ increase in concurrent PM2.5 is economically insignificant relative to mean individual output of 112 cases. This "precise zero" impact of concurrent pollution on worker output - in the example, a CI of $[-0.1 \%, 0.1 \%]$ expressed as a proportion of mean output in the sample - is robust across sites, pollution proxies, and specifications. Even the largest estimated effect reported in the tables - a 0.8 case drop in output for $\mathrm{SO}_{2}$ levels above $50 \mu \mathrm{g} / \mathrm{m}^{3}$ relative to a reference level below $25 \mu \mathrm{g} / \mathrm{m}^{3}$, in column (8), Table $3(\mathrm{I})$ - is economically small: this is only $0.7 \%$ (CI $[-1.5 \%, 0.1 \%])$ of mean output.

Our finding of insignificant output impact from concurrent pollution is further illustrated in Figure 5, which plots individual output residuals, where co-variation with all

\footnotetext{
${ }^{18}$ On estimation, we trim each individual output sample by dropping observations with output beyond three standard deviations of the mean. Trimming drops $1 \%$ of observations. Table A.3(I)-A.3(II) follows Table 3(I)-3(II) but uses untrimmed samples. Estimates are very similar.

${ }^{19}$ Jiangsu models additionally control for workers during their initial two months at the firm, and observations on the last three days of the month. Henan models additionally control for production on the second story, the addition of a preparatory task to the worker's production schedule, and work hours. See the notes to Table 3(I)-3(II) and summary statistics in Table 2(I)-2(II).
} 
controls bar concurrent pollution is netted out, against concurrent pollution residuals. These plots include locally weighted polynomials of best fit to emphasize that our result is not driven by functional form, i.e., pollution entering via bins or linearly, as specified in Table 3(I)-3(II). Our result is robust to variation in modeling choices not shown in the tables, including adding a correction term to account for the possibility of selection on pollution in our worker-day output samples-Table A.4(I)-A.4(II) reports on attendance regressed on immediate pollution exposure, where again we do not find effects that differ significantly from zero. We obtain similar estimates if we control for concurrent outdoor temperature and humidity in the output equation - these are excluded in our preferred specification given the temperature and humidity controlled work environment. We emphasize that our regressor of interest, pollution, varies substantially day to day even after seasonality is accounted for (Figure 3). The result also stands in contrast to Chang et al. (2016) who report a 6\% drop in the daily output of indoor pear-packers in California for a $10 \mu \mathrm{g} / \mathrm{m}^{3}$ increase in concurrent PM2.5 levels at an outdoor site.

More prolonged exposure to air pollution. A strand in the epidemiological literature (following Schwartz, 2000; Zanobetti et al., 2002, 2003) finds that studies that only examine variation in concurrent pollution underestimate the health response to acute (sub-chronic) exposure. For example, on specifying daily deaths to depend on PM10 on the same day and up to the previous 40 days, Zanobetti et al. (2003) concludes that "(overall), the estimated effect of PM10 was doubled for CVD; the effect was five times larger for respiratory mortality" (p.1191, CVD = cardiovascular disease).

If acute exposure to pollution is found to affect mortality with up to weeks of delay, a similar lag structure is conceivable for pollution's impact on worker productivity - a more subtle response, whether physiological or psychological. Taking individual output (rather than the aggregate death count) as the outcome variable, we follow Zanobetti et al. (2003) and specify a vector of pollution variables, of size $1+P$, containing 24 -hour mean concentrations on the day of the worked shift all the way back to the previous $P$ days - see Conceptual Framework. We consider PM2.5 and $\mathrm{SO}_{2}$ in separate models and specify exactly the same controls for determinants of output (other than pollution) 
as in Table 3(I)-3(II), where the effect of pollution was restricted to concurrent exposure, compared to the more general specification here. We estimate models by OLS and 2SLS, where lags of measured pollution exposure are instrumented by the corresponding lags of meteorology-predicted pollution. In our preferred specification, to raise precision (Zanobetti et al., 2003) we constrain the coefficients on pollution to follow a fourth-order polynomial, $Q=4 .^{20}$ In sum, we estimate a separate fourth-order polynomial distributed lag model for every combination of site, proxy for pollution exposure, and lag length, $5 \leq P \leq 30$, noting that we require $P-Q>0$, thus, for a quartic, $P \geq 5$.

Figure 6(I)-6(II) reports point estimates and 95\% CI for the cumulative effect on individual output of concurrent and lagged pollution exposure, separately by work site. As before, standard errors are one-way clustered on day. In each figure, panels (a) (PM2.5) and (d) $\left(\mathrm{SO}_{2}\right)$ plot OLS estimates. Panels (b) and (e) (similarly, PM2.5 followed by $\mathrm{SO}_{2}$ ) plot OLS estimates in which we also control for concurrent day and previous day temperature and humidity in the output equation. Panels (c) and (f) plot 2SLS estimates. In each panel, for a choice of pollution proxy and estimator, along the horizontal axis we increase the maximum response delay in the output equation from $P=5$ to 30 days, estimating a different quartic distributed lag model, $\operatorname{PDL}(P, 4)$, for each lag increment. On the vertical axis, we report the output effect for $\mathrm{a}+10 \mu \mathrm{g} / \mathrm{m}^{3}$ increase in the given pollution proxy sustained over $1+P$ days (concurrent plus $P$ lags). For example, Figure 6(I), panel (a) reports, for $P=20$ lags (in days) on the horizontal axis, the OLS point estimate and $95 \%$ CI for the cumulative effect $\sum_{p=0}^{20} \beta_{p}$ of a 21-day sustained $+10 \mu \mathrm{g} / \mathrm{m}^{3}$ in PM2.5 levels on a Jiangsu worker's output. For ease of interpretation, we divide the estimated effect from cumulative exposure by mean output in each sample. For comparability across pollution proxies, recall that PM2.5 levels are about double those for $\mathrm{SO}_{2}$ (Figure 3).

We find that output effects from cumulative $+10 \mu \mathrm{g} / \mathrm{m}^{3}$ PM2.5 exposure begin to decline gradually from $0 \%$ for a model with a 5 -day lag structure, and peak at: (I) about $-0.5 \%$ of mean output at the Jiangsu site, and (II) -1 to $-3 \%$ of mean output at the Henan site when about 25 to 30 days of delay are allowed-panels (a) to (c). Estimates are

\footnotetext{
${ }^{20}$ In robustness tests reported below, we unconstrain the distributed lag, or constrain it further.
} 
statistically significantly different than zero for PM2.5 exposure models with about $P \geq 25$ and $P \geq 10$ days in Jiangsu and Henan, respectively. Output effects from cumulative +10 $\mu \mathrm{g} / \mathrm{m}^{3} \mathrm{SO}_{2}$ exposure peak at about $-1 \%$ and -2 to $-3 \%$ of mean output in Jiangsu and Henan, respectively (for $P \approx 25$ days) - panels $(\mathrm{d})$ to $(\mathrm{f}$ ).

Cumulative effects on output are also reported in Table 4, at 5-day increments for the lag structure, $P$. For Henan, we present two complete sets of OLS and 2SLS estimates: 2015 sample or full output sample with pollution measured, respectively, at host-town or neighboring-city monitors (Figure 6(II) plotted the former under OLS and the latter under 2SLS). Henan 2SLS estimates based on the full sample and regional $\mathrm{SO}_{2}$ variation are more significant than OLS estimates. Differences in Henan 2SLS versus OLS estimates, whether based on the 2015 or the full output sample, are less pronounced for PM2.5 variation.

Table 4 further presents 2SLS estimates of $\operatorname{PDL}(P, 4)$ output regressions that are very similar when we include a selection correction term imputed from a $\operatorname{PDL}(P, 4)$ attendance regression, with the corresponding $P$. How cumulative concurrent and lagged pollution exposure drives attendance is shown in panels $(\mathrm{g})$ and $(\mathrm{j})$ of Figure 6(I)-6(II). Here, the outcome variable is one if the worker produced output on a department work day, and zero otherwise. An observation is a worker by day in which the worker either produced output or her first day of zero output immediately following a day she worked. We include the same controls for attendance determinants as in Table A.4(I)-A.4(II), other than the more general $P$-day pollution lag structure specified here. We plot 2 SLS estimates ${ }^{21}$ using the full sample period for Henan, but note that OLS estimates would be similar. Point estimates of the effect on attendance from cumulative pollution exposure, as we raise $P$, are negative in Jiangsu and mostly positive in Henan, but in both cases they are statistically insignificant and economically modest, peaking at $-1 \%$ and $+1 \%$, respectively, per $+10 \mu \mathrm{g} / \mathrm{m}^{3}$ sustained increase in a given pollution proxy. ${ }^{22}$

Individual heterogeneity. In the remaining panels of Figure 6(I)-6(II), we allow

\footnotetext{
${ }^{21}$ Intuitively, surface wind and atmospheric stability influence pollution but are excluded from the work day choice problem (5).

${ }^{22}$ Hanna and Oliva (2015) exploit a refinery closure in Mexico City and use administrative labor-market data to estimate that "a $20 \%$ increase in $\mathrm{SO}_{2}$ results in about a $1.3 \mathrm{~h}$ (or $3.5 \%$ ) decline in hours worked in the following week" (p.78).
} 
the output response to prolonged air pollution exposure to vary across workers: in (6), we specify vector $\beta_{i}$ instead of vector $\beta$, choose a $\operatorname{PDL}(P, 2)$ (quadratic) and impose no constraints on the $\beta_{i, p}$ across workers. For each site, we consider the 25 workers with the most output observations (and full sample period for Henan). Panels (h) and (k) plot the 25th, 50th and 75th percentiles in the cross-worker distributions of 2SLS estimates for $\sum_{p=0}^{P} \hat{\beta}_{i, p}$ as we vary $P$ (OLS would be similar). The median effect across workers is similar to the mean effect in panels (c) and (f); at the peak, the 75 th percentile can reach twice the median. We then rank the 25 workers based on output sensitivity $\sum_{p=0}^{20} \hat{\beta}_{i, p}$, estimated for the $P=20$ model, labeling them in order of most sensitive (worker $1,2, \ldots$ ) to least sensitive $(\ldots, 24,25)$. Panels (i) and (j) show how the cumulative effect $\sum_{p=0}^{P} \hat{\beta}_{i, p}$ varies with the lag structure for five specific workers: workers 13 (median), 6 and 7 (near the most sensitive), and 18 and 19 (near the least sensitive).

Figure 7 further examines the individual worker response to prolonged pollution exposure. Panels (a) and (b) show that a worker's rank in terms of output sensitivity is similar whether we use PM2.5 or $\mathrm{SO}_{2}$ as a pollution proxy (again, sensitivity ranked based on the $P=20$ model). We rank workers according to their mean output in the sample and, in panels (c) to (f), show that a worker's output rank tends to correlate positively with her output sensitivity to pollution exposure. This is consistent with the Conceptual Framework, in particular, Figure 4, panel (b). We rank workers according their attendance sensitivity to prolonged pollution exposure, similarly based on a $\operatorname{PDL}(20,2)$, but do not find an association with the worker's output sensitivity rank - see panels (g) and (h).

Robustness. We perform a series of robustness tests. We unconstrain the distributed lag (Figure 8) or constrain it further by specifying a quadratic, $Q=2$ (Figure 9 ). Instead of trimming each sample by dropping observations with output beyond three standard deviations of the mean, we use untrimmed samples (Figure 10). Instead of specifying year-month fixed effects to account for seasonal variation, we include a quadratic time trend coupled with separate dummies for each winter month from November to February, during which pollution tends to be most severe (Figure 11). Estimates are robust, and can be more significant, e.g., compare Figure 11, panel (c) to Figure 6(II), panel (c). 


\section{Concluding remarks}

In a recent ranking of population-weighted ambient PM2.5 within "Global Burden of Disease" regions, East Asia came out on top, both for its mean level, estimated (from satellite observations) at $50 \mu \mathrm{g} / \mathrm{m}^{3}$ in $2001-2010$, and for its trend, at $+1.6 \mu \mathrm{g} / \mathrm{m}^{3} /$ year in 1998-2012 (Van Donkelaar et al., 2015). In particular, in the two industrial towns that host the workers we examine, ambient PM2.5 levels averaged 69 and $99 \mu \mathrm{g} / \mathrm{m}^{3}$ over the sample periods. Air pollution is severe, yet the severity varies within season, from day to day. We take advantage of this wide range of pollution variation and detailed daily worker output records. Across the different sites, pollution proxies, and estimators, we find a precisely estimated zero response of output to concurrent (same-shift) pollution.

This result, while at variance with a recent study that reported a $6 \%$ drop in daily worker output per $+10 \mu \mathrm{g} / \mathrm{m}^{3}$ increase in concurrent PM2.5 exposure, is consistent with what we heard from managers during field trips to over 10 manufacturing firms in four different provinces, evidence that we believe deserves some weight. All managers stated their perception that day-to-day fluctuation in pollution - shifts as high as 50-100 $\mu \mathrm{g} / \mathrm{m}^{3}$, which at this severity are visible - did not appear to impact a worker's output during the day of exposure. We believe managers did state their perceptions and that in their setting they would notice an output effect on the order of $-6 \%$ per $+10 \mu \mathrm{g} / \mathrm{m}^{3}$ PM2.5.

Following the epidemiological literature, we probe further and examine pollution exposure in the past 30 days. Countering the zero effect from concurrent pollution, we uncover statistically significant adverse effects. The magnitude of the estimated effect, however, is not large, and is less likely to be perceptible to managers. Raising the level of pollution exposure by an equivalent of $10 \mu \mathrm{g} / \mathrm{m}^{3}$ PM2.5 during the entire 3-4 week period prior to the day of production, is associated with a 0.5 to $3 \%$ shortfall in worker output.

We caution that our estimate of the effect of pollution on labor supply is for short run exposure, and does not include chronic effects, from years or decades of exposure to severe pollution. It is possible that the relatively young and healthy workers whom we observe are selected for their innate or acquired ability to cope with high levels of pollution. Similarly, we are not observing their later life outcomes. In any event, our hope is that economists 
examining the impacts of sub-chronic exposure to air pollution on socioeconomic outcomes follow the lead from the health literature and, like us, systematically investigate more prolonged (but still acute) exposure beyond the day the socioeconomic outcome is realized. We also hope that researchers make greater effort at sharing their data, particularly when records such as those of anonymous workers working at anonymous firms in relatively fragmented industries are less likely to be sensitive.

\section{References}

Adhvaryu, A., Kala, N., and Nyshadham, A. (2016). Management and shocks to worker productivity. Mimeo.

Aragon, F. M., Miranda, J. J., and Oliva, P. (2016). Particulate matter and labor supply: evidence from Peru. Working Paper 16-1, Simon Fraser University.

Bell, M. L. and Davis, D. L. (2001). Reassessment of the lethal London fog of 1952: Novel indicators of acute and chronic consequences of acute exposure to air pollution. Environmental Health Perspectives, 109:389-394.

Buonanno, G., Fuoco, F., Morawska, L., and Stabile, L. (2013). Airborne particle concentrations at schools measured at different spatial scales. Atmospheric Environment, $67: 38-45$.

Chang, T., Graff Zivin, J., Gross, T., and Neidell, M. (2016). Particulate pollution and the productivity of pear packers. American Economic Journal: Economic Policy, 8(3):141169.

Chen, Y., Ebenstein, A., Greenstone, M., and Li, H. (2013). Evidence on the impact of sustained exposure to air pollution on life expectancy from China's Huai River policy. Proceedings of the National Academy of Sciences, 110(32):12936-12941.

Cyrys, J., Pitz, M., Bischof, W., Wichmann, H.-E., and Heinrich, J. (2004). Relationship between indoor and outdoor levels of fine particle mass, particle number concentrations 
and black smoke under different ventilation conditions. Journal of Exposure Science and Environmental Epidemiology, 14(4):275-283.

Diette, G. B., Markson, L., Skinner, E. A., Nguyen, T. T., Algatt-Bergstrom, P., and Wu, A. W. (2000). Nocturnal asthma in children affects school attendance, school performance, and parents' work attendance. Archives of Pediatrics $\&$ Adolescent Medicine, 154(9):923-928.

Dustmann, C. and Rochina-Barrachina, M. E. (2007). Selection correction in panel data models: An application to the estimation of females' wage equations. Econometrics Journal, 10(2):263-293.

Economist (2015). The cost of clean air: Measures to combat air pollution are biting hard in industrial areas already hit by an economic slowdown. Print edition, February 7 .

Gupta, A. and Cheong, K. (2007). Physical characterization of particulate matter and ambient meteorological parameters at different indoor-outdoor locations in Singapore. Building and Environment, 42(1):237-245.

Hanna, R. and Oliva, P. (2015). The effect of pollution on labor supply: Evidence from a natural experiment in Mexico City. Journal of Public Economics, 122:68-79.

Hausman, J. A., Ostro, B. D., and Wise, D. A. (1984). Air pollution and lost work. NBER Working Paper No. 1263.

Lazear, E. P. (2000). Performance pay and productivity. American Economic Review, 90(5):1346-1361.

Morawska, L., He, C., Hitchins, J., Gilbert, D., and Parappukkaran, S. (2001). The relationship between indoor and outdoor airborne particles in the residential environment. Atmospheric Environment, 35(20):3463-3473.

Ostro, B. D. (1983). The effects of air pollution on work loss and morbidity. Journal of Environmental Economics and Management, 10(4):371-382. 
Schwartz, J. (2000). The distributed lag between air pollution and daily deaths. Epidemiology, 11(3):320-326.

Shi, J. and Skuterud, M. (2015). Gone fishing! Reported sickness absenteeism and the weather. Economic Enquiry, 53(1):388-405.

Van Donkelaar, A., Martin, R. V., Brauer, M., and Boys, B. L. (2015). Use of satellite observations for long-term exposure assessment of global concentrations of fine particulate matter. Environmental Health Perspectives, 123(2):135-143.

Wooldridge, J. M. (1995). Selection corrections for panel data models under conditional mean independence assumptions. Journal of Econometrics, 68(1):115-132.

World Health Organization (2006). WHO air quality guidelines for particulate matter, ozone, nitrogen dioxide and sulfur dioxide: Global update 2005, summary of risk assessment. Technical report, World Health Organization.

Zanobetti, A., Schwartz, J., Samoli, E., Gryparis, A., Touloumi, G., Atkinson, R., Le Tertre, A., Bobros, J., Celko, M., Goren, A., Forsberg, B., Michelozzi, P., Rabczenko, D., Ruiz, E. A., and Katsouyanni, K. (2002). The temporal pattern of mortality responses to air pollution: A multicity assessment of mortality displacement. Epidemiology, 13(1):87-93.

Zanobetti, A., Schwartz, J., Samoli, E., Gryparis, A., Touloumi, G., Peacock, J., Anderson, R. H., Le Tertre, A., Bobros, J., Celko, M., Goren, A., Forsberg, B., Michelozzi, P., Rabczenko, D., Hoyos, S. P., Wichmann, H. E., and Katsouyanni, K. (2003). The temporal pattern of respiratory and heart disease mortality in response to air pollution. Environmental Health Perspectives, 111(9):1188-1193. 


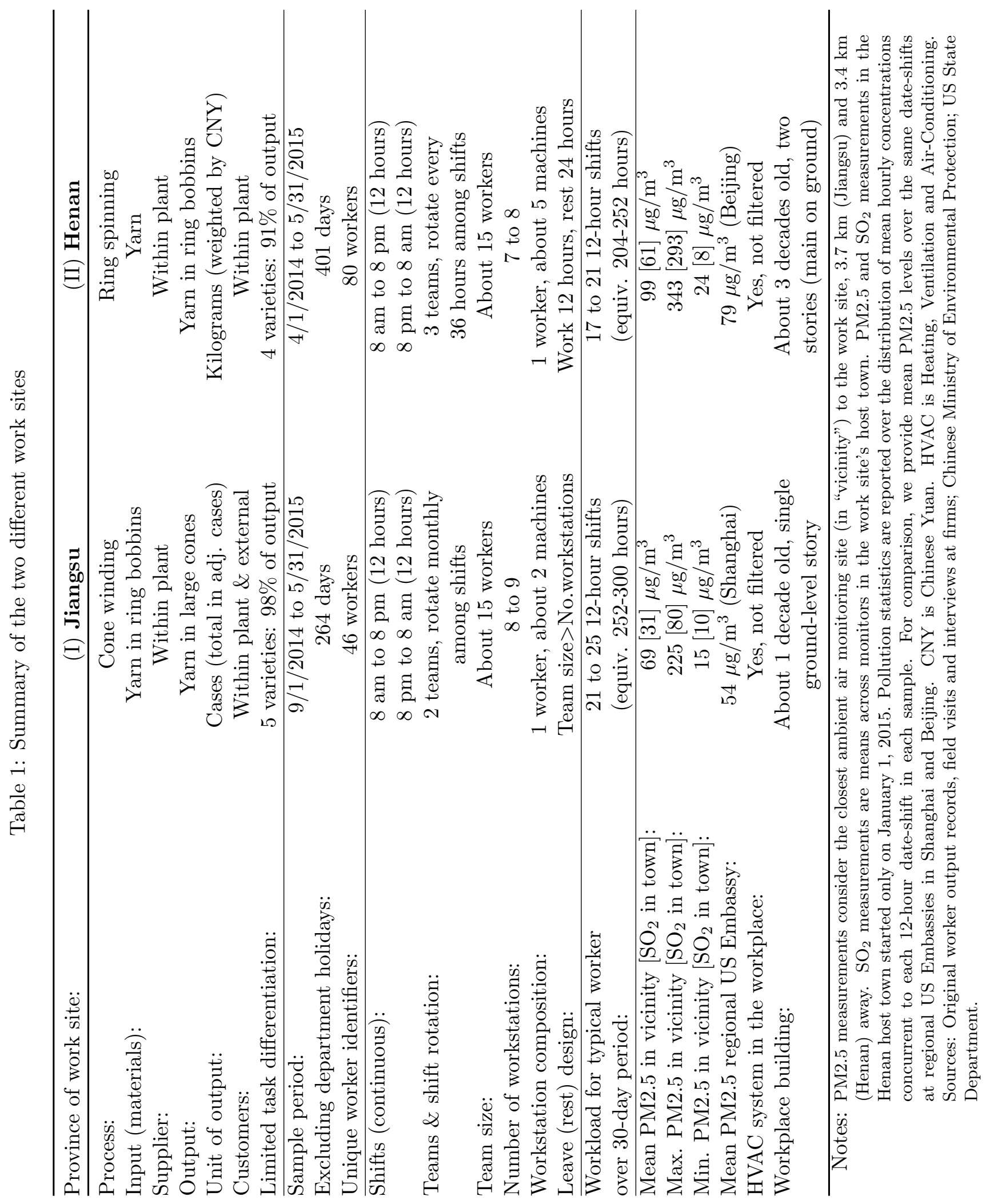


Table 2(I): Descriptive statistics for the Jiangsu work site

\begin{tabular}{|c|c|c|c|c|c|}
\hline Variables & $\mathrm{N}$ & Mean & Std.Dev. & Min. & Max. \\
\hline Output (cases/worker/shift) & 4,500 & 111.58 & 22.11 & 8.00 & 170.14 \\
\hline Number of machines & 4,500 & 1.90 & 0.30 & 0.50 & 2.50 \\
\hline \multicolumn{6}{|l|}{ Output share by product type (\%) } \\
\hline$\ldots 34$ s to 50 s thread & 4,500 & 0.37 & 0.42 & 0.00 & 1.00 \\
\hline$\ldots 60$ s to 80 s thread & 4,500 & 0.51 & 0.43 & 0.00 & 1.00 \\
\hline$\ldots 100$ s and 120 s thread & 4,500 & 0.12 & 0.21 & 0.00 & 1.00 \\
\hline \multicolumn{6}{|l|}{ Number of products produced } \\
\hline ... exactly one variety & 4,500 & 0.32 & 0.47 & 0.00 & 1.00 \\
\hline ... exactly two varieties & 4,500 & 0.48 & 0.50 & 0.00 & 1.00 \\
\hline ... three or more varieties & 4,500 & 0.20 & 0.40 & 0.00 & 1.00 \\
\hline Initial two months at the firm (yes=1) & 4,500 & 0.09 & 0.28 & 0.00 & 1.00 \\
\hline$\overline{\text { PM2.5, closest monitor }\left(\mu \mathrm{g} / \mathrm{m}^{3}\right)}$ & 524 & 68.85 & 35.30 & 15.39 & 224.67 \\
\hline $\mathrm{SO}_{2}$, average town $\left(\mu \mathrm{g} / \mathrm{m}^{3}\right)$ & 524 & 30.80 & 13.83 & 9.52 & 80.08 \\
\hline Temperature at the surface $\left({ }^{\circ} \mathrm{C}\right)$ & 525 & 13.67 & 7.32 & -0.84 & 27.94 \\
\hline Relative humidity at the surface (\%) & 525 & 67.27 & 18.37 & 22.29 & 99.59 \\
\hline Precipitation at the surface (mm/hour) & 525 & 0.11 & 0.47 & 0.00 & 6.09 \\
\hline Wind speed at the surface $(\mathrm{m} / \mathrm{s})$ & 525 & 2.66 & 1.46 & 0.00 & 8.00 \\
\hline \multicolumn{6}{|c|}{ Wind direction at the surface (all hours from a given direction=1) } \\
\hline ... from North & 525 & 0.20 & 0.36 & 0.00 & 1.00 \\
\hline ... from East & 525 & 0.42 & 0.46 & 0.00 & 1.00 \\
\hline ... from South & 525 & 0.12 & 0.30 & 0.00 & 1.00 \\
\hline ... from West & 525 & 0.26 & 0.43 & 0.00 & 1.00 \\
\hline \multicolumn{6}{|c|}{ Temperature difference $\left({ }^{\circ} \mathrm{C}\right)$ between altitudes at specific atmospheric pressure levels } \\
\hline ... from 1000 to $925 \mathrm{mb}$ & 525 & -3.50 & 2.15 & -6.60 & 8.00 \\
\hline$\ldots$ from 925 to $850 \mathrm{mb}$ & 525 & -2.58 & 2.19 & -6.60 & 5.40 \\
\hline ... from 850 to $700 \mathrm{mb}$ & 525 & -5.50 & 3.66 & -12.90 & 5.60 \\
\hline$\ldots$ from 700 to $500 \mathrm{mb}$ & 525 & -14.12 & 2.79 & -20.90 & -3.80 \\
\hline
\end{tabular}

Notes: An observation is a worker by date-shift pair (top panel) or a date-shift (bottom panel). The sample period is September 1, 2014 to May 31, 2015. We exclude date-shifts on which the department was on holiday. 
Table 2(II): Descriptive statistics for the Henan work site

\begin{tabular}{|c|c|c|c|c|c|}
\hline Variables & $\mathrm{N}$ & Mean & Std.Dev. & Min. & Max. \\
\hline Output (CNY/worker/shift) & 5,307 & 125.40 & 31.32 & 2.69 & 237.06 \\
\hline Worker produced on the second story (yes=1) & 5,307 & 0.03 & 0.18 & 0.00 & 1.00 \\
\hline Number of machines $\times$ ground-level production & 5,281 & 4.98 & 1.42 & 0.00 & 12.30 \\
\hline \multicolumn{6}{|l|}{ Output share by product type (\%) } \\
\hline$\ldots 32 \mathrm{~s}$ to 40 s thread & 5,307 & 0.68 & 0.35 & 0.00 & 1.00 \\
\hline Preparatory task added to output (yes $=1$ ) & 5,307 & 0.02 & 0.15 & 0.00 & 1.00 \\
\hline \multicolumn{6}{|l|}{ Number of products produced } \\
\hline ... exactly one variety & 5,307 & 0.22 & 0.41 & 0.00 & 1.00 \\
\hline ... exactly two varieties & 5,307 & 0.53 & 0.50 & 0.00 & 1.00 \\
\hline$\ldots$ three or more varieties & 5,307 & 0.25 & 0.43 & 0.00 & 1.00 \\
\hline Work hours & 5,307 & 11.57 & 1.16 & 1.00 & 12.00 \\
\hline Department produce & 784 & 0.13 & 0.33 & 0.00 & 1.00 \\
\hline PM2.5, closest monitor $\left(\mu \mathrm{g} / \mathrm{m}^{3}\right)$ & 257 & 99.06 & 49.79 & 23.55 & 342.58 \\
\hline $\mathrm{SO}_{2}$, average town $\left(\mu \mathrm{g} / \mathrm{m}^{3}\right)$ & 257 & 60.97 & 40.84 & 8.33 & 293.10 \\
\hline PM2.5, three neighboring cities $\left(\mu \mathrm{g} / \mathrm{m}^{3}\right)$ & 783 & 84.73 & 48.07 & 9.47 & 395.87 \\
\hline $\mathrm{SO}_{2}$, three neighboring cities $\left(\mu \mathrm{g} / \mathrm{m}^{3}\right)$ & 783 & 40.95 & 25.82 & 9.02 & 160.40 \\
\hline Temperature at the surface $\left({ }^{\circ} \mathrm{C}\right)$ & 784 & 16.95 & 9.73 & -4.67 & 38.33 \\
\hline Relative humidity at the surface (\%) & 784 & 47.26 & 20.39 & 1.67 & 96.91 \\
\hline Prec & 784 & 0.08 & 0.36 & 0.00 & 5.77 \\
\hline Wind speed at the surface $(\mathrm{m} / \mathrm{s})$ & 778 & 2.00 & 1.18 & 0.00 & 8.00 \\
\hline \multicolumn{6}{|c|}{ Wind direction at the surface (all hours from a given direction=1) } \\
\hline ... from North & 784 & 0.12 & 0.28 & 0.00 & 1.00 \\
\hline ... from East & 784 & 0.41 & 0.45 & 0.00 & 1.00 \\
\hline ... from $\mathrm{S}$ & 784 & 0.25 & 0.38 & 0.00 & 1.00 \\
\hline ... from West & 784 & 0.21 & 0.37 & 0.00 & 1.00 \\
\hline \multicolumn{6}{|c|}{ Temperature difference $\left({ }^{\circ} \mathrm{C}\right)$ between altitudes at specific atmospheric pressure levels } \\
\hline ...from 1000 to $925 \mathrm{mb}$ & 784 & -3.18 & 2.25 & -6.40 & 7.80 \\
\hline ...from 925 to $850 \mathrm{mb}$ & 784 & -3.73 & 1.82 & -7.20 & 4.30 \\
\hline ...from 850 to $700 \mathrm{mb}$ & 784 & -8.29 & 3.48 & -15.60 & 3.00 \\
\hline ...from 700 to $500 \mathrm{mb}$ & 784 & -14.72 & 3.03 & -22.60 & -1.40 \\
\hline
\end{tabular}

Notes: An observation is a worker by date-shift pair (top panel) or a date-shift (bottom panel). The sample period is April 1, 2014 to May 31, 2015. We exclude date-shifts on which the department was on holiday. We observe the number of machines for production on the main ground-level story. Ambient air monitoring in the Henan town that hosts the work site we study started on January 1, 2015, so we additionally report, for the full output sample period, mean pollution statistics from three neighboring cities at most $60 \mathrm{~km}$ away. 


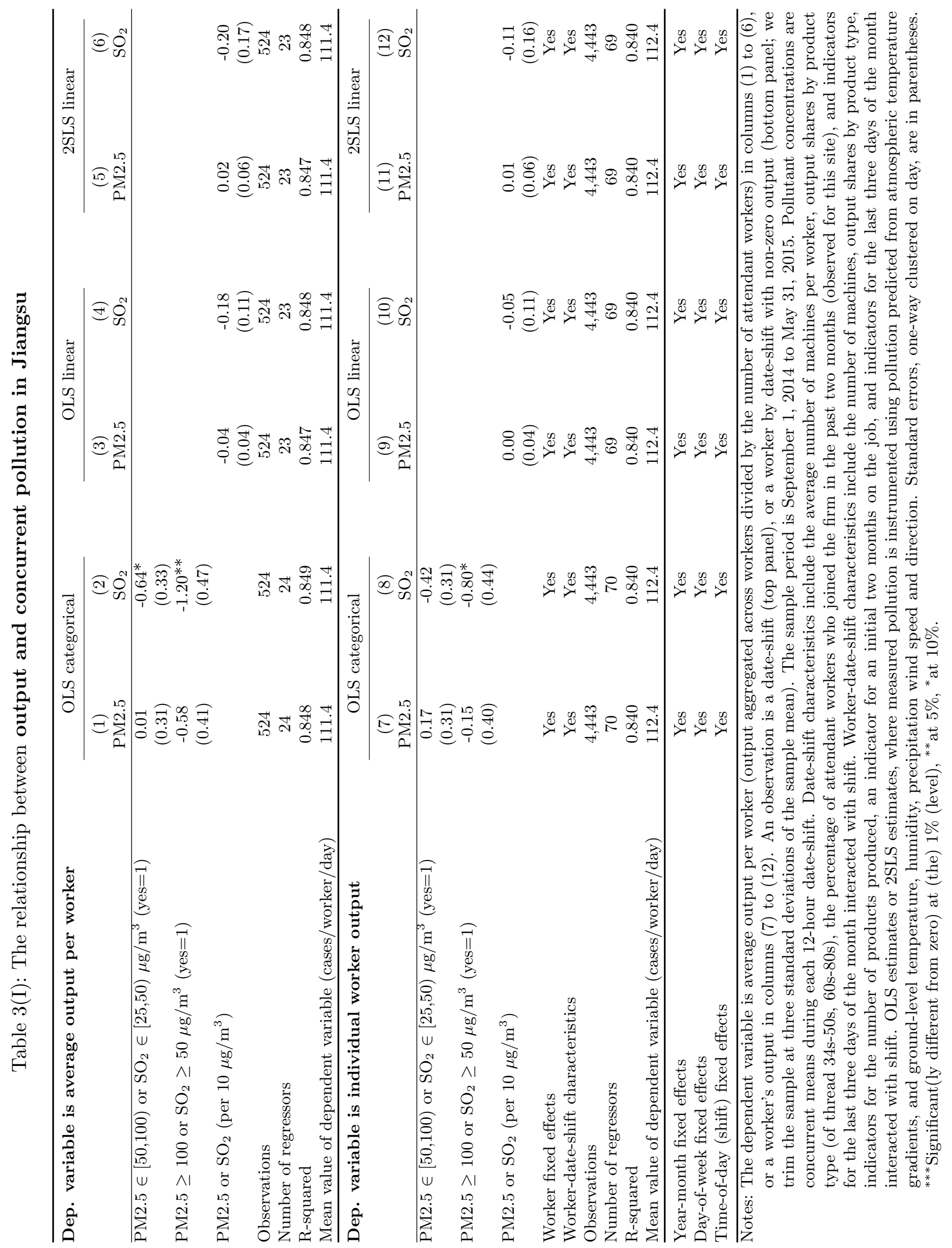




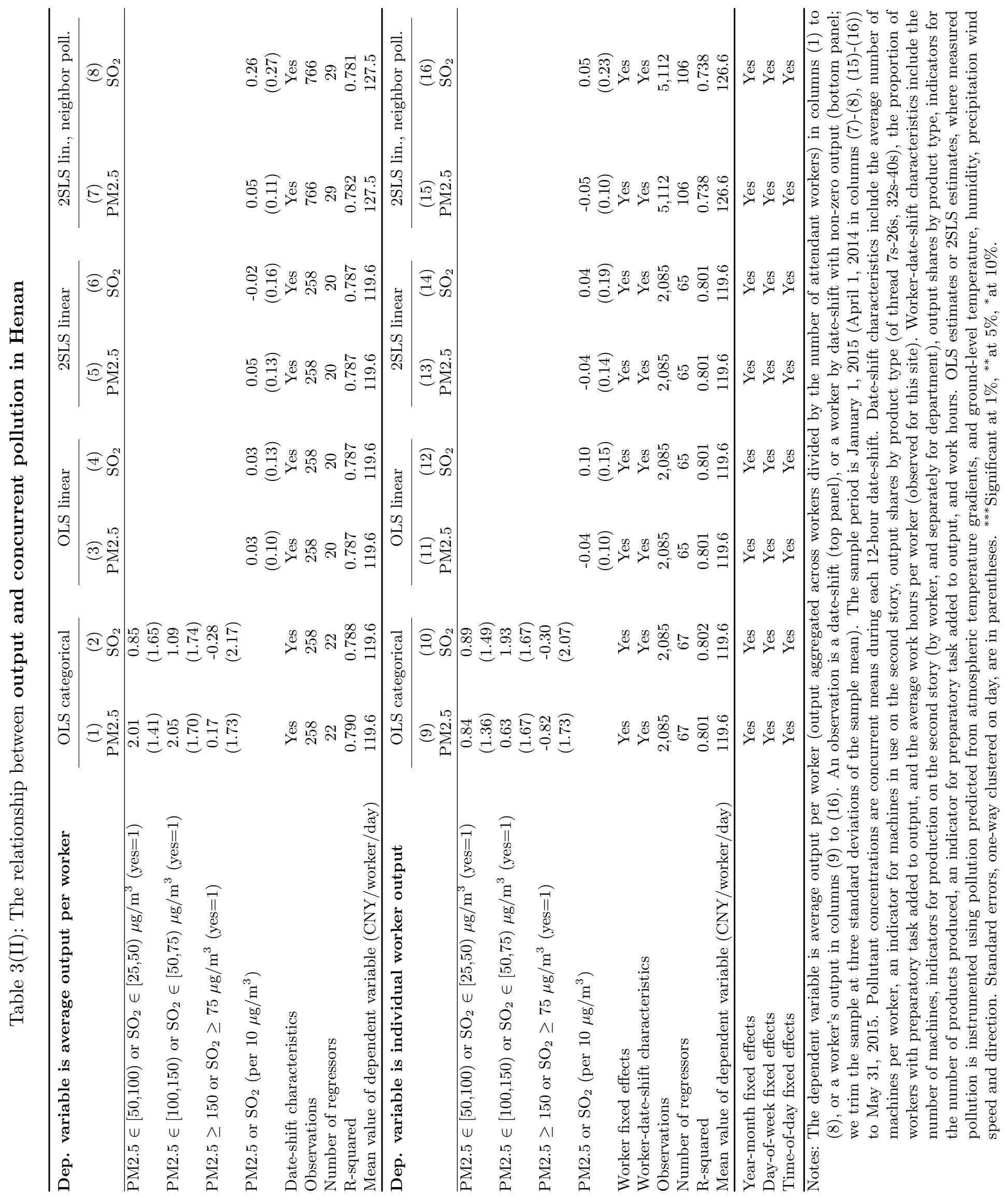


Table 4: The relationship between output and more prolonged pollution exposure

\begin{tabular}{|c|c|c|c|c|c|c|}
\hline \multirow{2}{*}{$\begin{array}{l}\text { Lag structure } \\
\qquad(P)\end{array}$} & \multicolumn{2}{|c|}{ OLS } & \multicolumn{2}{|c|}{$2 \mathrm{SLS}$} & \multicolumn{2}{|c|}{ 2SLS w/ selection corr. } \\
\hline & PM2.5 & $\mathrm{SO}_{2}$ & PM2.5 & $\mathrm{SO}_{2}$ & PM2.5 & $\mathrm{SO}_{2}$ \\
\hline & \multicolumn{6}{|c|}{ Jiangsu } \\
\hline \multirow[t]{2}{*}{5} & 0.046 & -0.069 & 0.089 & $-0.389^{*}$ & 0.070 & $-0.591^{* *}$ \\
\hline & $(0.088)$ & $(0.167)$ & $(0.113)$ & $(0.202)$ & $(0.119)$ & $(0.236)$ \\
\hline \multirow[t]{2}{*}{10} & -0.000 & 0.024 & -0.019 & -0.192 & -0.020 & -0.372 \\
\hline & $(0.121)$ & $(0.203)$ & $(0.147)$ & $(0.228)$ & $(0.147)$ & $(0.248)$ \\
\hline \multirow[t]{2}{*}{15} & 0.019 & 0.122 & -0.045 & -0.092 & -0.043 & -0.228 \\
\hline & $(0.137)$ & $(0.226)$ & $(0.157)$ & $(0.246)$ & $(0.160)$ & $(0.250)$ \\
\hline \multirow[t]{2}{*}{20} & -0.160 & 0.242 & -0.170 & -0.038 & -0.171 & -0.286 \\
\hline & $(0.155)$ & $(0.286)$ & $(0.171)$ & $(0.318)$ & $(0.172)$ & $(0.340)$ \\
\hline \multirow[t]{2}{*}{25} & $-0.338^{*}$ & $-0.712^{*}$ & $-0.350^{*}$ & $-0.952^{* *}$ & $-0.347^{*}$ & $-1.003^{* *}$ \\
\hline & $(0.173)$ & $(0.409)$ & $(0.180)$ & $(0.451)$ & $(0.180)$ & $(0.451)$ \\
\hline \multirow[t]{3}{*}{30} & -0.279 & -0.658 & -0.243 & -0.691 & -0.241 & -0.700 \\
\hline & $(0.171)$ & $(0.433)$ & $(0.179)$ & $(0.458)$ & $(0.180)$ & $(0.457)$ \\
\hline & \multicolumn{6}{|c|}{ Henan, pollution in the host town ( 2015 only) } \\
\hline \multirow[t]{2}{*}{5} & -0.290 & 0.158 & $-0.747^{* *}$ & 0.205 & -0.579 & 0.280 \\
\hline & $(0.276)$ & $(0.599)$ & $(0.355)$ & $(0.758)$ & $(0.391)$ & $(0.966)$ \\
\hline \multirow[t]{2}{*}{10} & $-0.923^{* *}$ & 0.777 & $-1.471^{* *}$ & 0.802 & $-1.370^{* *}$ & 1.224 \\
\hline & $(0.411)$ & $(0.844)$ & $(0.599)$ & $(1.100)$ & $(0.608)$ & (1.189) \\
\hline \multirow[t]{2}{*}{15} & -0.894 & -0.294 & $-1.792^{* *}$ & 0.824 & -1.330 & 0.916 \\
\hline & $(0.728)$ & (1.158) & $(0.898)$ & $(1.677)$ & $(0.937)$ & $(1.675)$ \\
\hline \multirow[t]{2}{*}{20} & $-2.271^{* * *}$ & -1.325 & $-2.623^{* *}$ & -2.187 & $-2.462^{* *}$ & -2.144 \\
\hline & $(0.873)$ & $(1.561)$ & $(1.155)$ & $(2.330)$ & $(1.141)$ & $(2.294)$ \\
\hline \multirow[t]{2}{*}{25} & $-2.171^{* *}$ & -2.745 & $-2.985^{* *}$ & -2.273 & $-2.434^{*}$ & -2.267 \\
\hline & (1.099) & (1.798) & $(1.378)$ & $(2.397)$ & $(1.381)$ & $(2.371)$ \\
\hline \multirow[t]{3}{*}{30} & $-2.991^{* *}$ & $-3.048^{*}$ & $-3.302^{* *}$ & -2.226 & $-2.908^{* *}$ & -2.217 \\
\hline & $(1.261)$ & $(1.828)$ & $(1.443)$ & $(2.469)$ & $(1.462)$ & $(2.474)$ \\
\hline & \multicolumn{6}{|c|}{ Henan, pollution in neighboring cities (full output sample) } \\
\hline \multirow[t]{2}{*}{5} & $-0.170^{*}$ & 0.040 & -0.217 & 0.364 & -0.100 & 0.354 \\
\hline & $(0.102)$ & $(0.261)$ & $(0.146)$ & $(0.327)$ & $(0.239)$ & $(0.335)$ \\
\hline \multirow[t]{2}{*}{10} & $-0.317^{* *}$ & 0.110 & -0.264 & -0.248 & -0.118 & -0.216 \\
\hline & $(0.141)$ & $(0.336)$ & $(0.189)$ & $(0.460)$ & $(0.224)$ & $(0.462)$ \\
\hline \multirow[t]{2}{*}{15} & -0.173 & -0.017 & -0.177 & -0.654 & 0.126 & -0.662 \\
\hline & $(0.180)$ & $(0.424)$ & $(0.223)$ & $(0.509)$ & $(0.281)$ & $(0.505)$ \\
\hline \multirow[t]{2}{*}{20} & -0.184 & -0.369 & -0.295 & $-1.793^{* * *}$ & -0.271 & $-1.837^{* * *}$ \\
\hline & $(0.200)$ & $(0.569)$ & $(0.215)$ & $(0.691)$ & $(0.219)$ & $(0.696)$ \\
\hline \multirow[t]{2}{*}{25} & -0.101 & -0.811 & -0.399 & $-1.939^{* * *}$ & -0.377 & $-1.934^{* * *}$ \\
\hline & $(0.228)$ & $(0.565)$ & $(0.267)$ & $(0.639)$ & $(0.282)$ & $(0.638)$ \\
\hline \multirow[t]{2}{*}{30} & -0.435 & -0.632 & $-0.586^{*}$ & $-2.151^{* * *}$ & -0.566 & $-2.152^{* * *}$ \\
\hline & $(0.273)$ & $(0.606)$ & $(0.334)$ & $(0.697)$ & $(0.347)$ & $(0.701)$ \\
\hline
\end{tabular}

Notes: Each row and column reports the coefficient and standard error on the cumulative effect on worker output from concurrent and lagged pollution exposure, $\sum_{p=0}^{P} \beta_{p}$, estimated from a quartic distributed lag model, $\operatorname{PDL}(P, 4)$, where $P$ is the number of lags in days, and pollution variables are daily 24-hour means. We report estimates as a proportion of mean worker output. Sample periods are September 1, 2014 to May 31, 2015 (Jiangsu), January 1 to May 31, 2015 (Henan with host town pollution) and April 1, 2014 to May 31, 2015 (Henan with neighboring city pollution). The last two columns report 2SLS estimates that include a selection correction imputed from a $\operatorname{PDL}(P, 4)$ attendance regression as in Figure 6(I)-6(II). Other specifications (OLS or 2SLS, worker-date-shift controls, fixed effects, standard errors) as in Table $3(\mathrm{I})-3(\mathrm{II}) . \quad 37{ }^{* * *}$ Significant at $1 \%,{ }^{* *}$ at $5 \%,{ }^{*}$ at $10 \%$. 


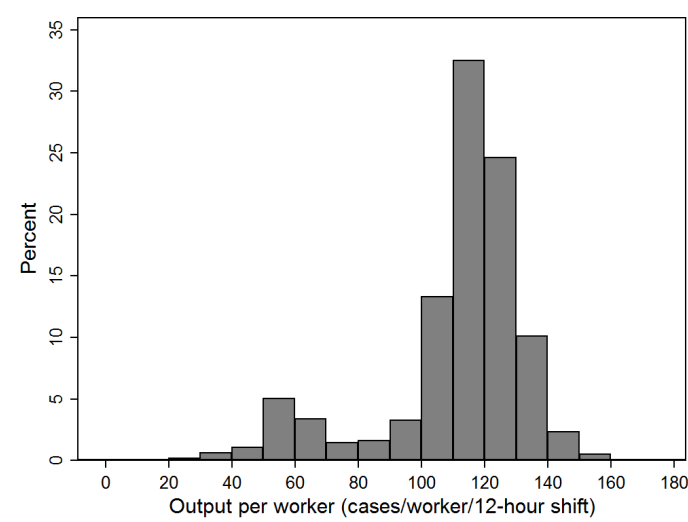

(a) Across workers and days

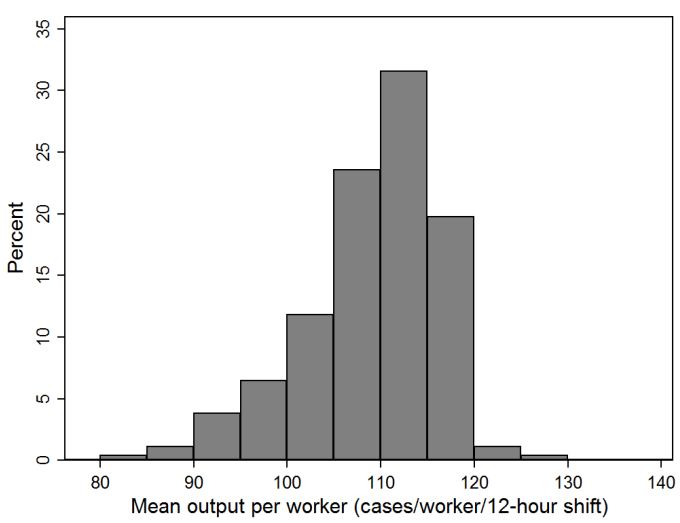

(c) Across days, 8 am shift

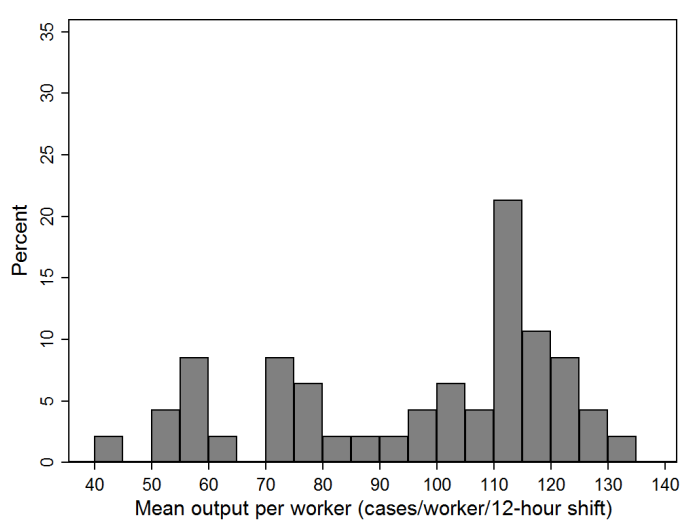

(b) Across workers

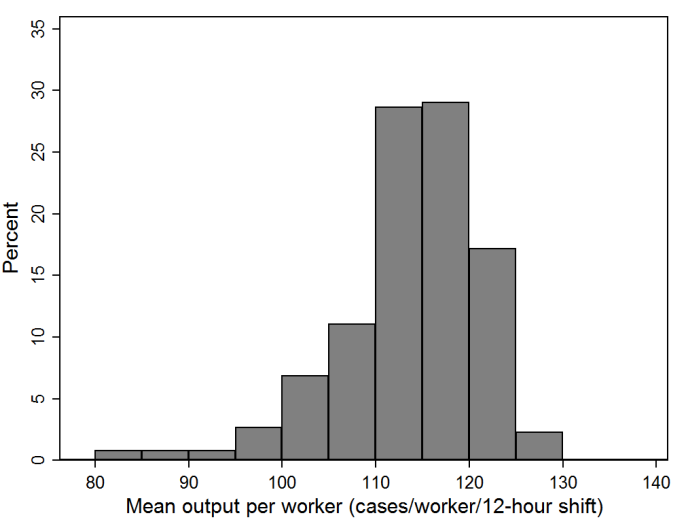

(d) Across days, 8 pm shift

Figure 1(I): Distributions in the Jiangsu worker sample of (a) individual output across workers and over time, (b) mean output across workers, and (c) to (d) mean output across days (by shift). An observation in (a) is a worker by date-shift pair. An observation in (b) is a worker. An observation in (c) to (d) is a day. 


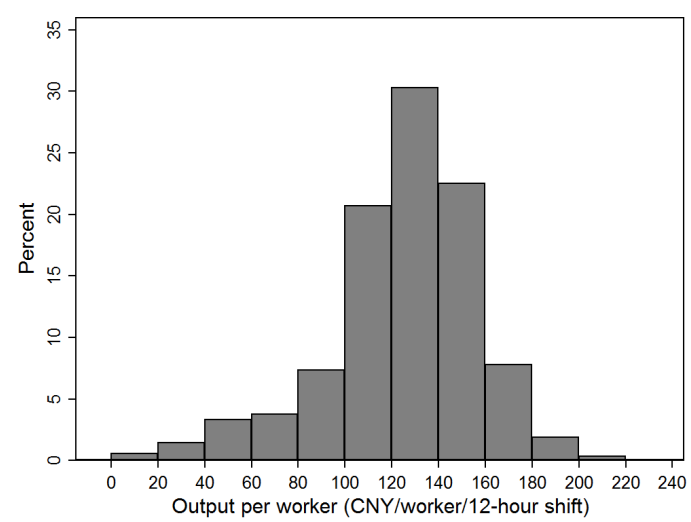

(a) Across workers and days

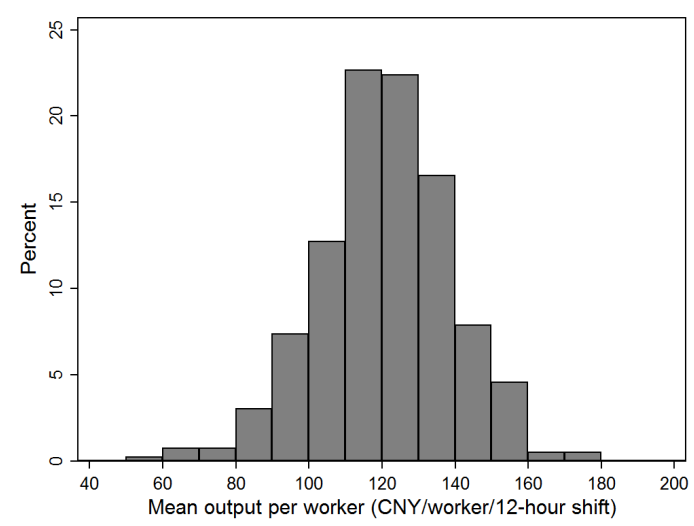

(c) Across days, 8 am shift

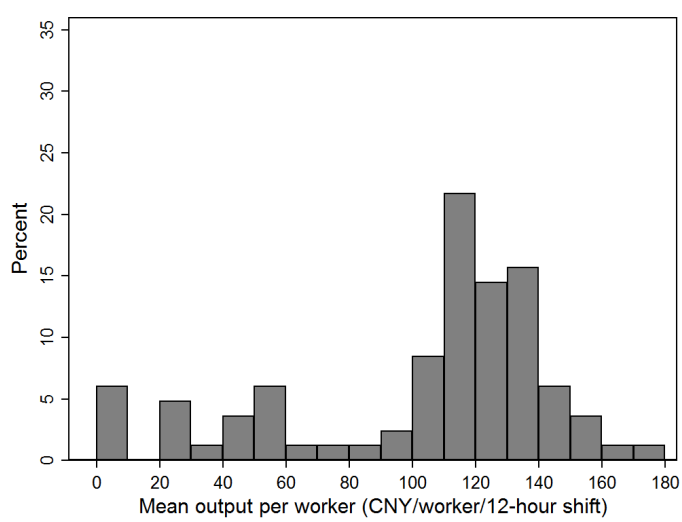

(b) Across workers

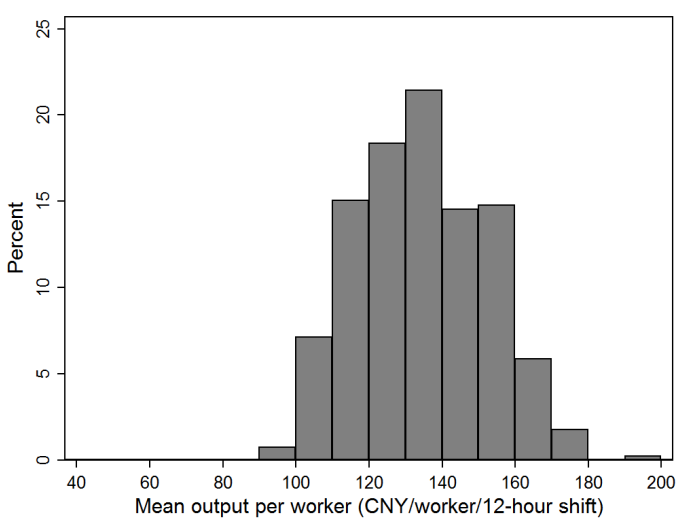

(d) Across days, 8 pm shift

Figure 1(II): Distributions in the Henan worker sample of (a) individual output across workers and over time, (b) mean output across workers, and (c) to (d) mean output across days (by shift). An observation in (a) is a worker by date-shift pair. An observation in (b) is a worker. An observation in (c) to (d) is a day. 

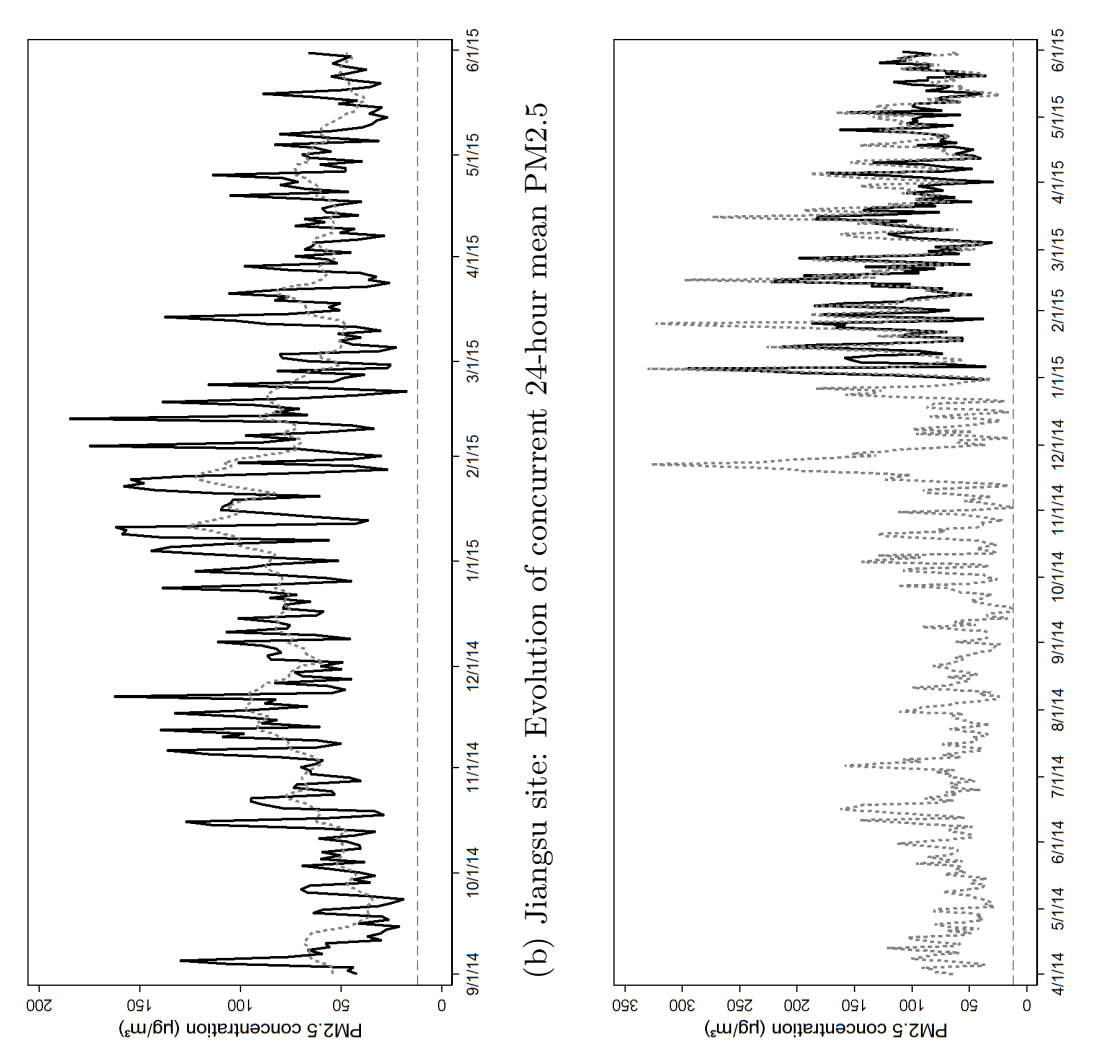

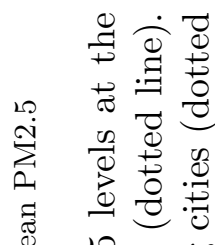

10. 80.00

$\sum \pi$

సै दे

శ్

a

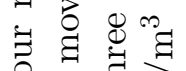

表要

小

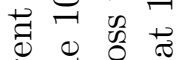

듬

苟

范范

羊莽苛

ส

की

(0) 党

렁
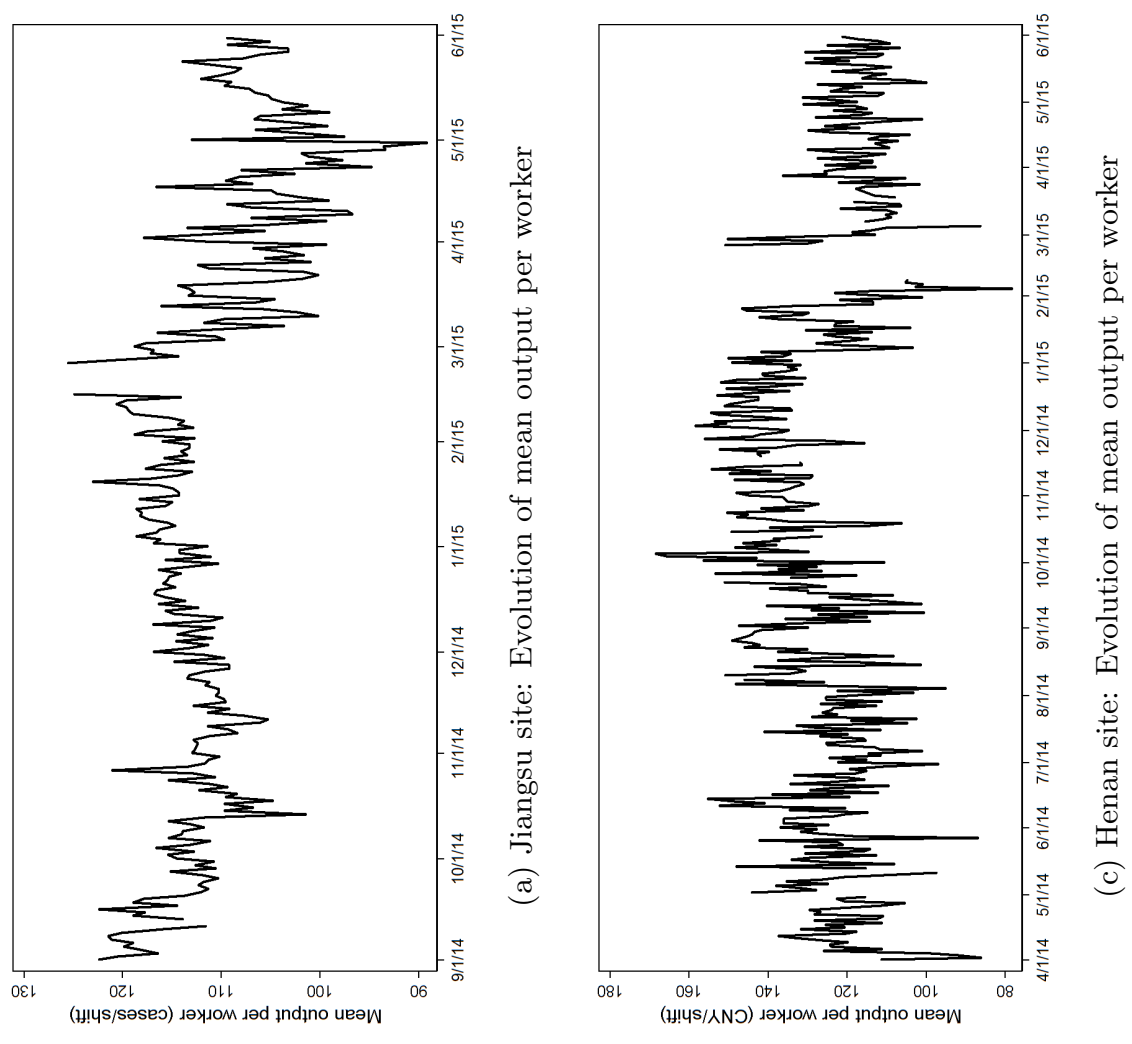

$\smile \circ$.

它

过

इ 000

范

․ㅠ

ลี

志.

สี ง

过

छ

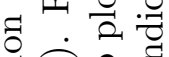

过 $\dot{0}$

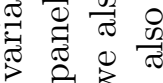

它牙

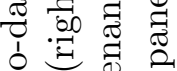

薄莐

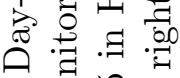

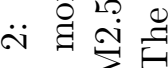

䓎完

sol 


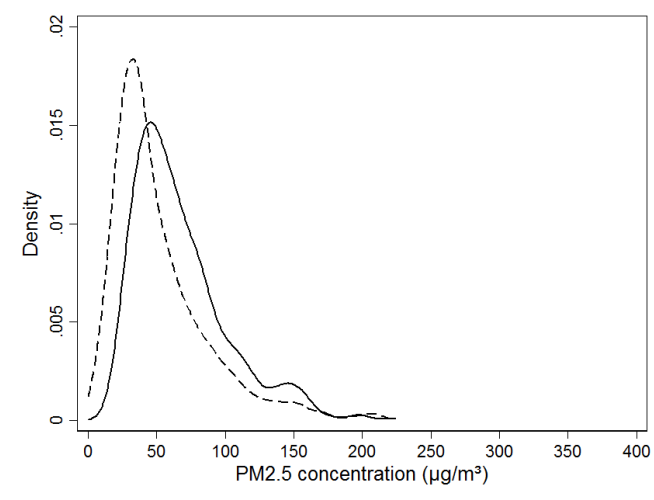

(a) Jiangsu town \& US Embassy Shanghai

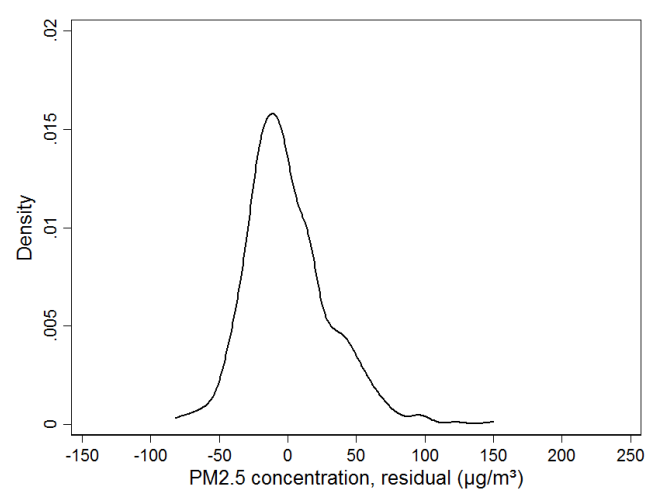

(c) Jiangsu town: Deseasoned

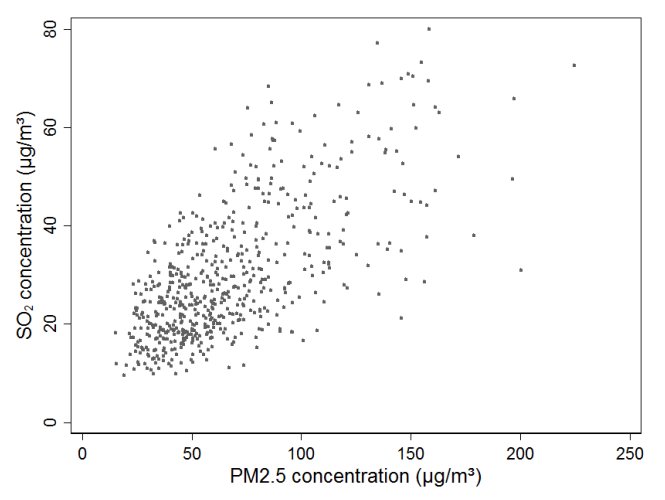

(e) Jiangsu town: PM2.5 versus $\mathrm{SO}_{2}$

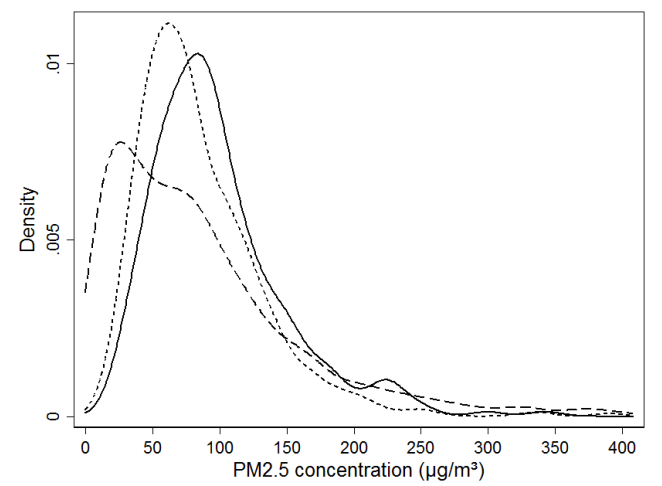

(b) Henan town, neighbors \& US Emb. Beijing

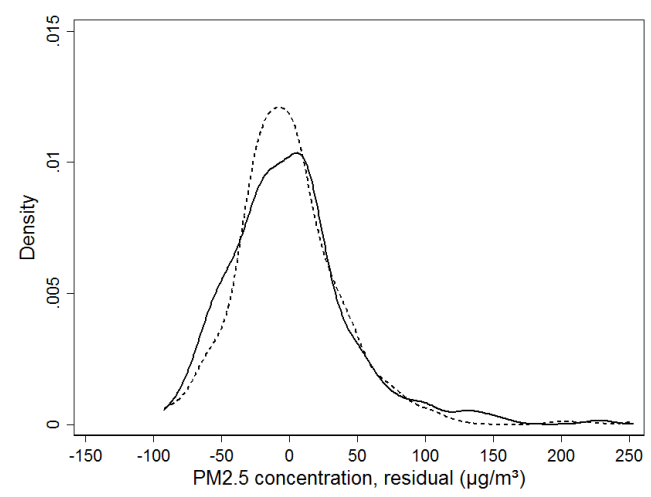

(d) Henan town \& neighbors: Deseasoned

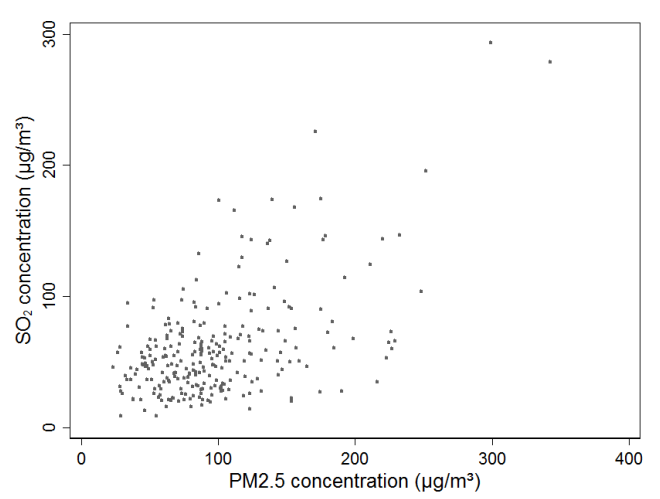

(f) Henan town: PM2.5 versus $\mathrm{SO}_{2}$

Figure 3: Distribution of concurrent pollution across date-shifts in the output samples. An observation is a 12-hour date-shift. The top panels depict PM2.5 levels at the closest monitor (solid line) and, for comparison, at the regional US Embassy (dashed line). We also show mean PM2.5 at the three cities that neighbor the Henan host town (dotted line). The middle panels depict residual PM2.5 levels at the corresponding locations (including neighboring cities) once year-month, day-of-week and time-of-day (shift) variation is accounted for. The bottom panels plot $\mathrm{SO}_{2}$ against PM2.5, in the host town and closest monitor respectively. 


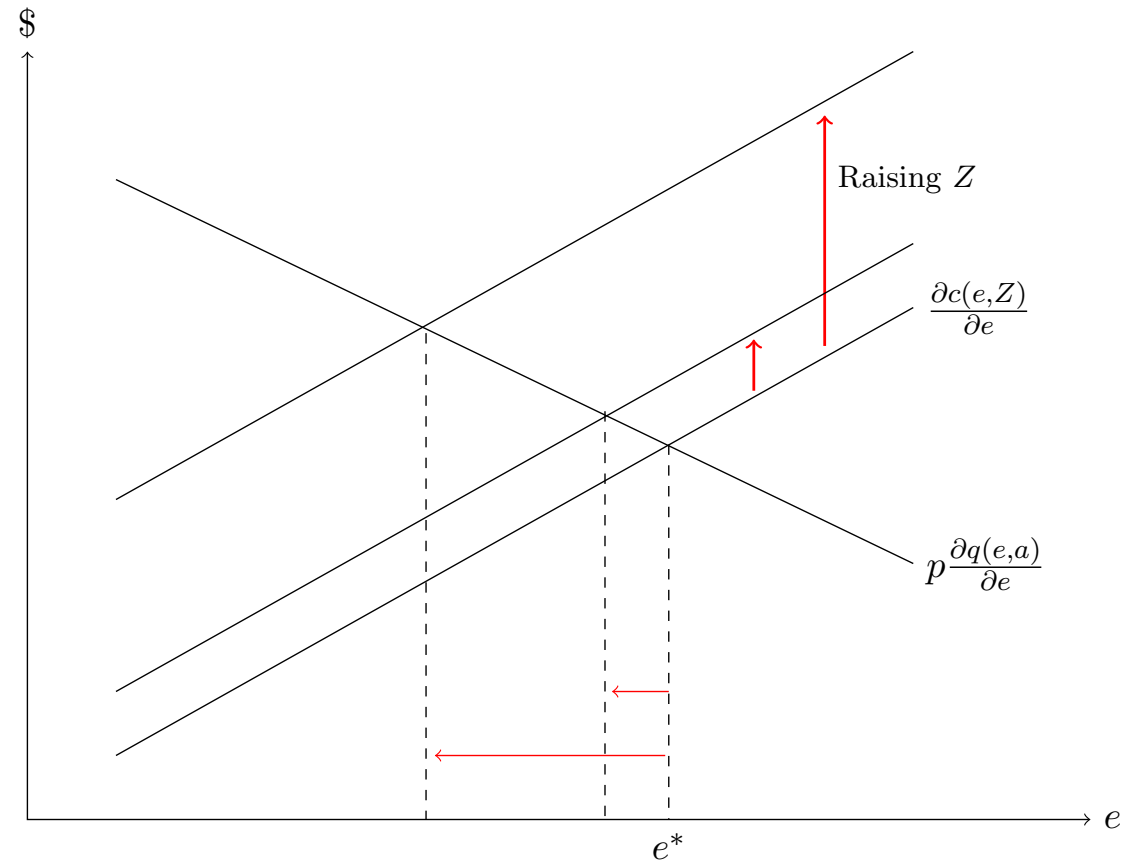

(a) Raising pollution exposure: Less sensitive versus more sensitive workers.

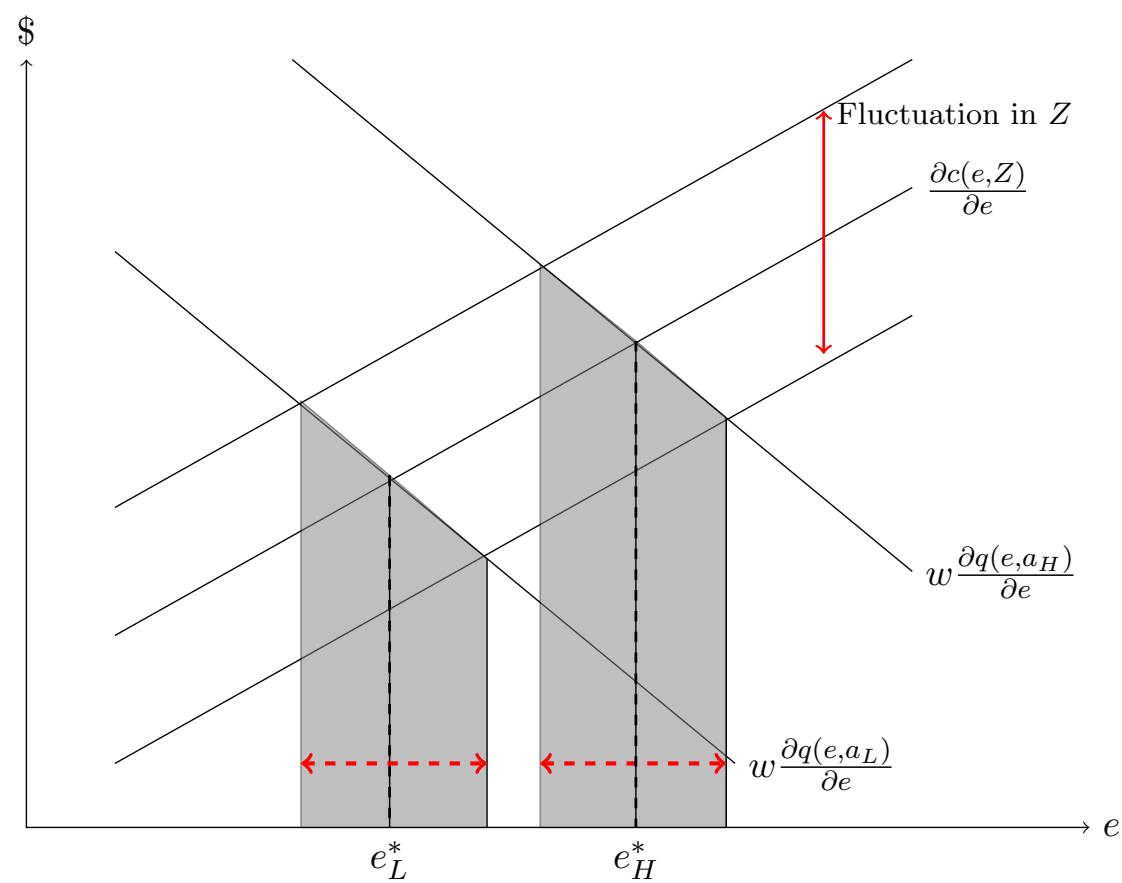

(b) Effort choice by workers of varying ability. As drawn, the optimal response of effort to pollution exposure is similar across the two workers, implying that the output response is increasing in ability.

Figure 4: The response of effort and revenue product to pollution exposure. 


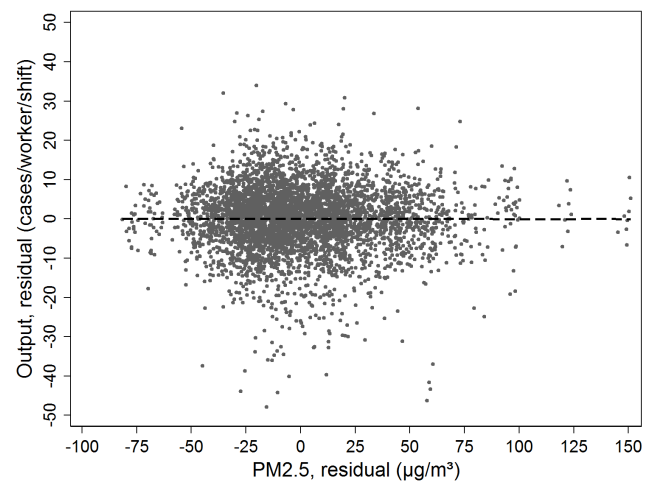

(a) Jiangsu output against PM2.5 in vicinity

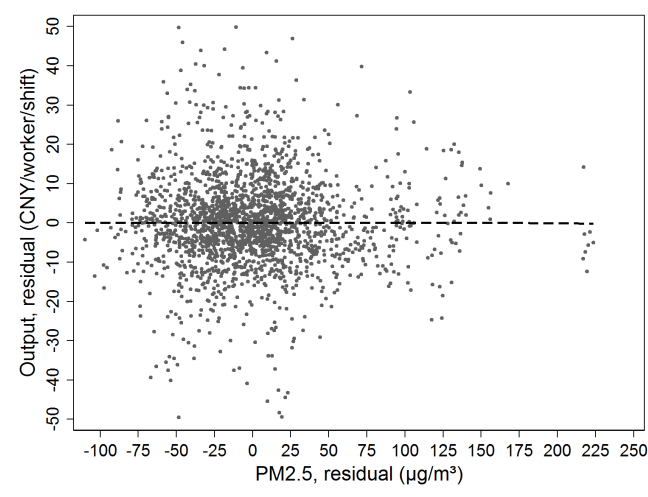

(c) Henan output against PM2.5 in vicinity

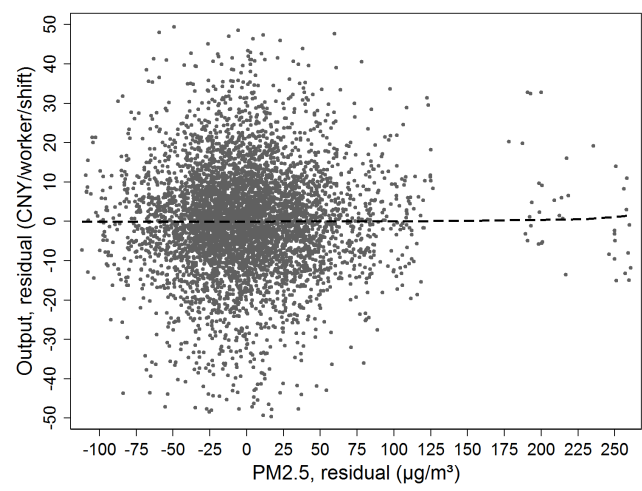

(e) Henan output against PM2.5 $60 \mathrm{~km}$ away

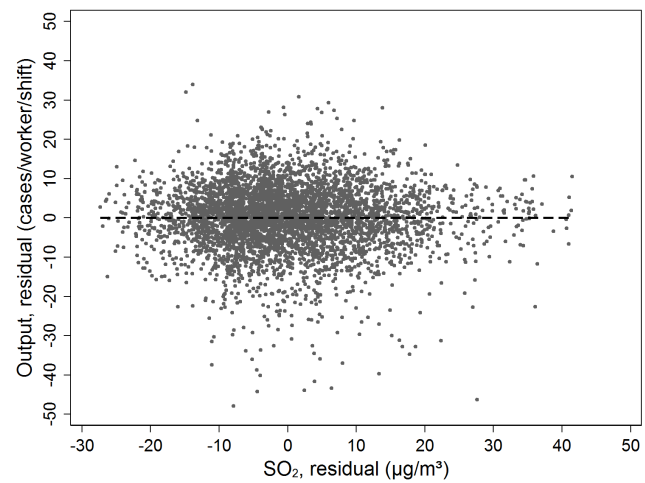

(b) Jiangsu output against $\mathrm{SO}_{2}$ in town

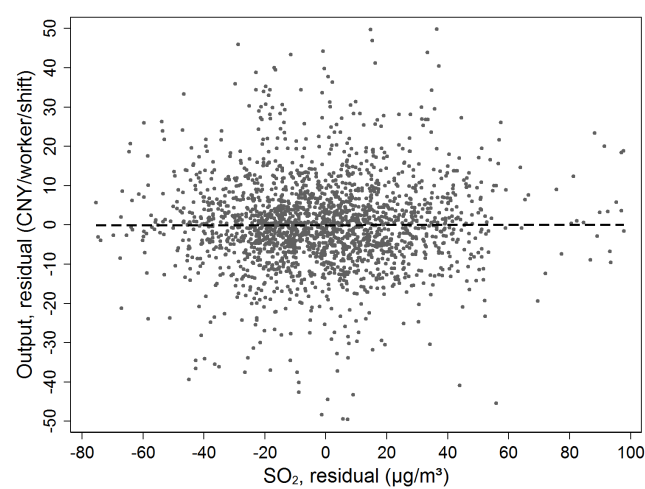

(d) Henan output against $\mathrm{SO}_{2}$ in town

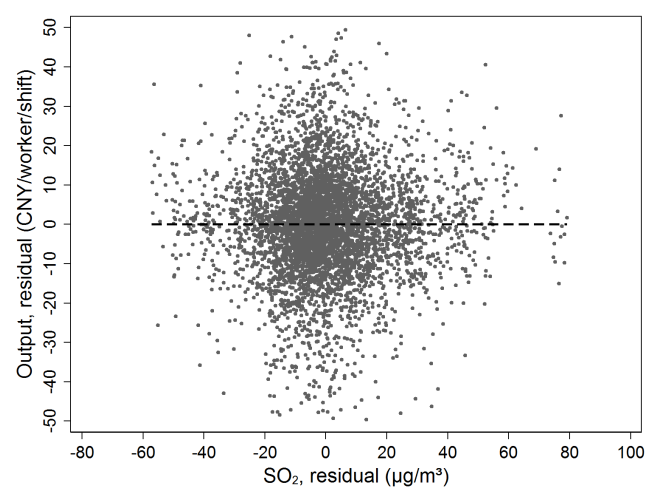

(f) Henan output against $\mathrm{SO}_{2} 60 \mathrm{~km}$ away

Figure 5: Individual worker output residuals against concurrent within-shift mean pollutant concentration residuals: PM2.5 in the left panels and $\mathrm{SO}_{2}$ in the right panels. An observation is a worker by date-shift with non-zero output. To generate residuals, output and pollution levels are regressed on the vectors of controls listed in the bottom panels of Table 3(I)-3(II) (Jiangsu and Henan, separately). To help read the scatterplots, we fit kernel-weighted local polynomial smoothing curves (dashed lines). (To magnify the scatters, the plot ranges leave out between $0.1 \%$ and $1 \%$ of observations.) 


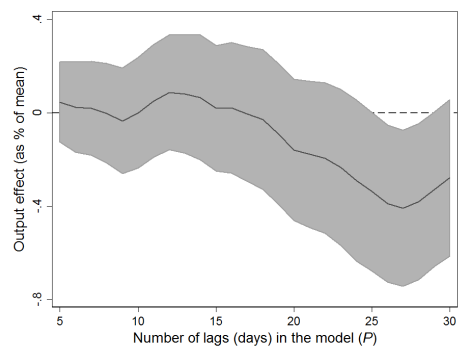

(a) PM2.5, OLS

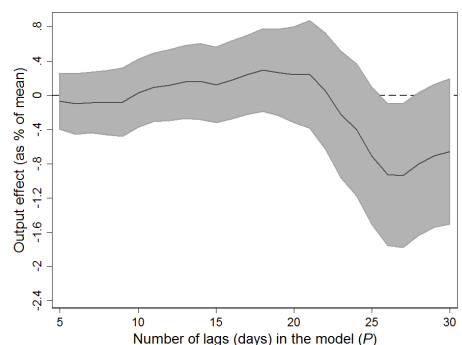

(d) $\mathrm{SO}_{2}$, OLS

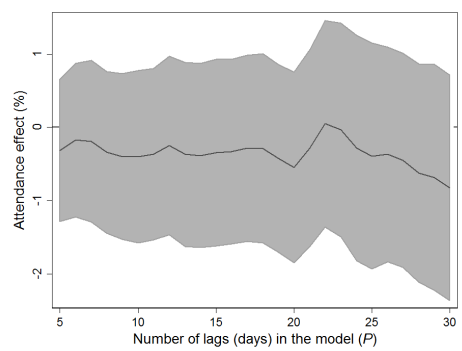

(g) PM2.5, 2SLS

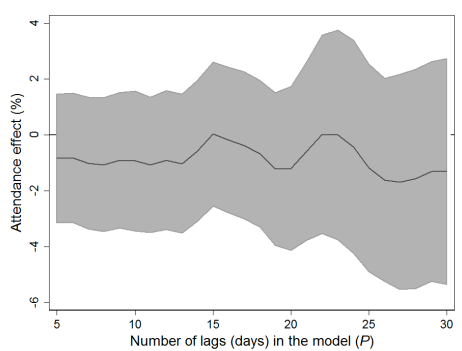

(j) $\mathrm{SO}_{2}, 2 \mathrm{SLS}$

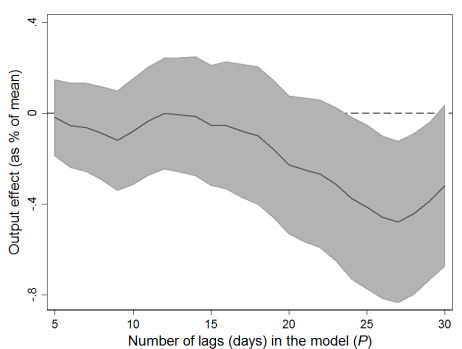

(b) PM2.5, OLS, with temp., humidity

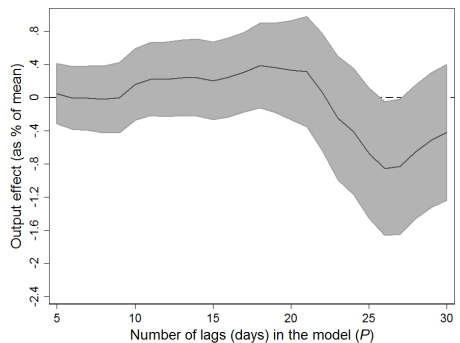

(e) $\mathrm{SO}_{2}$, OLS, with temp., humidity

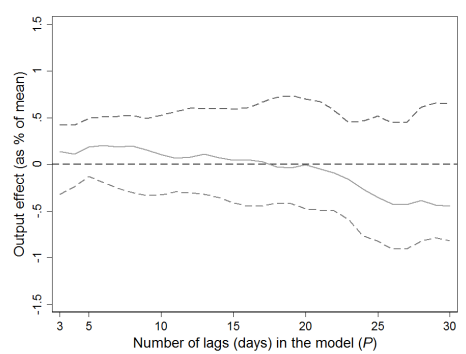

(h) PM2.5, 2SLS, 25, 50, 75th percentile

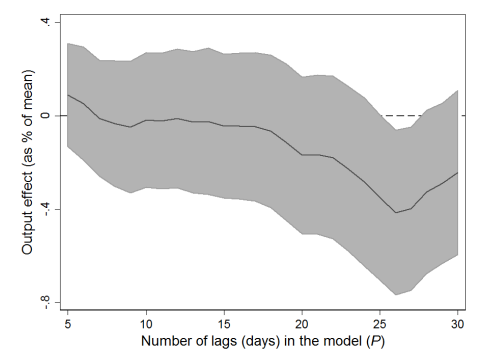

(c) PM2.5, 2SLS

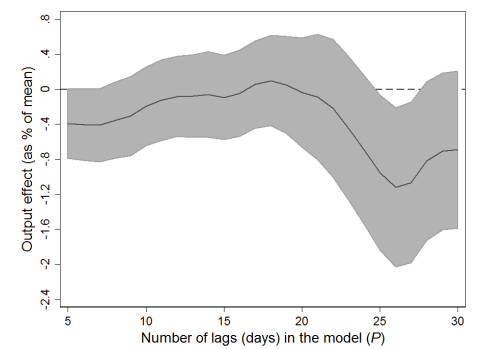

(f) $\mathrm{SO}_{2}, 2 \mathrm{SLS}$

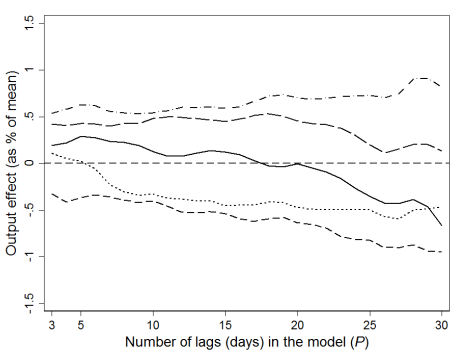

(i) PM2.5, 2SLS, worker 6, 7, 13, 18, 19

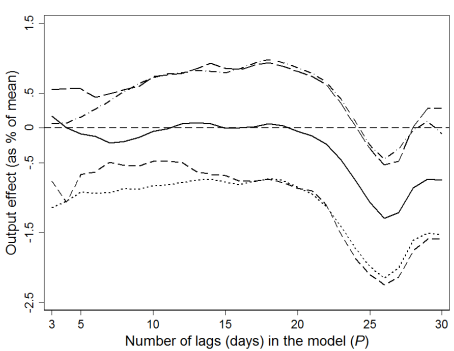

(l) $\mathrm{SO}_{2}, 2 \mathrm{SLS}$, worker $6,7,13,18,19$

Figure 6(I): Cumulative impact on Jiangsu worker supply of $+10 \mu \mathrm{g} / \mathrm{m}^{3}$ exposure to pollution (PM2.5 or $\mathrm{SO}_{2}$ proxy) on each of the concurrent and previous $P$ days. Each value along the horizontal axis reports the point estimate and $95 \%$ confidence interval on $\sum_{p=0}^{P} \beta_{p}$ from a different quartic distributed lag model, $\operatorname{PDL}(P, 4)$, as we raise $P$. All panels but $(\mathrm{g})$ and $(\mathrm{j})$ report the effect on output (per shift) as a proportion of mean output in the sample; panels $(\mathrm{g})$ and $(\mathrm{j})$ report the attendance effect (in percentage points). Panels (h), (i), (k) and (l) report individual effects based on $\operatorname{PDL}(P, 2)$ models instead. See the text. 


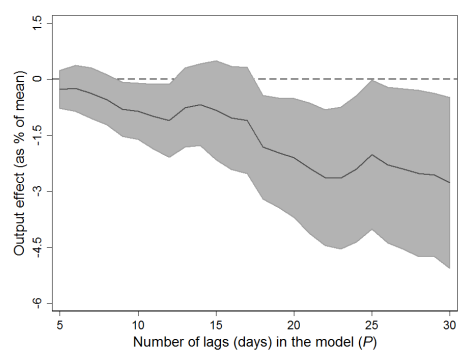

(a) PM2.5, OLS

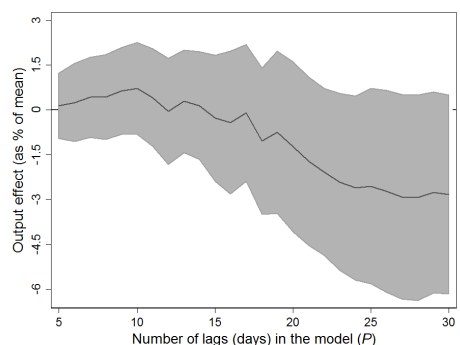

(d) $\mathrm{SO}_{2}$, OLS

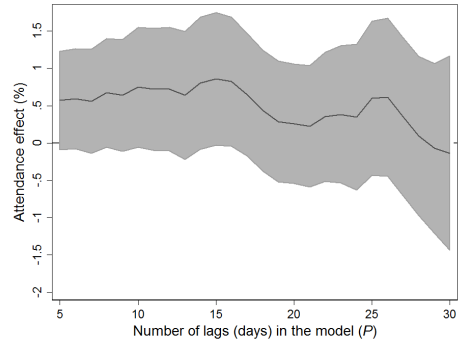

(g) PM2.5, 2SLS

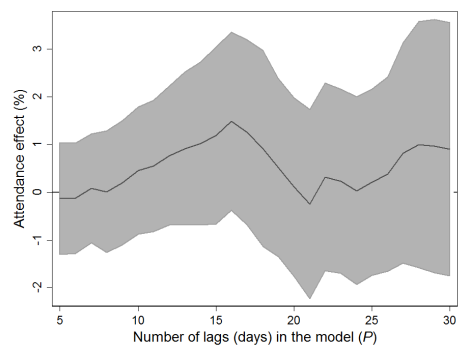

(j) $\mathrm{SO}_{2}, 2 \mathrm{SLS}$

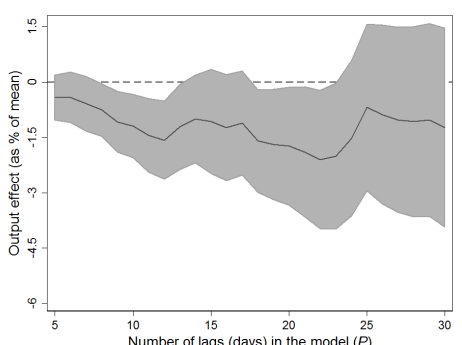

(b) PM2.5, OLS, with temp., humidity

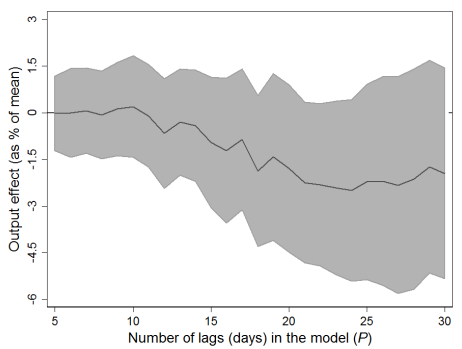

(e) $\mathrm{SO}_{2}$, OLS, with temp., humidity

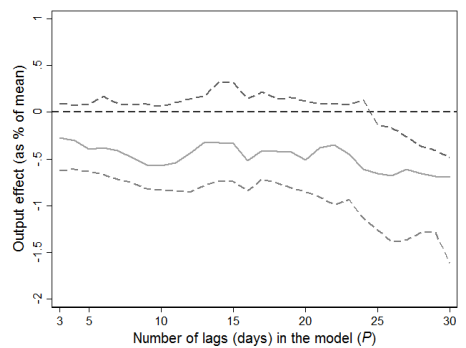

(h) PM2.5, 2SLS, 25, 50, 75th percentile

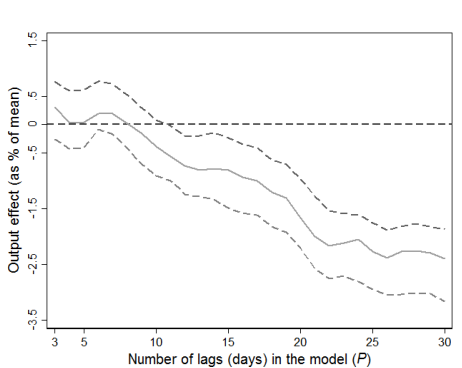

(k) $\mathrm{SO}_{2}, 2 \mathrm{SLS}, 25,50,75$ th percentile

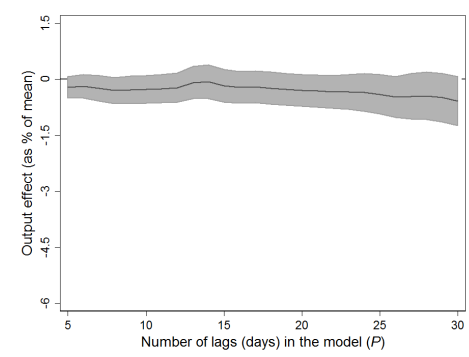

(c) PM2.5, 2SLS

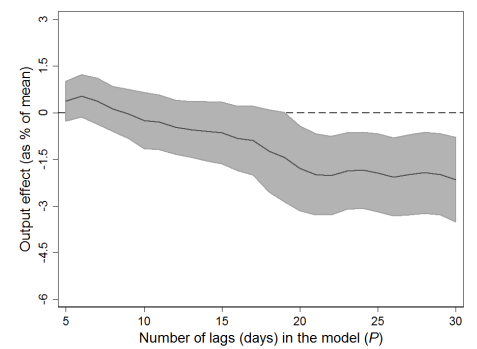

(f) $\mathrm{SO}_{2}, 2 \mathrm{SLS}$

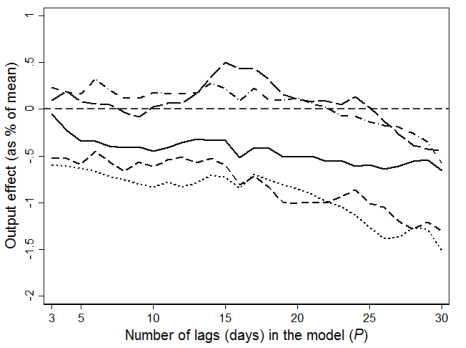

(i) PM2.5, 2SLS, worker 6, 7, 13, 18, 19

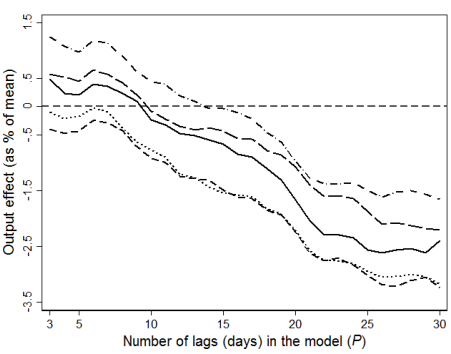

(l) $\mathrm{SO}_{2}, 2 \mathrm{SLS}$, worker $6,7,13,18,19$

Figure 6(II): Cumulative impact on Henan worker supply of $+10 \mu \mathrm{g} / \mathrm{m}^{3}$ exposure to pollution (PM2.5 or $\mathrm{SO}_{2}$ proxy) on each of the concurrent and previous $P$ days. Each value along the horizontal axis reports the point estimate and $95 \%$ confidence interval on $\sum_{p=0}^{P} \beta_{p}$ from a different quartic distributed lag model, $\operatorname{PDL}(P, 4)$, as we raise $P$. All panels but $(\mathrm{g})$ and $(\mathrm{j})$ report the effect on output (per shift) as a proportion of mean output in the sample; panels $(\mathrm{g})$ and $(\mathrm{j})$ report the attendance effect (in percentage points). Panels (h), (i), (k) and (l) report individual effects based on $\operatorname{PDL}(P, 2)$ models instead. See the text. 


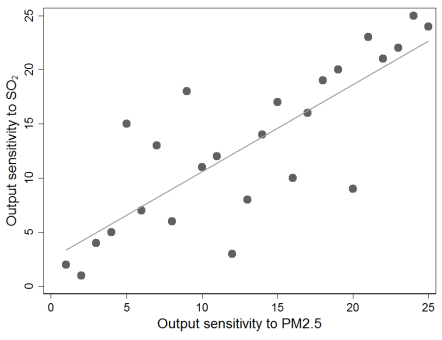

(a) $q$ sens., PM2.5 \& $\mathrm{SO}_{2}$, Jiangsu

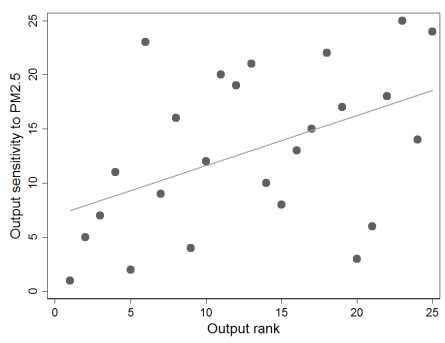

(c) Ability \& $q$ sens., PM2.5, Jiangsu

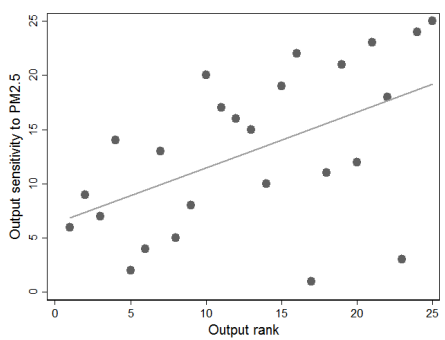

(e) Ability \& $q$ sens., PM2.5, Henan

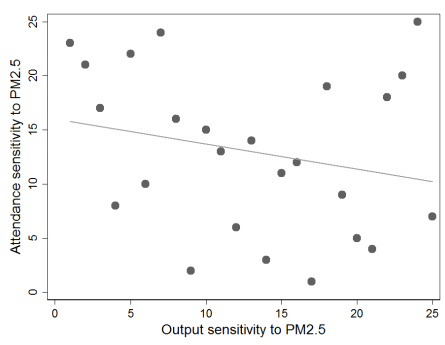

(g) Both $q \& d$ sens., PM2.5, Jiangsu

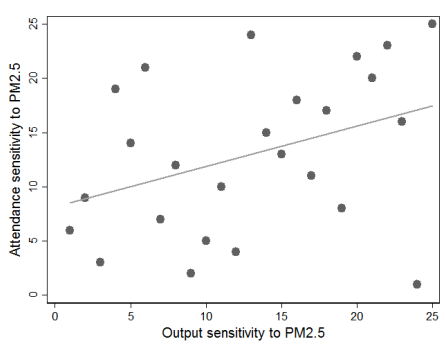

(i) Both $q \& d$ sens., PM2.5, Henan

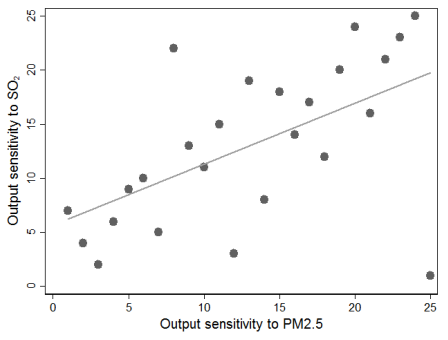

(b) $q$ sens., $\mathrm{PM} 2.5 \& \mathrm{SO}_{2}$, Henan

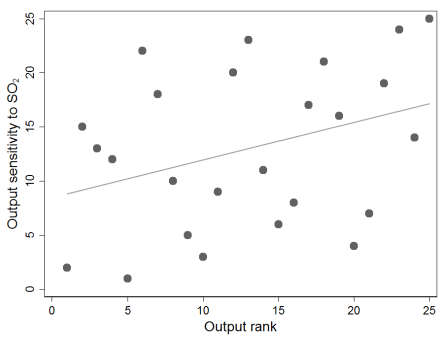

(d) Ability \& $q$ sens., $\mathrm{SO}_{2}$, Jiangsu

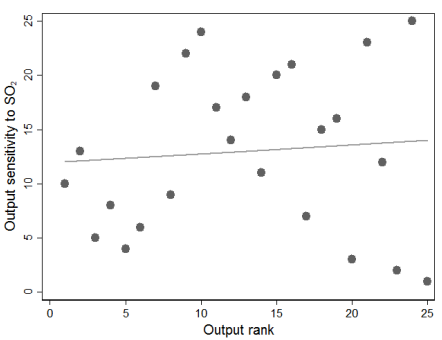

(f) Ability \& $q$ sens., $\mathrm{SO}_{2}$, Henan

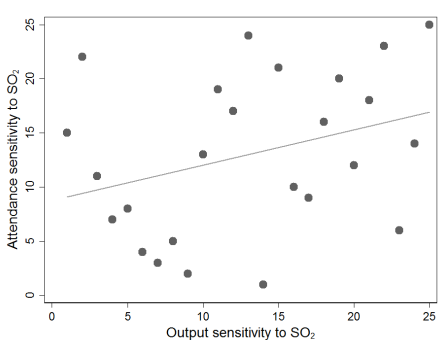

(h) Both $q \& d$ sens., $\mathrm{SO}_{2}$, Jiangsu

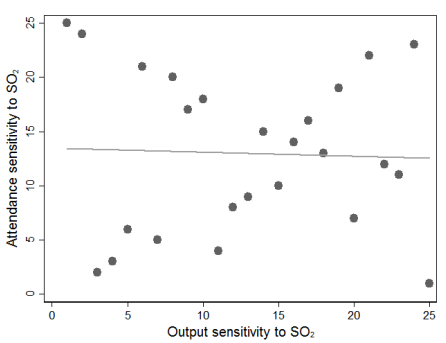

(j) Both $q \& d$ sens., $\mathrm{SO}_{2}$, Henan

Figure 7: Individual heterogeneity: In each panel, an observation is a worker in the sample of 25 workers with most output observations at the given work site. Workers are ranked according to their mean output in the sample ("output rank"), and their output sensitivity (" $q$ sens.") or their attendance sensitivity (" $d$ sens.") to cumulative pollution exposure, according to 20-day quadratic distributed lag models, PDL(20,2), estimated by 2 SLS. 


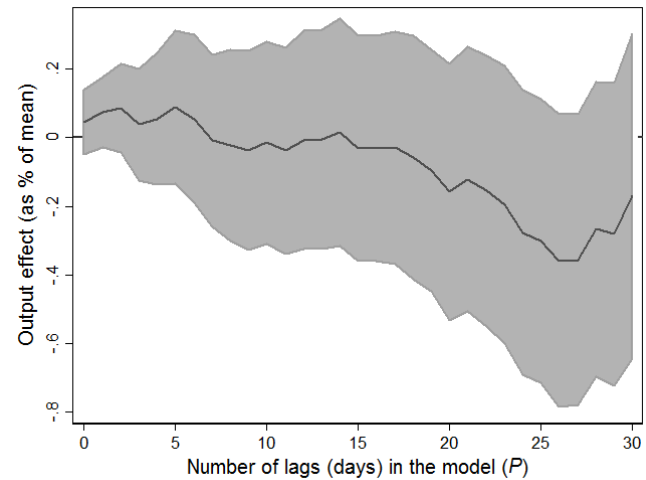

(a) PM2.5, 2SLS, Jiangsu

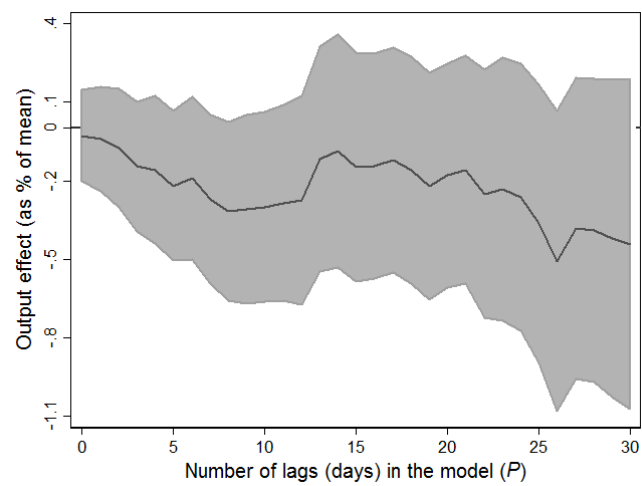

(c) PM2.5, 2SLS, Henan

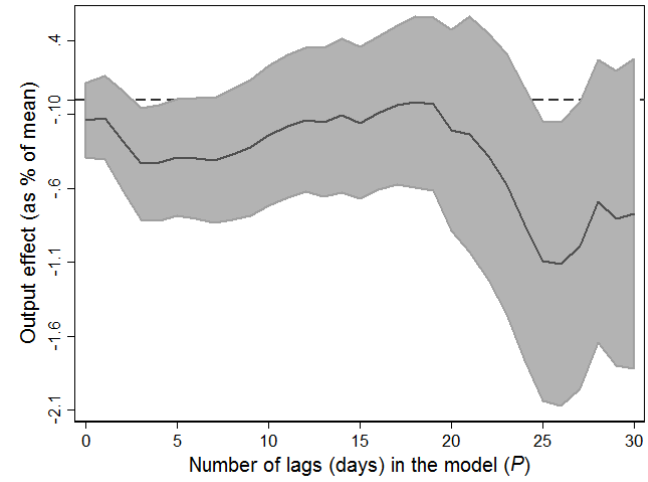

(b) $\mathrm{SO}_{2}, 2 \mathrm{SLS}$, Jiangsu

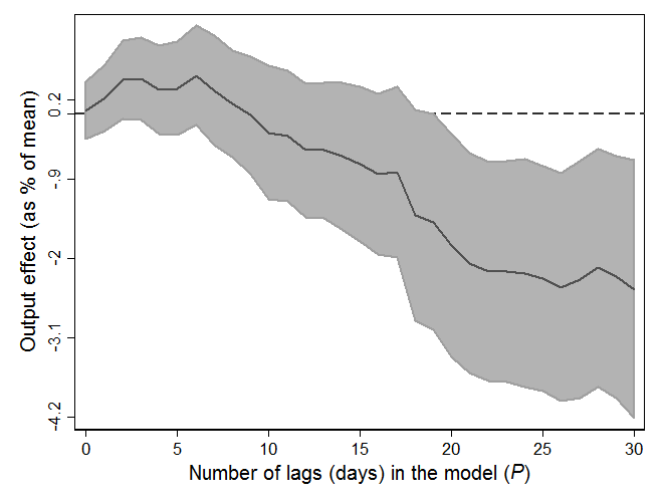

(d) $\mathrm{SO}_{2}, 2 \mathrm{SLS}$, Henan

Figure 8: Robustness test to removing the smoothness constraint on the lagged pollution coefficients, $\beta_{p}$ : Unconstrained distributed lag, UDL $(P)$. As in Figure 6(I)-6(II), in particular, panels (c) (PM2.5, 2SLS) and (f) $\left(\mathrm{SO}_{2}, 2 \mathrm{SLS}\right)$, we show the cumulative impact on output of $+10 \mu \mathrm{g} / \mathrm{m}^{3}$ exposure to pollution on each of the concurrent and previous $P$ days. Each value along the horizontal axis reports the point estimate and $95 \%$ confidence interval on $\sum_{p=0}^{P} \beta_{p}$ from a different $\mathrm{UDL}(P)$ model, estimated by $2 \mathrm{SLS}$, as we vary $P$. We report the effect on output (per shift) as a proportion of mean output in the sample. 


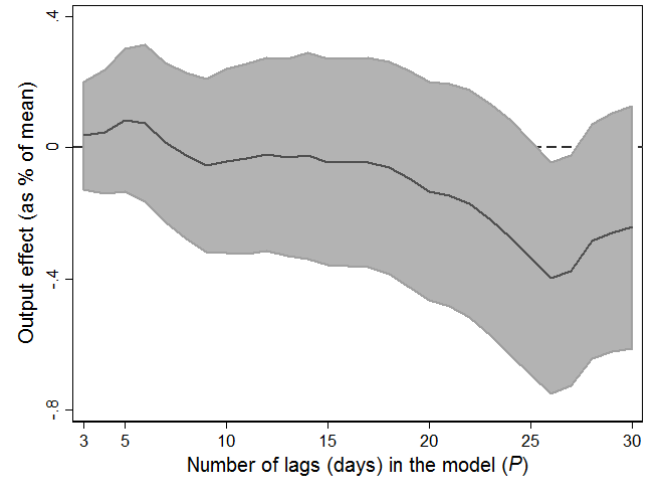

(a) PM2.5, 2SLS, Jiangsu

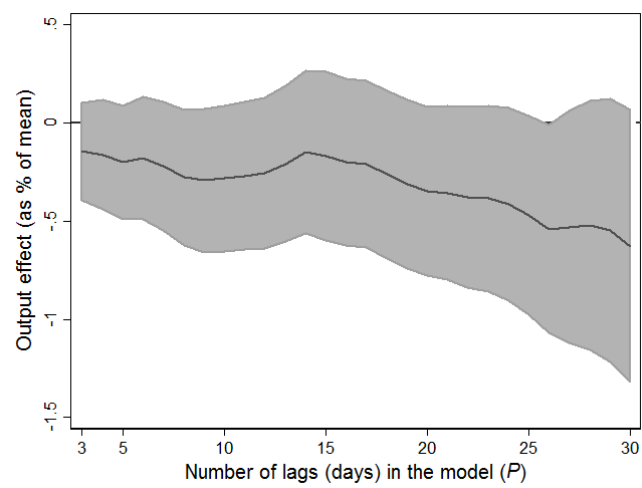

(c) PM2.5, 2SLS, Henan

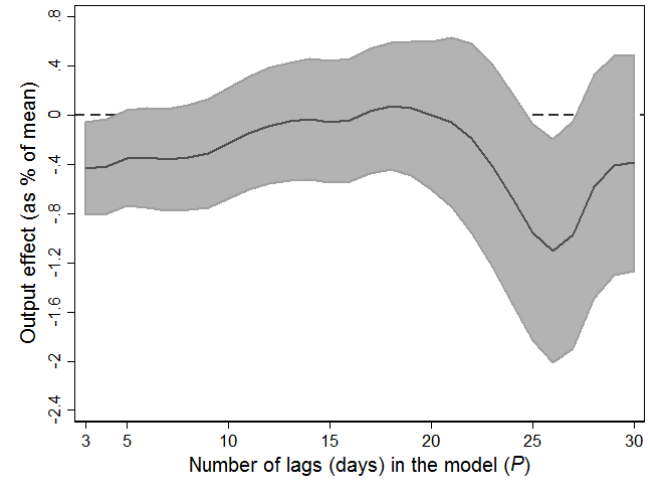

(b) $\mathrm{SO}_{2}, 2 \mathrm{SLS}$, Jiangsu

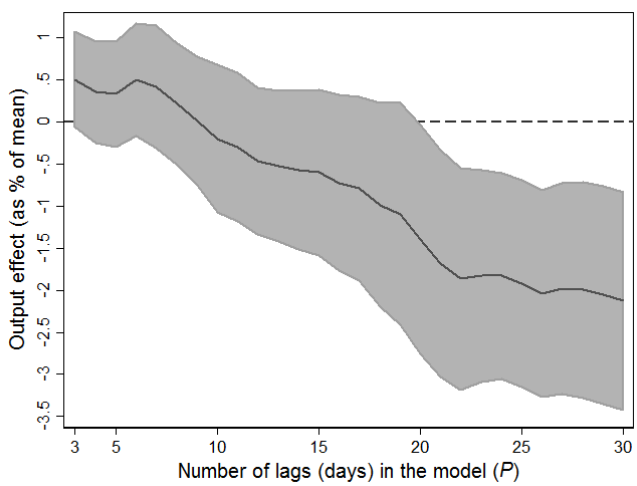

(d) $\mathrm{SO}_{2}, 2 \mathrm{SLS}$, Henan

Figure 9: Robustness test to constraining the lagged pollution coefficients, $\beta_{p}$, further: Quadratic distributed lag, PDL $(P, 2)$. As in Figure 6(I)-6(II), in particular, panels (c) (PM2.5, 2SLS) and (f) $\left(\mathrm{SO}_{2}, 2 \mathrm{SLS}\right)$, we show the cumulative impact on output of +10 $\mu \mathrm{g} / \mathrm{m}^{3}$ exposure to pollution on each of the concurrent and previous $P$ days. Each value along the horizontal axis reports the point estimate and $95 \%$ confidence interval on $\sum_{p=0}^{P} \beta_{p}$ from a different $\operatorname{PDL}(P, 2)$ model, estimated by 2 SLS, as we vary $P$. We report the effect on output (per shift) as a proportion of mean output in the sample. 


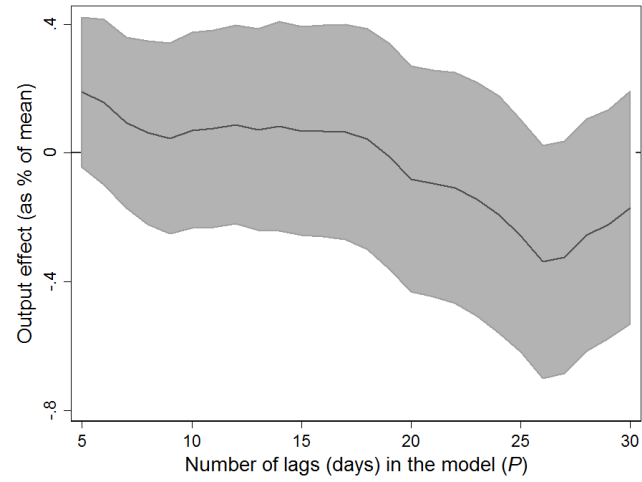

(a) PM2.5, 2SLS, Jiangsu

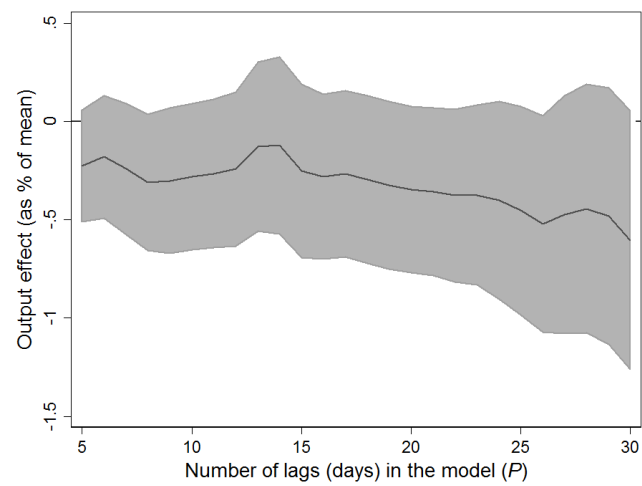

(c) PM2.5, 2SLS, Henan

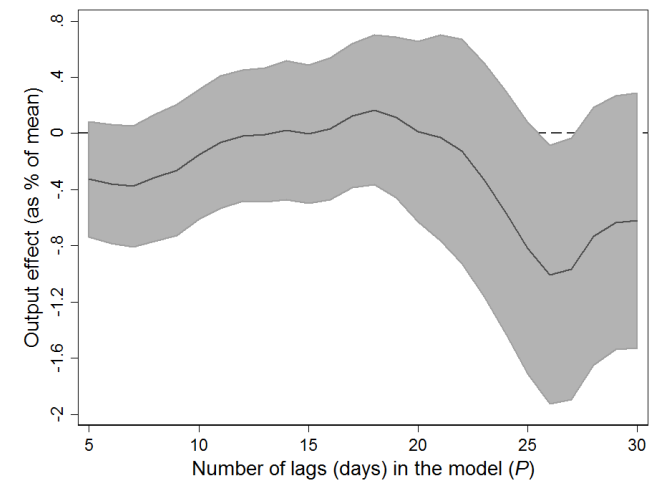

(b) $\mathrm{SO}_{2}, 2 \mathrm{SLS}$, Jiangsu

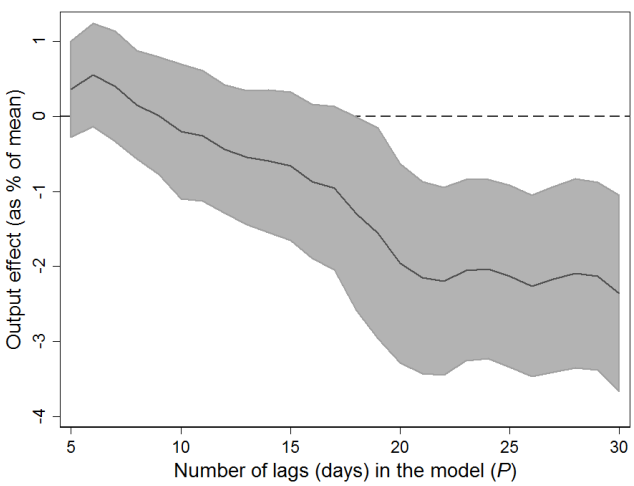

(d) $\mathrm{SO}_{2}, 2 \mathrm{SLS}$, Henan

Figure 10: Robustness test to not trimming the output sample at three standard deviations of the sample mean. As in Figure 6(I)-6(II), in particular, panels (c) (PM2.5, 2SLS) and (f) $\left(\mathrm{SO}_{2}, 2 \mathrm{SLS}\right)$, we show the cumulative impact on output of $+10 \mu \mathrm{g} / \mathrm{m}^{3}$ exposure to pollution on each of the concurrent and previous $P$ days. Each value along the horizontal axis reports the point estimate and $95 \%$ confidence interval on $\sum_{p=0}^{P} \beta_{p}$ from a different quartic distributed lag model, $\operatorname{PDL}(P, 4)$, estimated by 2 SLS, as we vary $P$. We report the effect on output (per shift) as a proportion of mean output in the sample. 


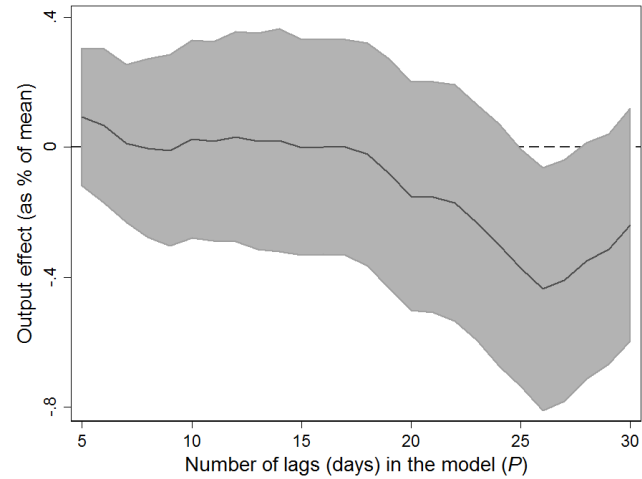

(a) PM2.5, 2SLS, Jiangsu

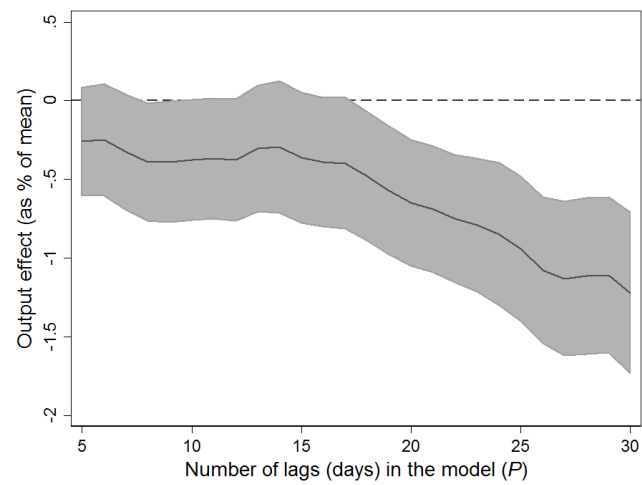

(c) PM2.5, 2SLS, Henan

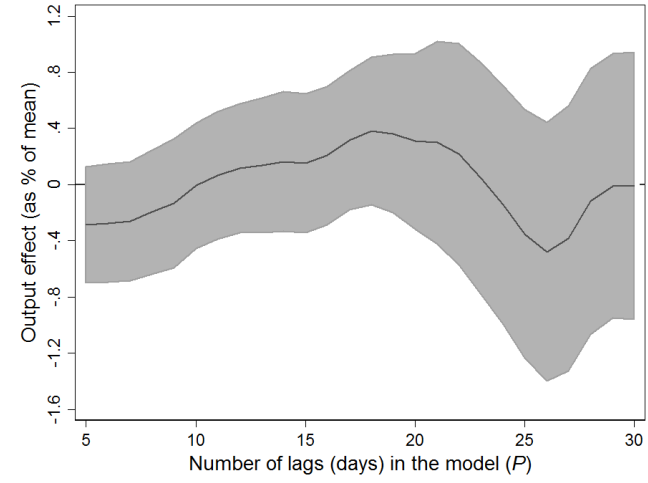

(b) $\mathrm{SO}_{2}, 2 \mathrm{SLS}$, Jiangsu

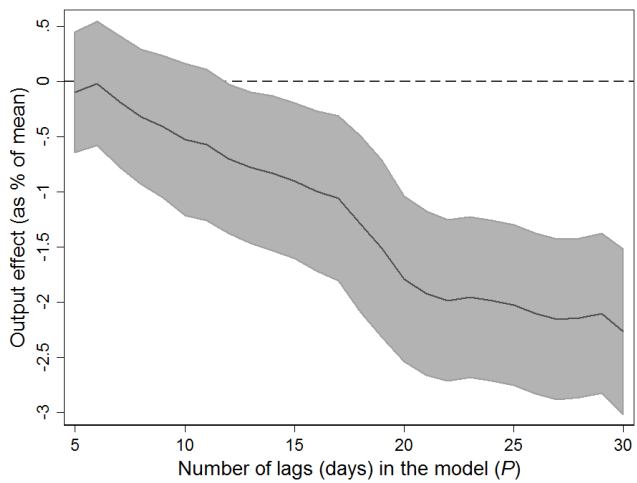

(d) $\mathrm{SO}_{2}, 2 \mathrm{SLS}$, Henan

Figure 11: Robustness test to controls for seasonality: Replacing year-month fixed effects by a quadratic time trend coupled with indicators for winter months, November to February. As in Figure 6(I)-6(II), in particular, panels (c) (PM2.5, 2SLS) and (f) ( $\left.\mathrm{SO}_{2}, 2 \mathrm{SLS}\right)$, we show the cumulative impact on output of $+10 \mu \mathrm{g} / \mathrm{m}^{3}$ exposure to pollution on each of the concurrent and previous $P$ days. Each value along the horizontal axis reports the point estimate and $95 \%$ confidence interval on $\sum_{p=0}^{P} \beta_{p}$ from a different quartic distributed lag model, $\mathrm{PDL}(P, 4)$, estimated by $2 \mathrm{SLS}$, as we vary $P$. We report the effect on output (per shift) as a proportion of mean output in the sample. 


\section{A Further discussion of institutions and data}

Worker tasks, products and piece rates. A Jiangsu worker operates machines (most often two) as they wind yarn threads from long narrow ring bobbins into large cones. Over time and following a production schedule, the team leader assigns workers to products and machines, but the worker keeps to her workstation, with the assigned products and machines, for at least an entire shift. As days, weeks, or months pass, a worker may operate different machines, but these machines are similar. Each machine has 16 magazines and each magazine can hold 5 ring bobbins at a time. It takes 10-15 minutes for a machine to completely wind the yarn, depending on the thickness of the yarn, at which point the worker has to replace the bobbins. To do so, one end of thread in a new bobbin needs to be pulled out and attached to the magazine, which requires skill and effort from the worker. In addition, threads naturally break apart during machine operation. The Jiangsu machines - which are more sophisticated than at the Henan department - can connect broken threads automatically, taking 5-10 seconds each time. However, this process may fail, in which case a red light alerts the worker, who needs to intervene and manually reconnect the thread as quickly as possible, for the machine to resume operation. The Jiangsu department produces products with some differentiation, with 80s accounting for the largest share of output in our sample (a mean of $32 \%$ of the within-shift department output across date-shifts), followed by 50s (22\%), 60s (18\%), 45s (14\%), and 100s (12\%). These five products thus account for $98 \%$ of combined compensation-adjusted output. Another four products (34s, 40s, 70s, and 120s) together account for only $2 \%$ of output.

Henan workers perform similar tasks. They walk up and down the aisles in their workstation, each worker attending to about five machines, and reconnecting the threads that break during machine operation. Again, a team leader assigns workers to products and machines, and a worker keeps to the assigned products and machines through the shift. One product, 32s, accounts for about half the department's output (a mean of $48 \%$ of the aggregate output across date-shifts), followed by 40s (18\%), 21s (13\%), and 24s (10\%). Jointly, these four products account for $89 \%$ of output, and six other products account for the remainder $(7 \mathrm{~s}, 16 \mathrm{~s}, 18 \mathrm{~s}, 19.5 \mathrm{~s}, 26 \mathrm{~s}$, and $32.5 \mathrm{~s})$. As in the Jiangsu department, a 
worker's product-machine assignment is persistent over days and weeks.

Piece rates in Henan, expressed in CNY $/ \mathrm{kg}$, are: 0.410 for output of product 40s, 0.370 for $32 \mathrm{~s}$ on an extended machine, 0.290 for $32 \mathrm{~s}$ on a regular machine, 0.250 for $24 \mathrm{~s}, 0.235$ for $26 \mathrm{~s}, 0.205$ for $21 \mathrm{~s}, 0.190$ for $19.5 \mathrm{~s}$ and $18 \mathrm{~s}, 0.165$ for $16 \mathrm{~s}$, and 0.100 for $7 \mathrm{~s}$. In addition to these products, a "preparatory task" whose output is recorded is compensated at piece rates of $0.22 \mathrm{CNY} / \mathrm{kg}$ on an extended machine and $0.205 \mathrm{CNY} / \mathrm{kg}$ on a regular machine.

To determine compensation, the Jiangsu department aggregates output across individual products using the following weights, expressed in adjusted cases/physical case for each product: 1.50 for output of $120 \mathrm{~s}, 1.40$ for $100 \mathrm{~s}, 1.30$ for $80 \mathrm{~s}, 1.15$ for $70 \mathrm{~s}, 1.06$ for 60s, 1.00 for $50 \mathrm{~s}, 0.98$ for $45 \mathrm{~s}$ and 40s, and 0.96 for 34s. A worker's aggregate number of adjusted cases is converted into "counts" at a rate of 105 counts/adjusted case. For output produced in the 12-hour shift, expressed in counts, a worker enjoys a bonus of 0.01 CNY per count in excess of 11,000 counts but no greater than 12,000 counts (i.e., $10 \mathrm{CNY}$ per 1,000 excess counts), a bonus of $0.02 \mathrm{CNY}$ per count in excess of 12,000 counts but no greater than 13,000 counts, and a bonus of $0.03 \mathrm{CNY}$ per count for output in excess of 13,000 counts. The penalty scheme for 12-hour output that falls short of 11,000 counts is symmetric to the bonus scheme around the reference output of 11,000 counts. This variable compensation scheme can more readily be understood by way of a plot, shown in Figure A.2.

Differences in piece rates across products reflect differences in the standard rates of output from variation in product thread. Worker tasks are very similar across products. Figure A.3 shows that the assignment of product varieties to workers exhibits strong dayto-day persistence at both work sites. To prepare the plots by work site, we take the four or five varieties in a work site with double-digit output shares, and aggregate the remaining varieties into a residual category labeled "Other." We consider pairs of consecutive work shifts by a worker, with 12 hours and up to 24 hours of rest in between work in Jiangsu and Henan, respectively, given the standard shift designs. We then compute the empirical probability that, conditional on a worker producing a given variety on a shift, she also produced that variety in her preceding shift (likely among others-Table 2(I)-2(II)). These 
product-level transition probabilities within worker are of the order of 60 to $80 \% .{ }^{23}$

Jiangsu's monthly work shift transition. To preserve the continuity of operations, the monthly shift transition (day shift versus night shift) happens at the end of each month over a few days, rather than abruptly on day 1 of the subsequent month. Following the example in the text, October 2014 records indicate that Team 1 worked the day shift and Team 2 worked the night shift. However, on October 30, 2014, we observe a total of 12 Team 1 workers and 5 Team 2 workers with non-zero output. Given the required staff of 8 to 9 workers per shift (17 machines at 2 machines per worker), the asymmetry in the number of workers from each team who worked on this date approaching November is due to the fact that, while some Team 2 workers took leave, some Team 1 workers already transitioned to working the night shift alongside the other Team 2 workers. Since output records do not mention who the Team 1 workers newly transitioned to the night shift were, nor when the transition started (e.g., October 28 or 29), our regression models include indicators for the last three days of the month interacted with shift, to account for measurement error in the time of day for these few days and for some workers (3 Team 1 workers in the example). It is during the last three days of each month that the numbers of Team 1 and Team 2 workers with non-zero output are most unbalanced. Estimates are robust to alternatively dropping these month-end observations.

Cleaning the worker output samples. For each department, we observe worker output by date-shift pair. Table A.1 describes the minimal data cleaning we apply to the raw records. We drop the one shift that precedes (resp., follows) a department holiday, during which machines are turned off early (resp., late) for cleaning (resp., setting up). We drop a few date-shifts for which exceptional conditions were annotated, such as the occurrence of a power outage that affects all workers who worked on that shift. For the analysis of individual output, we additionally drop a few observations for which exceptional conditions were annotated, such as the worker being unusually assigned multiple tasks during the shift, beyond working at her single workstation, or was not working in the

\footnotetext{
${ }^{23}$ Of note, Adhvaryu et al. (2016) study how managers may reallocate tasks that require different levels of worker effort in response to hourly pollution-related shocks to the productivity of workers on an assembly line in an Indian garment factory.
} 
main ground-level production facility (Henan).

Air pollution data availability. Hourly PM2.5 and $\mathrm{SO}_{2}$ mass concentration measurements at official air monitoring sites in both industrial towns that host the workplaces we study are quite complete during the sample periods. ${ }^{24}$ The exception is the Henan workplace during 2014, for which ambient air data are available only at three neighboring cities at most $60 \mathrm{~km}$ away. As stated below, the few missing observations are fairly evenly distributed throughout the sample periods and do not cluster on specific days, suggesting that the sites are well maintained.

For the PM2.5 monitor $3.7 \mathrm{~km}$ from the Jiangsu workplace, only $3 \%$ of all 7272 hours during the period August 2, 2014 (30 days prior to the start of the output sample) to May 31, 2015 exhibit missing concentrations in the raw data, say due to equipment failure. We impute the relatively few hourly values that are missing for the closest monitor using the mean value recorded contemporaneously at three other PM2.5 monitors located in the same town. Pairwise correlation coefficients for PM2.5 measured hour by hour at the closest monitor and at each of the other three same-town monitors range between 0.93 and 0.96, indicating high levels of spatial correlation within the Jiangsu town.

Similarly, for the $\mathrm{SO}_{2}$ monitor $3.7 \mathrm{~km}$ from the Jiangsu workplace, $4 \%$ of all hourly observations are missing during the period, and we impute the few missing values using the mean value recorded at three other $\mathrm{SO}_{2}$ monitors located in the same town. We noticed that the $\mathrm{SO}_{2}$ series for a given monitor can exhibit short-lived and isolated spikes, fluctuations that are often not observed around the same hours at the other $\mathrm{SO}_{2}$ monitors. For example, the five hourly readings starting at 8 am on August 15, 2014 at the closest monitor are $13,15,219,30$ and $39 \mu \mathrm{g} / \mathrm{m}^{3}$. For this reason, when using $\mathrm{SO}_{2}$ as a proxy for pollution in our preferred specifications, we use mean $\mathrm{SO}_{2}$ levels across monitors in the town. The correlation coefficient between mean $\mathrm{SO}_{2}$ across monitors in the town and PM2.5 at the monitor closest to the work site is 0.61 (again, hourly series).

For the PM2.5 monitor $3.4 \mathrm{~km}$ from the Henan workplace, only $2 \%$ of all 3624 hourly

\footnotetext{
${ }^{24}$ Local pollutant concentrations can be acquired from the Chinese Ministry of Environmental Protection via http://www.pm25.in. PM2.5 concentrations from the US State Department for its regional US embassies, which we describe in the text, are available via www.stateair.net/web/post/1/1.html.
} 
records during the period January 1, 2015 to May 31, 2015 are missing. We recode to missing 24 successive hourly records starting at noon on January 18, 2015 that are fixed at $60 \mu \mathrm{g} / \mathrm{m}^{3}$, when observations at three other monitors in the same town vary from hour to hour and in step. As in Jiangsu, we then impute the few values that are missing for the workplace's closest monitor using the mean contemporaneous value at the same town's three other PM2.5 monitors. Again, hourly PM2.5 readings exhibit high levels of spatial correlation; pairwise correlation coefficients for measurements at the closest monitor and measurements at the other same-town monitors are at least 0.9. Starting in March 2014 (one month prior to the start of the output sample), hourly data availability is similarly high at PM2.5 monitors in three neighboring cities at most $60 \mathrm{~km}$ away, 17 monitors in all. For the overlapping 2015 period, the correlation coefficient for PM2.5 measured 3.4 $\mathrm{km}$ from the Henan workplace and mean PM2.5 across the neighboring cities is 0.80 .

Similar comments to those above apply to hourly $\mathrm{SO}_{2}$ concentrations measured in the town that hosts the Henan workplace (4 monitors, the closest being $3.4 \mathrm{~km}$ away) and at the neighboring cities (17 monitors). For the overlapping 2015 period, the correlation coefficient for mean $\mathrm{SO}_{2}$ measured at the host town and mean $\mathrm{SO}_{2}$ measured across the neighboring cities is 0.76 .

Surface and atmospheric meteorological data availability. As stated in the text, we obtain local ground-level temperature, humidity and precipitation readings, at three-hour intervals, from NASA. For each workplace, we select the geographic cell $(0.25$ degree by 0.25 degree) in the NASA data that is centered on its host town. We obtain surface-level wind speed and direction readings, as well as of atmospheric temperature differences, at 12-hour intervals, from NOAA. For each workplace, we select the reference location in the NOAA data that is closed to the host town, namely station identification codes CHM00058362 for the Jiangsu site and CHM00057083 for the Henan site. ${ }^{25}$

Both datasets are quite complete during the sample periods. For example, surface-level data in the NOAA data for stations CHM00058362 and CHM00057083 are missing for one and six 12-hour reading, respectively. Whenever the wind direction or wind speed reading

\footnotetext{
${ }^{25}$ NASA and NOAA data are available via http://daac.gsfc.nasa.gov/ and http://www1.ncdc.noaa. gov/pub/data/igra/.
} 
on the surface is missing, we take the corresponding parameter reading at an atmospheric pressure point of $1000 \mathrm{mbar}$, if the latter is available (this corresponds to an atmospheric height between 113 and 314 feet from ground); failing that, we take the wind direction or speed reading at an atmospheric pressure point of 925 mbar (atmospheric height between 663 and 929 feet from ground).

Meteorological determinants of air pollution. We separately regress our alternative proxies for worker pollution exposure, namely PM2.5 levels at the closest monitor and $\mathrm{SO}_{2}$ levels averaged across monitors in the town, on meteorological conditions and seasonal controls. The purpose is twofold. First, an analysis of the covariance of pollution, meteorology and season serves as a check on the quality of the data. Second, the analysis provides the first stage to the 2SLS estimator we report on, whereby pollution exposure predicted from variation in surface and atmospheric meteorology in these regressions serves as an instrument for the measured pollution exposure variable that is included in the output regression. The assignment of pollution in neighboring cities as a proxy for exposure in the Henan workplace may be particularly prone to measurement error.

Table A.2(I) reports estimates. The left and right panels consider pollution in the towns that host the Jiangsu and Henan workplaces, respectively, during the respective output sample period, and the preceding 30 days. Since we do not observe pollution in the town that hosts the Henan workplace prior to 2015, Table A.2(II) considers average pollution in the neighboring cities during the entire 2014/2015 output sample (March 2, 2014 to May 31, 2015). An observation in these regressions is a 12-hour period in each sample, coinciding with a date-shift starting at 8 am or at 8 pm, e.g., January 1, 2015, 8 am to $8 \mathrm{pm}$. As regressors, all columns include concurrent meteorological conditions entering either linearly (ground temperature, relative humidity and wind speed; temperature gradients between specific pairs of pressure points in the lower atmosphere) or indicating an occurrence (precipitation, wind blowing from a specific direction). All columns also control for year-month, day-of-week, a separate indicator for each public holiday, and time-of-day. Compared to columns marked (1) and (4), columns marked (2) and (5) include squares of concurrent meteorological conditions that enter the model 
linearly, and columns marked (3) and (6) include mean meteorological conditions in the preceding 24 hours.

As expected, meteorology is an important determinant of both $\mathrm{PM} 2.5$ and $\mathrm{SO}_{2}$ levels. For example, surface-level wind speed has a negative impact on pollutant concentrations. A more positive temperature gradient in the lower atmosphere-i.e., temperature falls less as one ascends, or even rises, indicating a temperature (thermal) inversion-particularly close to the ground, drives pollutant concentrations up (not reported for brevity). Including meteorological conditions in the preceding 24 hours to the model, as well as non-linear terms, raises the model's predictive power even further. 
Table A.1: Procedure to prepare the raw worker output data

\begin{tabular}{|c|c|c|c|c|}
\hline \multirow[b]{2}{*}{ Procedure } & \multicolumn{2}{|c|}{ Observations } & \multicolumn{2}{|c|}{ No. of workers } \\
\hline & Dropped & Remaining & Dropped & Remaining \\
\hline \multicolumn{5}{|l|}{ (I) Jiangsu } \\
\hline Initial number of observations (worker-day pair) & & 4579 & & 47 \\
\hline (-) One shift prior to/after dept. holiday (clean/setup) & 32 & 4547 & 0 & 47 \\
\hline (=) Number of observations for aggregate analysis & & 4547 & & 47 \\
\hline (-) Observations with exceptional duties recorded & 47 & 4500 & 1 & 46 \\
\hline (=) Number of observations for individual analysis & & 4500 & & 46 \\
\hline Proportion of raw data in the final sample & & $98 \%$ & & $98 \%$ \\
\hline \multicolumn{5}{|l|}{ (II) Henan } \\
\hline Initial number of observations (worker-day pair) & & 5614 & & 83 \\
\hline (-) One shift prior to/after dept. holiday (clean/setup) & 124 & 5490 & 0 & 83 \\
\hline (-) Shifts with power outage recorded & 52 & 5438 & 0 & 83 \\
\hline (=) Number of observations for aggregate analysis & & 5438 & & 83 \\
\hline (-) Observations with exceptional duties recorded & 131 & 5307 & 3 & 80 \\
\hline (=) Number of observations for individual analysis & & 5307 & & 80 \\
\hline Proportion of raw data in the final sample & & $95 \%$ & & $96 \%$ \\
\hline
\end{tabular}




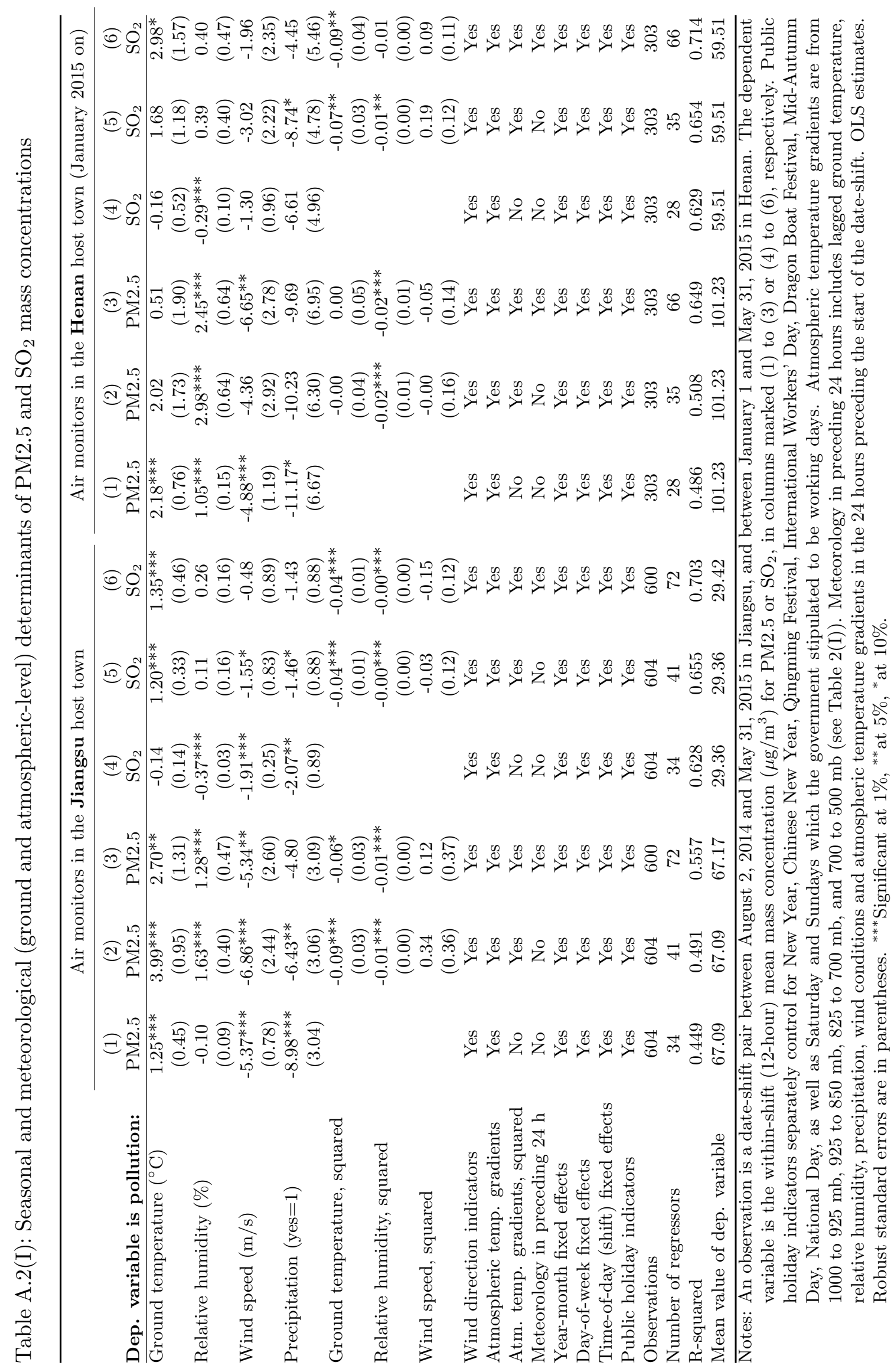

A. 9 


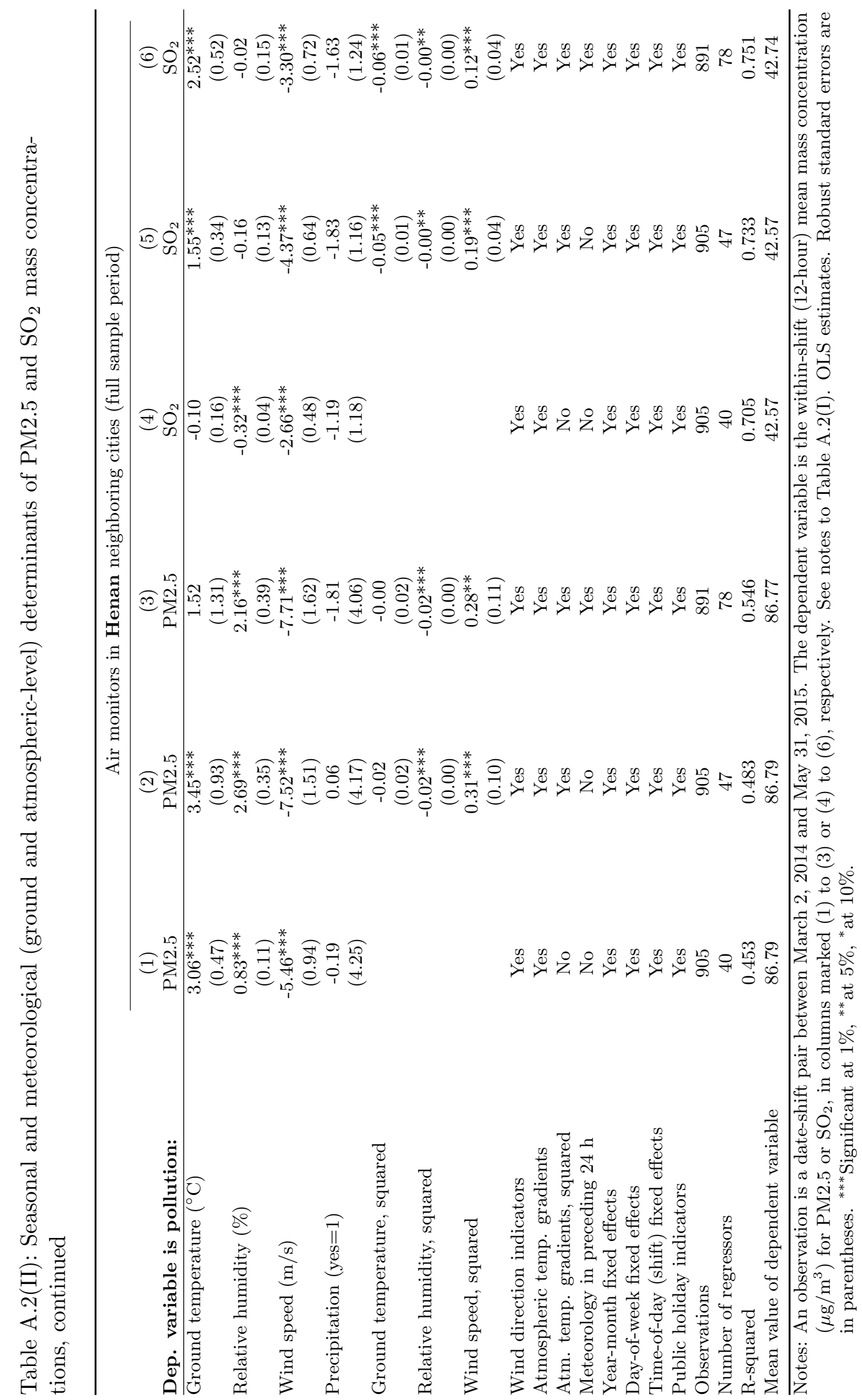

A. 10 


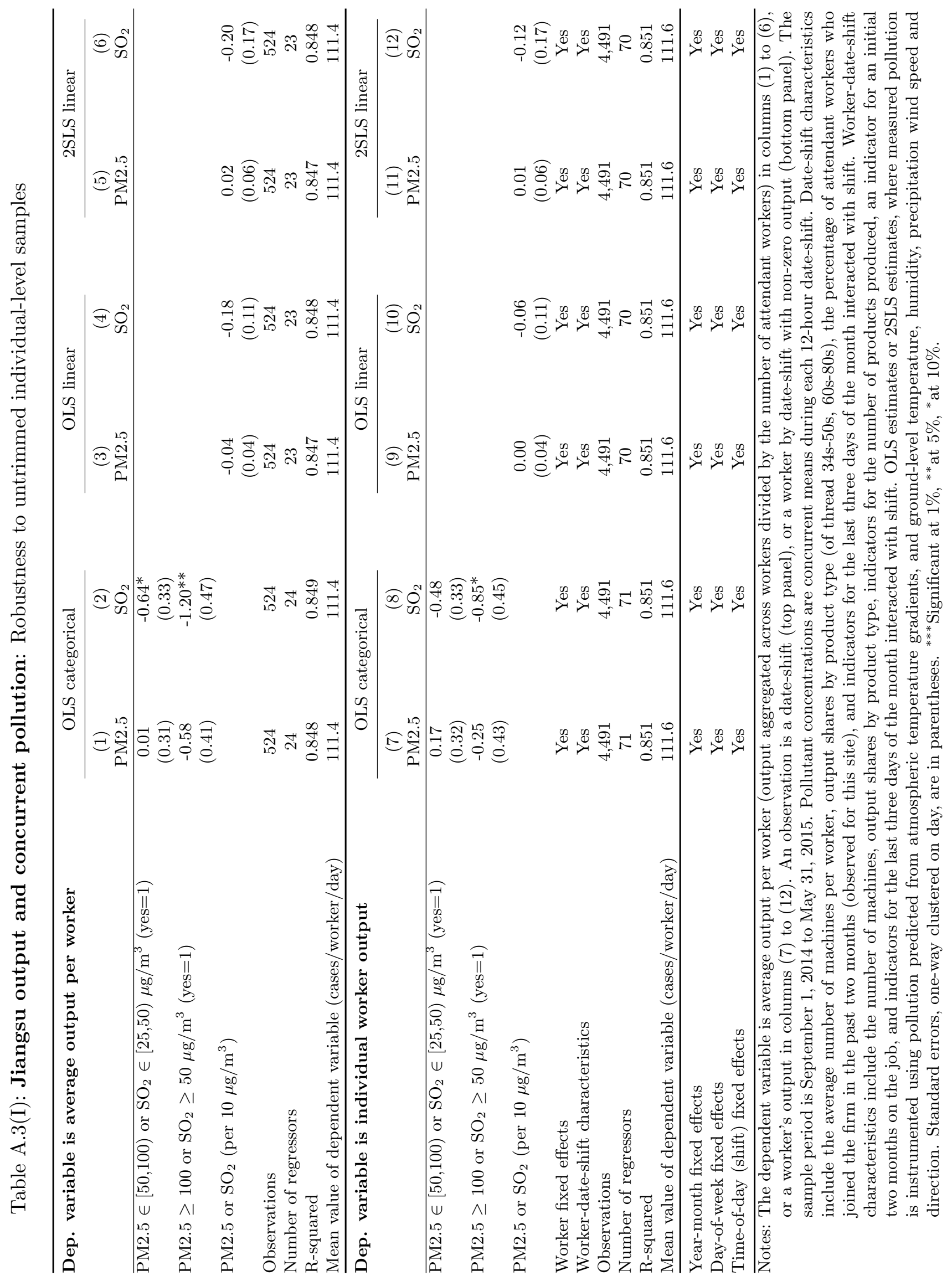




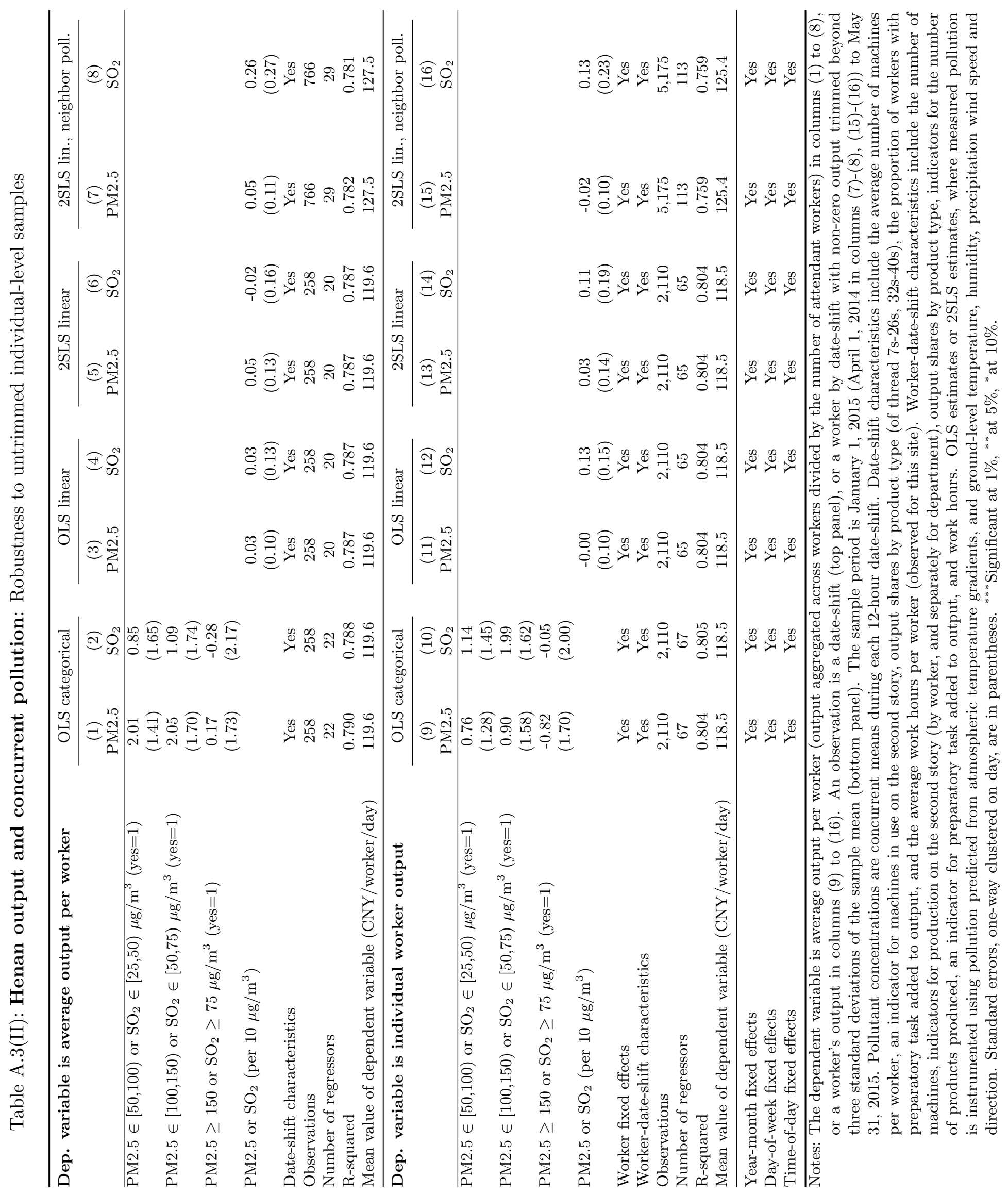




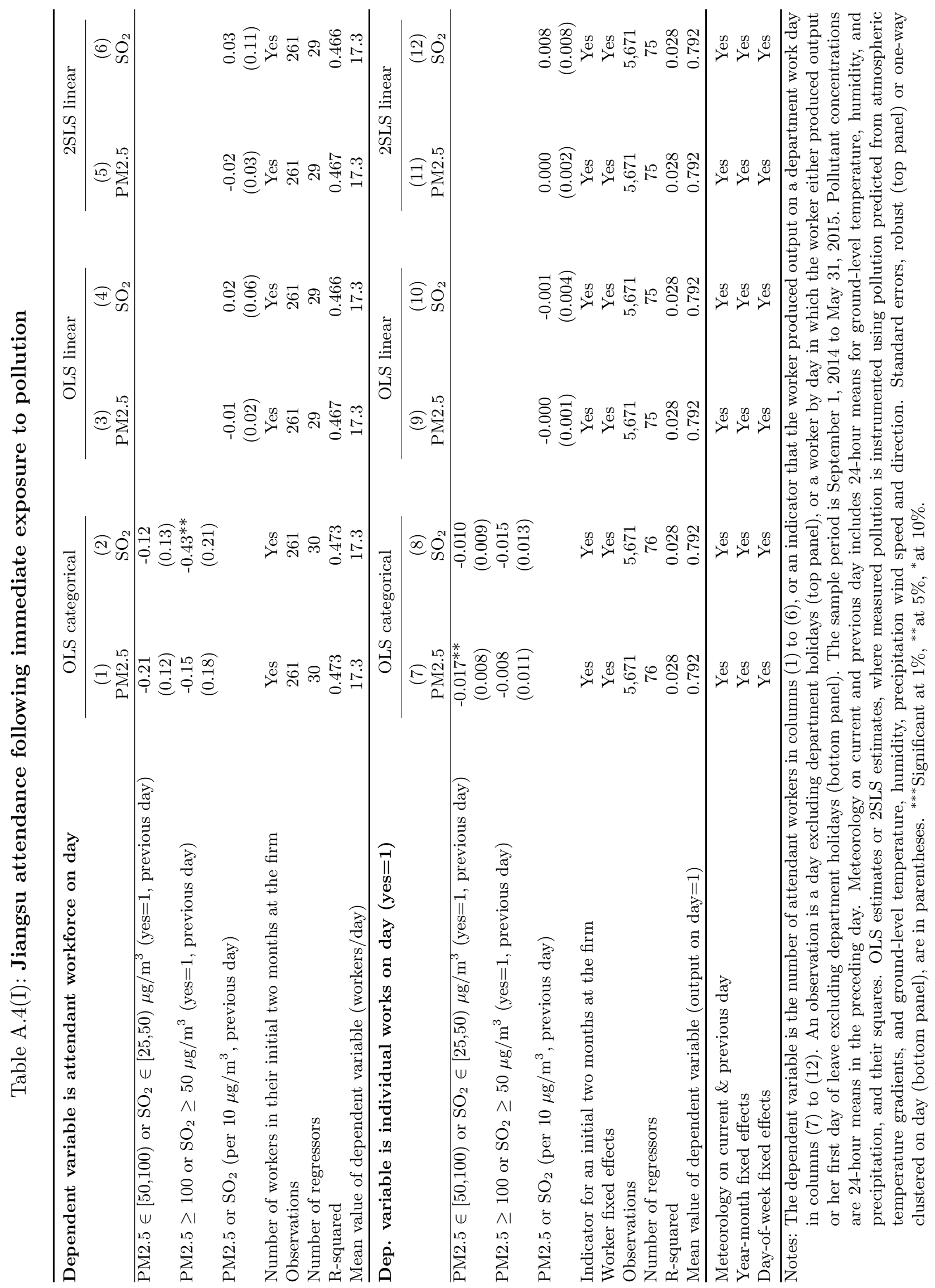

A. 13 


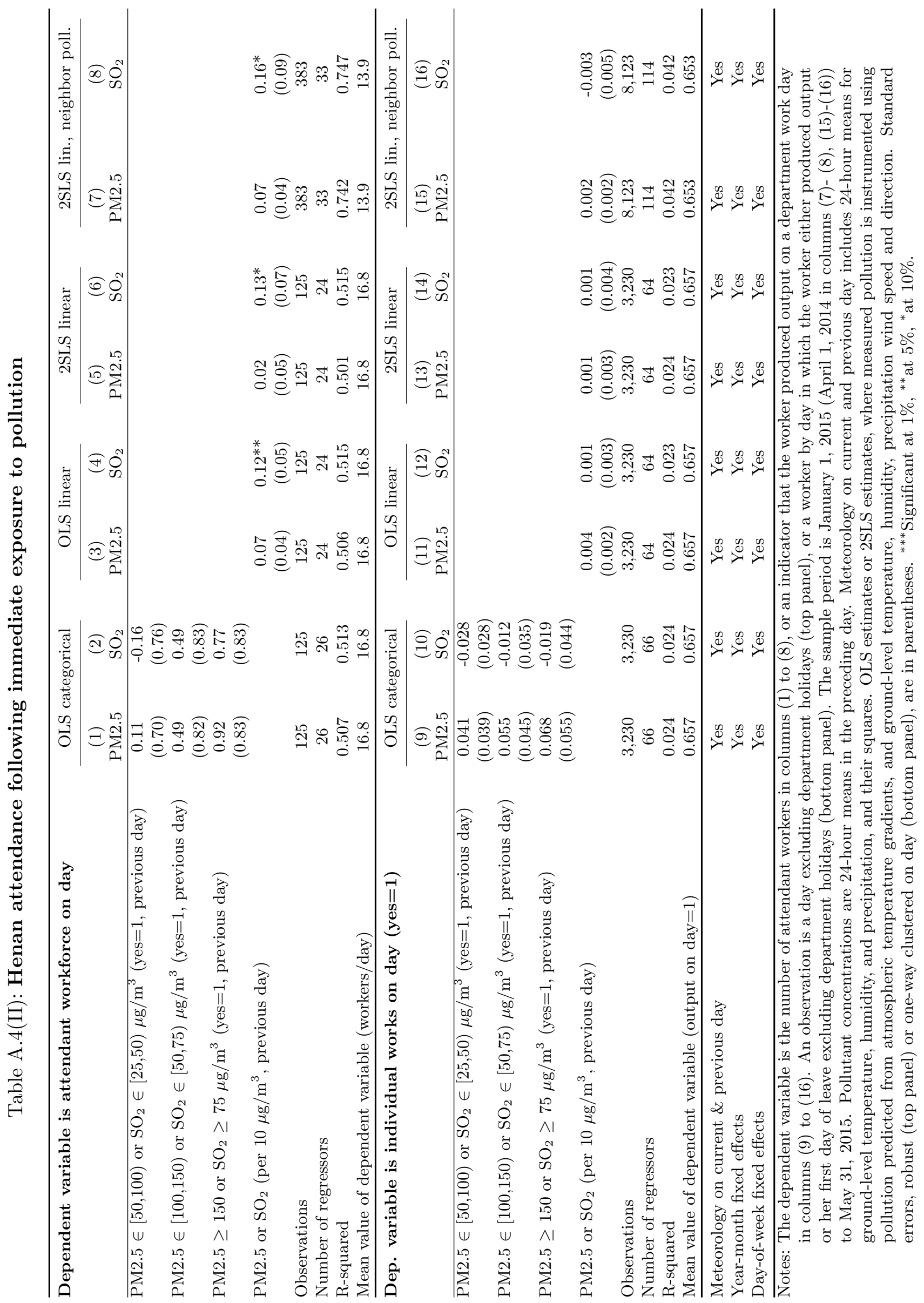

A. 14 


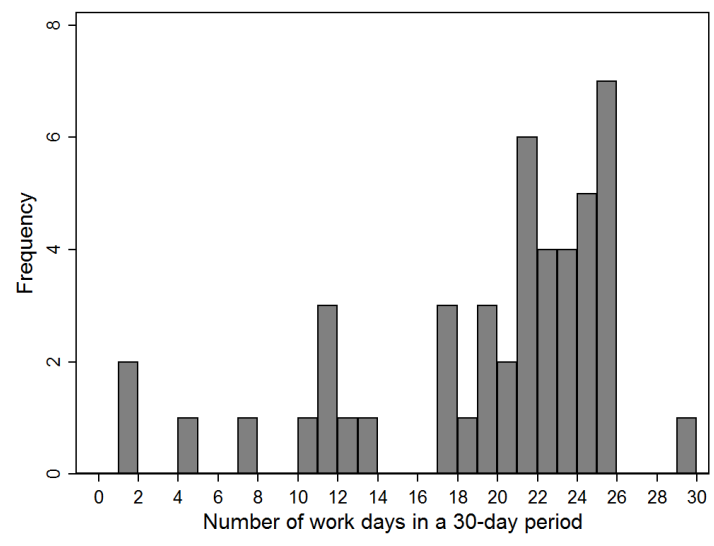

(a) Jiangsu worker sample

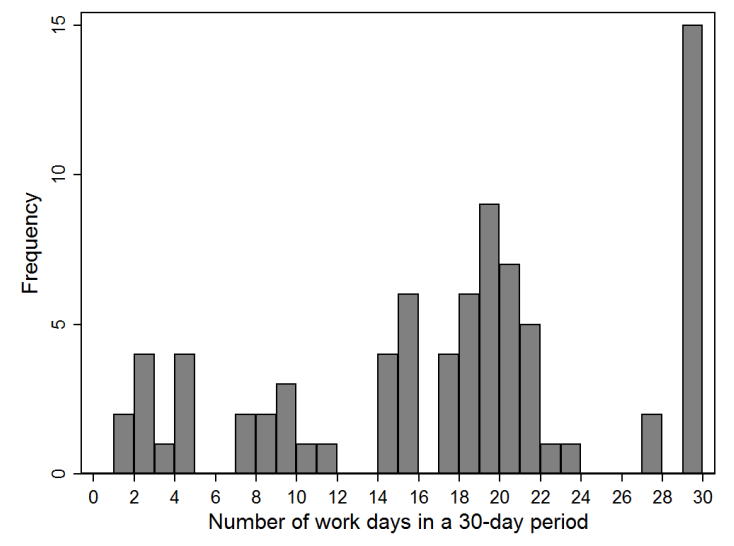

(b) Henan worker sample

Figure A.1: Frequency chart across workers (46 in Jiangsu, 80 in Henan) of the number of 12-hour shifts worked per 30-day period of department activity. This is calculated as a worker's number of positive output records (work days) in the sample divided by the number of days with department activity between the worker's first and last work day in the sample, multiplied by 30 days (i.e., per 30 -day period).

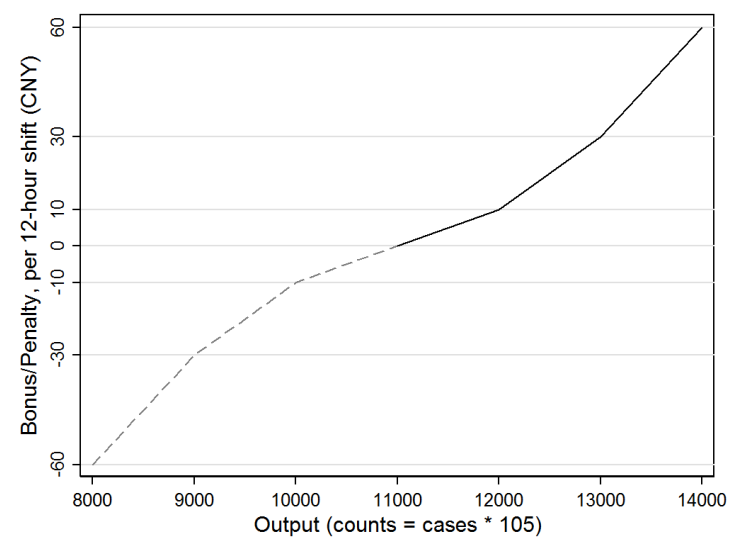

Figure A.2: Variable compensation scheme adopted by the Jiangsu department. A worker's output during a 12-hour shift is aggregated across individual products into "adjusted cases" using the weights listed in the Appendix, and then converted into "counts" at a rate of 105 counts/adjusted case. The worker is paid a bonus of: $0.01 \mathrm{CNY}$ per count in excess of 11,000 counts but no greater than 12,000 counts, $0.02 \mathrm{CNY}$ per count in excess of 12,000 counts but no greater than 13,000 counts, and $0.03 \mathrm{CNY}$ per count for output in excess of 13,000 counts. The penalty scheme for output that falls short of 11,000 counts is symmetric to the bonus scheme around the reference output of 11,000 counts. 


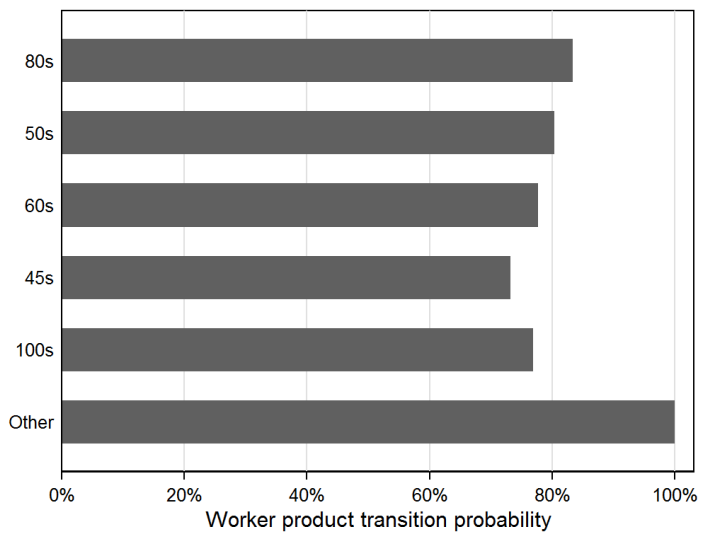

(a) Jiangsu worker sample

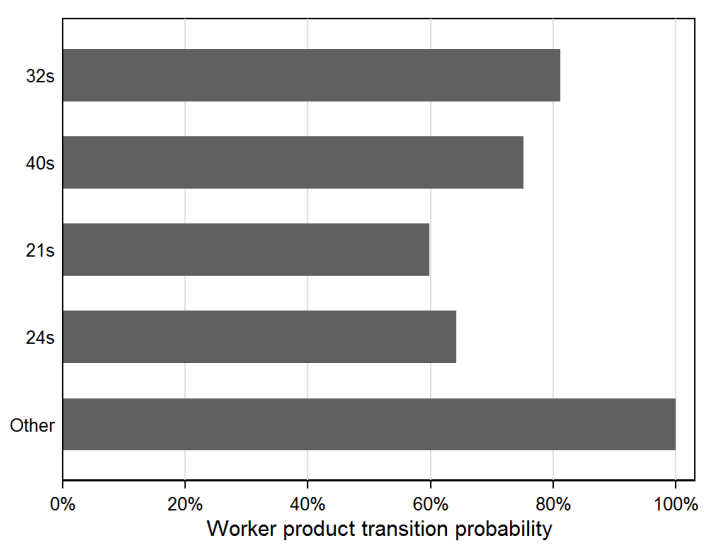

(b) Henan worker sample

Figure A.3: A worker's shift-to-shift own-product transition probabilities. To prepare each plot, we take the four or five varieties in a work site with double-digit output shares, and aggregate the remaining varieties into a residual category labeled "Other." We consider pairs of consecutive work shifts by a worker, with 12 hours and up to 24 hours of rest in between work in Jiangsu and Henan, respectively, given the standard shift designs. We then compute the empirical probability that, conditional on a worker producing a given variety on a shift, she also produced that variety in her preceding shift. 